Aus der Klinik für Unfallchirurgie und Orthopädie,

Plastische- und Wiederherstellungschirurgie

(Prof. Dr. med. K. M. Stürmer)

der Medizinischen Fakultät der Universität Göttingen

\title{
Einfluss des Lipoxygenaseinhibitors Baicalein in unterschiedlicher Dosierung auf den Skelettmuskel der ovariektomierten Ratte
}

\author{
INAUGURAL-DISSERTATION \\ zur Erlangung des Doktorgrades \\ der Medizinischen Fakultät der \\ Georg-August-Universität zu Göttingen \\ vorgelegt von \\ Jens Henning Kling \\ aus \\ Kassel
}

Göttingen 2015 
Dekan:

Referent/in:

Ko-Referent/in:

Drittreferent/in:
Prof. Dr. rer. nat. H.K. Kroemer

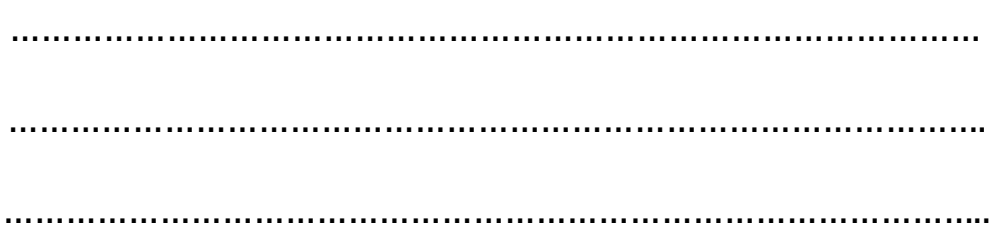

Datum der mündlichen Prüfung: 


\section{Inhaltsverzeichnis}

Abkürzungsverzeichnis

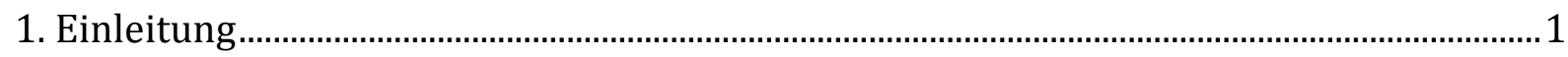

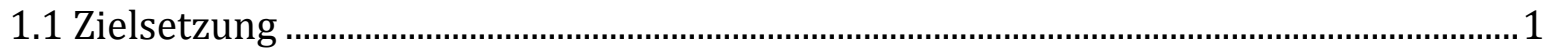

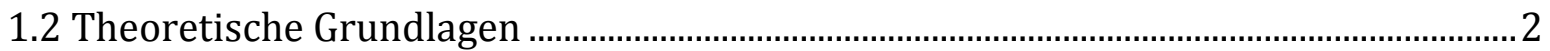

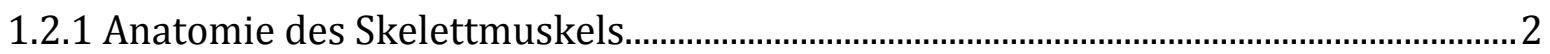

1.2.2 Uktrastruktureller Aufbau der Myofibrillen................................................................. 3

1.2.3 Extrazellulärmatrix des Skelettmuskels ........................................................................... 4

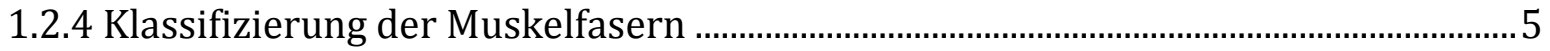

1.3 Anpassung des Skelettmuskels an körperliches Training ................................................ 7

1.4 Veränderungen des Muskels im Alter................................................................................ 8

1.5 Osteoporose Definition und Einteilung..........................................................................

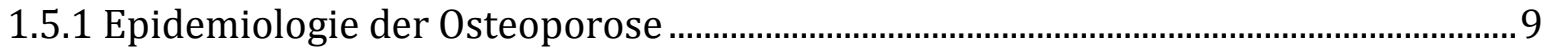

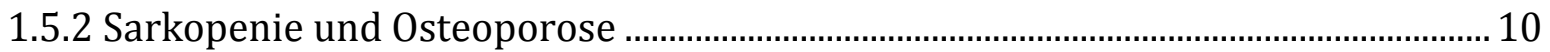

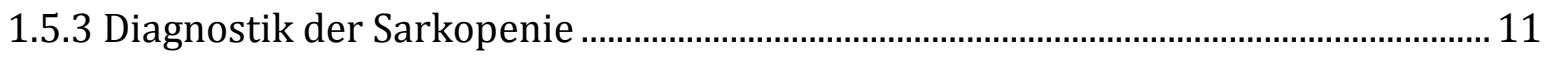

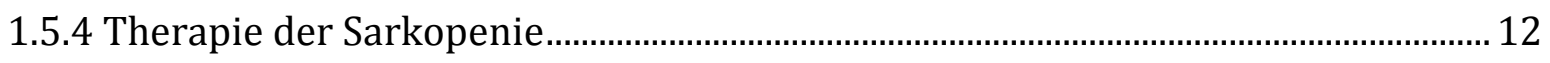

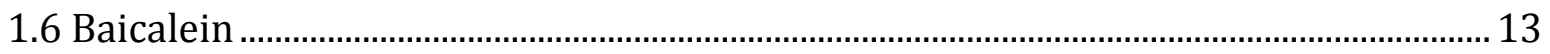

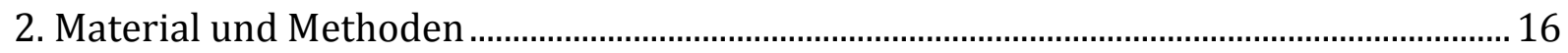

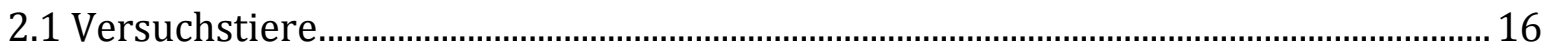

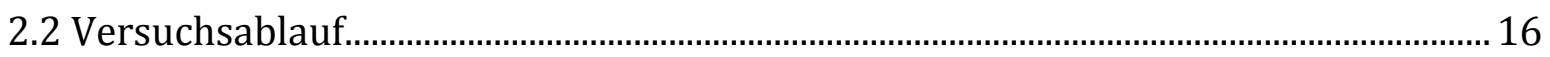

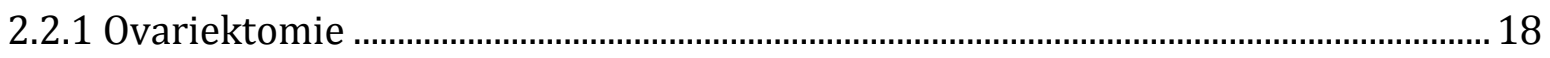

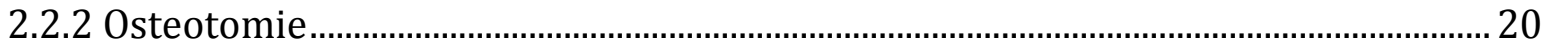

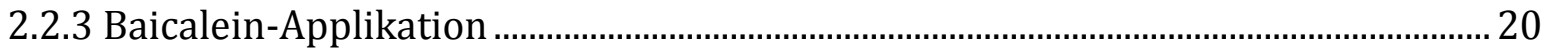

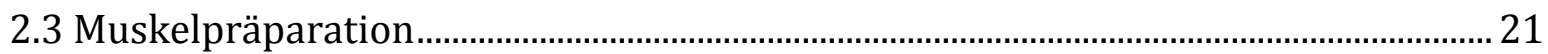

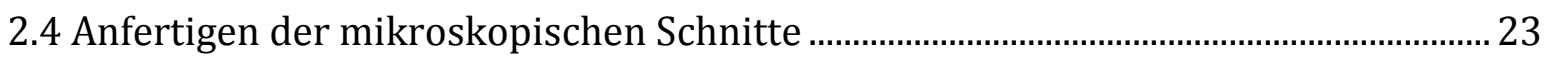

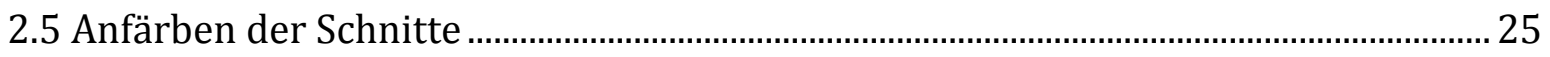

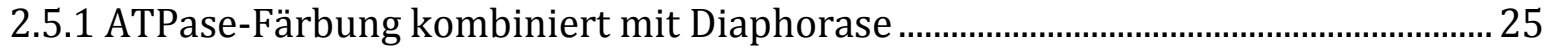

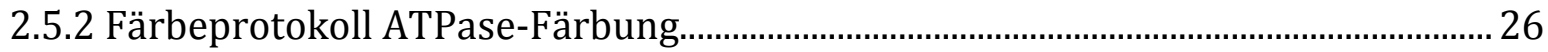


2.5.3 Amylase-PAS für Kapillarfärbung.

2.5.4 Färbeprotokoll Amylase-PAS-Kapillarfärbung............................................................ 28

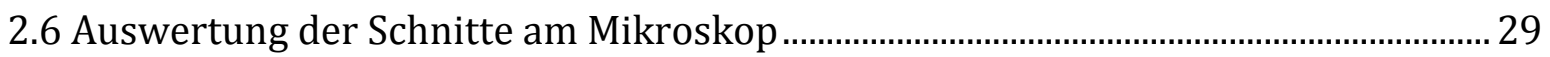

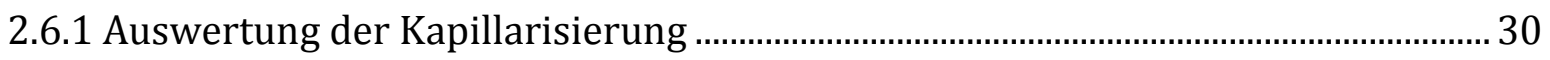

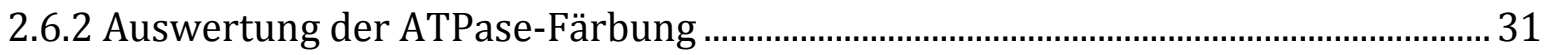

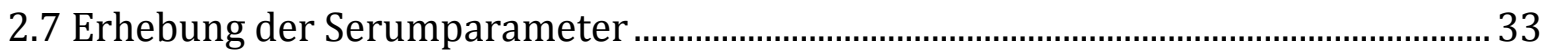

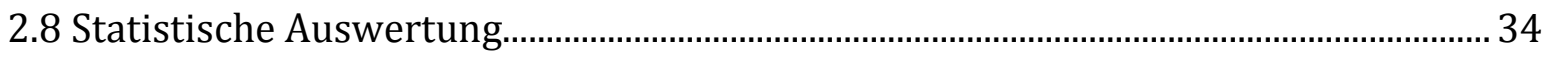

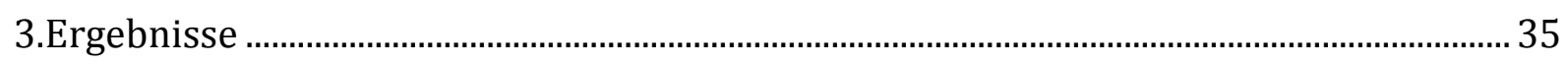

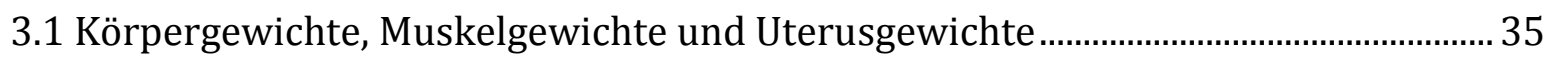

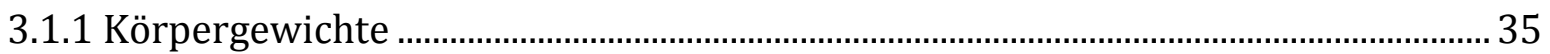

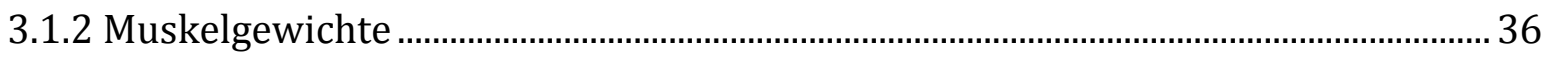

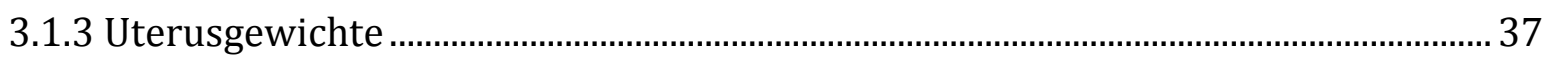

3.2 Verhältnis von Kapillaren zu Muskelfasern........................................................................ 38

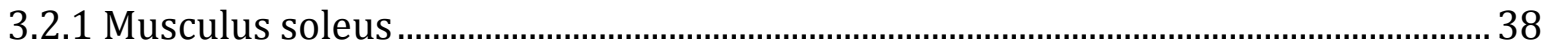

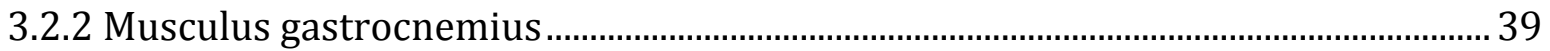

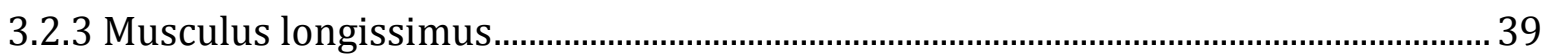

3.3 Muskelfaserdurchmesser und Flächen beim M. soleus ................................................. 40

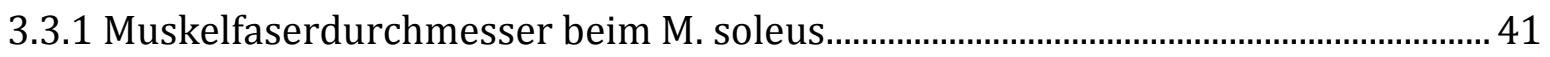

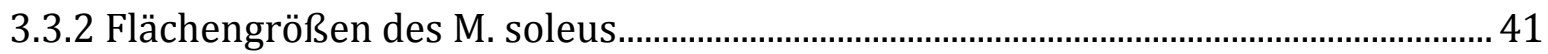

3.3.3 Verhältnisse der Muskelfaserdurchmesser zu den Gewichten beim M. soleus .... 42

3.3.4 Verhältnisse der Muskelfaserflächen zu den Gewichten beim M. soleus................ 44

3.4 Muskelfaserdurchmesser und Flächen beim M. gastrocnemius ................................... 45

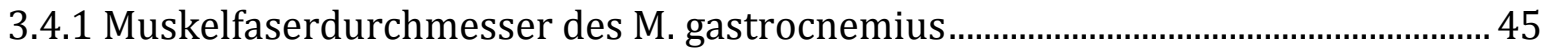

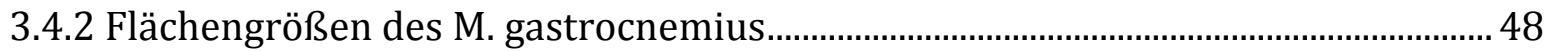

3.4.3 Verhältnisse der Muskelfaserdurchmesser zu den Gewichten beim

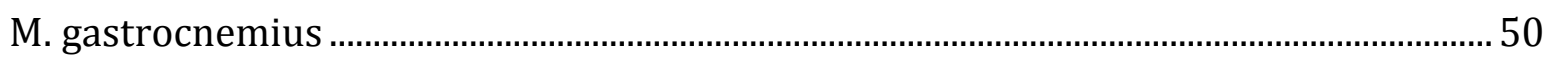

3.4.4 Verhältnisse der Muskelfaserflächen zu den Gewichten beim

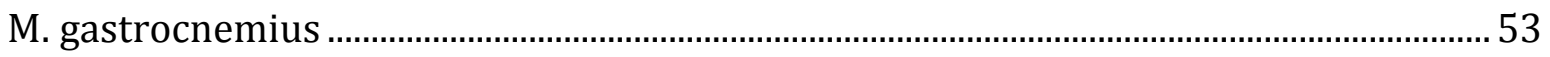

3.5 Analyse der Muskelfaserdurchmesser und der Flächen beim M. longissimus......... 57

3.5.1 Analyse der Muskelfaserdurchmesser des M. longissimus ..........................................57

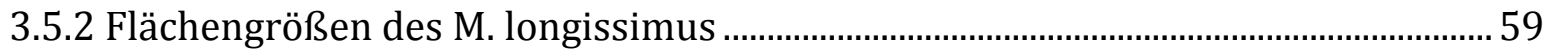

3.5.3 Verhältnisse der Muskelfaserdurchmesser zu den Gewichten beim

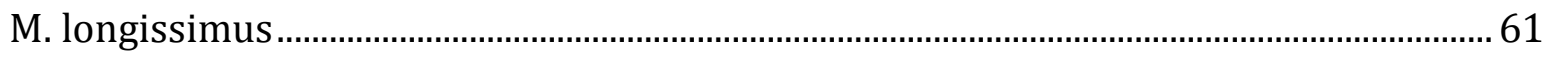

3.5.4 Verhältnisse der Muskelfaserflächen zu den Gewichten beim M. longissimus..... 63 
3.5.5 Verhältnisse der Muskelfasertypen im M. longissimus................................................65

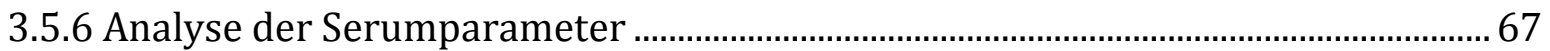

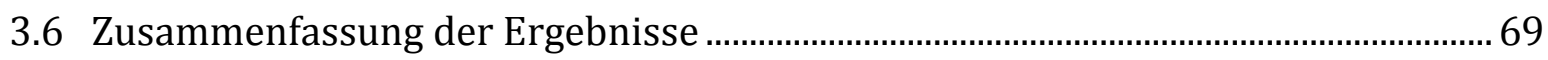

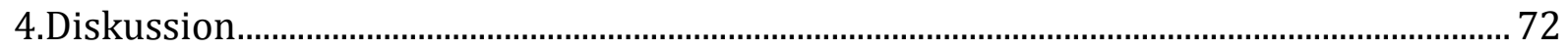

4.1 Die ovariektomierte Ratte als Tiermodell......................................................................... 72

4.2 Analyse der Körper- und Muskelgewichte......................................................................... 73

4.3 Analyse der Verhältnisse von Kapillarisierung zu Muskelfasern ................................. 74

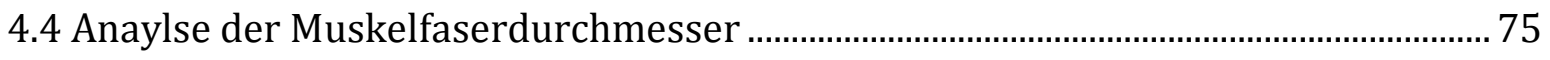

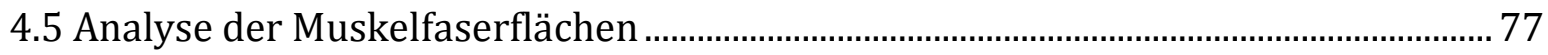

4.6 Analyse der Verhältnisse von Muskelfasertypen im M. longissimus............................ 80

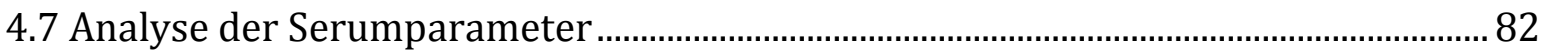

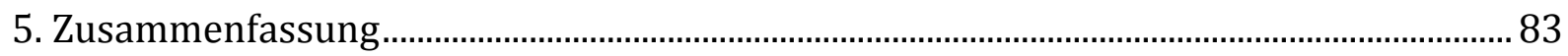

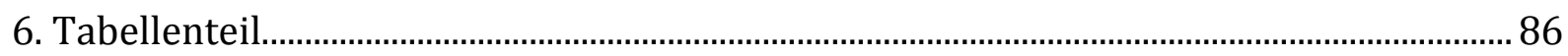

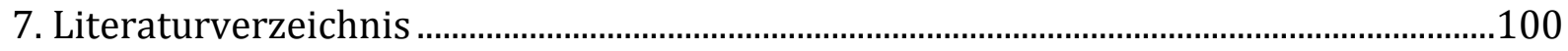

8. Tabellenverzeichnis ................................................................................................... 105-106

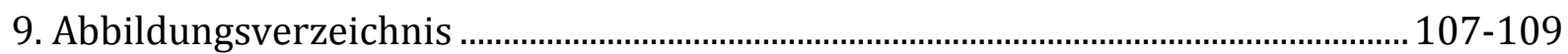




\section{Abkürzungsverzeichnis}

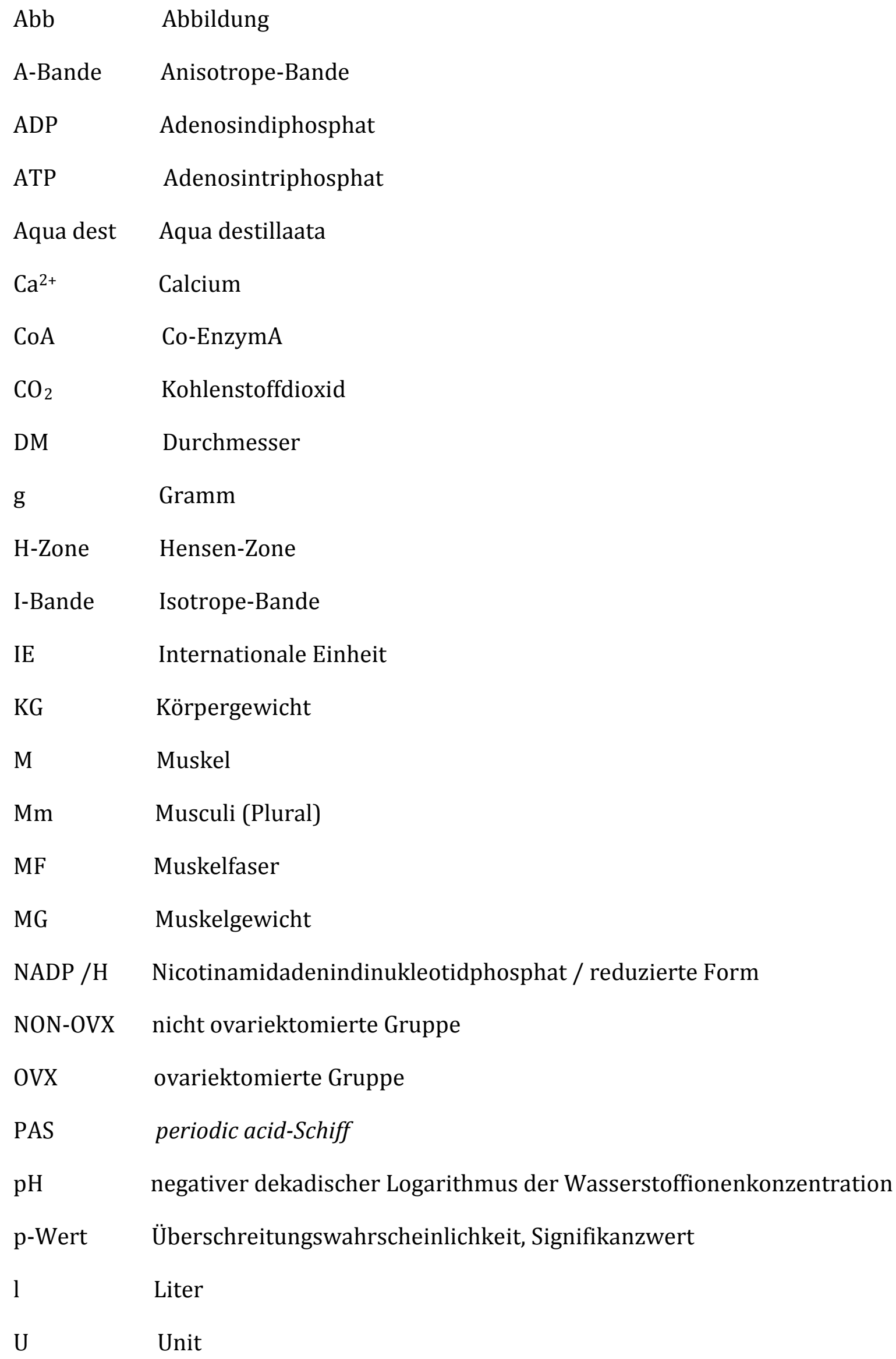


ROS reactive oxygen species

s $\quad$ Sekunde

SD standard deviation, Standardabweichung

SERCA sarcoplasmic/endoplasmic reticulum calcium ATPase

Z-Scheibe Zwischen-Scheibe 


\section{Einleitung}

\subsection{Zielsetzung}

Osteoporose ist eine weit verbreitete muskuloskelettale Erkrankung, deren Häufigkeit im Alter zunimmt. Allein in Deutschland betrug nach einer Auswertung der Krankenkassendaten zwischen 2006-2009 die Prävalenz 24\% bei Frauen über 50 Jahren. Hierzulande leben derzeit ungefähr 6,3 Millionen betroffene Männer und Frauen [Hadji et al. 2013]. Somit stellen die Behandlung der Osteoporose und deren Komplikationen eine erhebliche volkswirtschaftliche Belastung der Gesellschaft dar.

Mit der Osteoporose tritt einhergehend zumeist eine Sarkopenie auf, das heißt eine Abnahme der Skelettmuskelmasse, die sich entscheidend auf die Stabilität des muskuloskelettalen Systems und auf dessen Haltung auswirkt. Sarkopenie schränkt dabei maßgeblich die Lebensqualität der Betroffenen ein. Alltägliche Bewegungen sind hier ebenso beeinträchtigt, wie die Aufrechterhaltung des Gleichgewichtsapparats. Aus diesem Grund nimmt primär das Sturzrisiko und sekundär die Gefahr von Frakturen enorm zu. Laut einer Studie beruhen 90\% aller Frakturen bei alten Menschen auf Stürzen [Grisso et al. 1991]. Zum anderen besteht bei Sarkopenie eine Störung der sytemisch-humoralen Funktion des Muskels. Eine Vielzahl von endokrinen Stoffen, die vom Muskel synthetisiert den Knochen beeinflussen, ist bei Sarkopenie reduziert. So zum Beispiel die Gruppe von muscle-derived humoral bone anabolic factors, die vom Muskel ausgeschüttet Osteoblasten aktivieren [Kaji 2014]. Ein gesunder und damit endokrin aktiver Muskel ist somit entscheidend für die Funktion des Halte- und Stützapparates. Ebenso ist der sarkopenisch veränderte Muskel an der Pathophysiologie der Osteoporose und Entstehung von osteoporosebedingten Frakturen maßgeblich beteiligt.

In früheren Studien konnte aufgezeigt werden, dass bei Sarkopenie außerdem eine langanhaltende niedrig-gradige Entzündung im Muskel besteht. Diese verstärkt den im Alter stattfindenden degenerativen Prozess im Muskel [Roubenoff 2007].

Die Mechanismen, denen die Sarkopenie unterliegt, wie auftretende reaktive Sauerstoff Spezies, verminderte Regenerationsfähigkeit und niedrig-gradige systemische Entzündung, sind weitestgehend unklar. Hier ansetzende Therapeutika, die diesen Prozessen entgegensteuern, sind ebenfalls noch unerforscht. Erste Studien mit entzündungshemmenden Substanzen scheinen eine vielversprechende Wirkung auf die Sarkopenie auszuüben [Lightfoot et al. 2014].

Die Lipoxygenasen sind Schlüsselenzyme des Arachidonsäurestoffwechsels, der eine wichtige Säule von Entzündungsreaktionen darstellt. Ein Inhibitor dieses Enzyms ist Baicalein, das bereits seit langem in der Traditionellen Chinesischen Medizin eingesetzt wird. Es konnten bereits positive Effekte von Baicalein auf entzündlich degenerative 
Knochenerkrankungen, wie Rheumatoide Arthritis nachgewiesen werden [Chen 2011] jedoch wurde seine Wirkung auf die Sarkopenie noch nicht untersucht.

Ziel der vorliegenden Arbeit ist es herauszufinden, ob der LipoxygenaseInhibitor Baicalein- in verschiedenen Dosierungen verabreicht die mit Osteoporose einhergehende Sarkopenie und deren degenerative Prozesse im Skelettmuskel positiv beeinflusst. Die hierfür messbaren Parameter sind: Anzahl der Muskelfasern sowie deren Durchmesser, Verhältnis von Typ-1- zu Typ-2A- und Typ-2B-Muskelfasern sowie der Kapillarisierung der Skelettmuskeln, das heißt Anzahl von Kapillaren zu Muskelfasern. Diese Parameter werden an den Muskeln soleus, gastrocnemius und longissimus am Rattenmodell gemessen und ausgewertet. Zudem sollen die erhobenen Serumparameter Kreatinkinase, Calcium und Magnesium Aufschluss über den Zustand der Muskulatur geben.

\subsection{Theoretische Grundlagen}

\subsubsection{Anatomie des Skelettmuskels}

Der Skelettmuskel geht embryologisch aus dem mittleren Keimblatt, dem Mesoderm, hervor. Im Zuge des Wachstums und der Differenzierung kommt es zu einer Verschmelzung und Aneinanderreihung von Muskelzellvorläufern, sogenannten Myoblasten. Die aus dem Ektoderm stammenden kontraktilen Myoepithelzellen sollen hier nicht näher besprochen werden. Der Skelettmuskel, wie zum Beispiel der Musculus gastrocnemius der Ratte, besteht aus einer Vielzahl von Skelettmuskelfasern, die durch Bindegewebshüllen aneinandergehalten werden. Die Enden der Muskelfasern gehen in Sehnen über, die an Knochen ansetzen. Diese können zur Optimierung über ein Hypomochlion, das heißt eine Umlenkung, an einem Knochen inserieren.

Die wesentliche Eigenschaft der Skelettmuskulatur besteht in ihrer Fähigkeit, sich aktiv zu verkürzen, Kontraktion genannt. Diese Kontraktion ist essentiell im Rahmen einer Vielzahl lebenswichtiger Aktivitäten, so beispielsweise dem Auspressen des Feten beim Geburtsvorgang, der Atmung und des Herzschlags oder schlicht der Fortbewegung eines Individuums. Man unterscheidet hinsichtlich der Kontraktion zwischen willkürlicher und unwillkürlicher. Die willkürliche, schnelle Kontraktion ist dabei der Skelettmuskulatur zuzuordnen. Gesteuert wird diese willkürliche Funktion der Skelettmuskulatur vom somatischen Nervensystem über Motoneurone im Rückenmark, die unwillkürlichen autonomen Kontraktionsformen werden über das vegetative Nervensystem gesteuert und dienen vor allem zur Regulation der inneren Organe. Den 
molekularen Unterbau der Kontraktion stellen die Gleitfilamente Actin und Myosin dar. Diese Makroproteine sind in der Lage, sich unter der energieliefernden Hydrolyse von ATP zu ADP zu verkürzen, indem der Kopf des Myosinfilamentes Konformationsänderungen erfährt, woraufhin er sich entlang des Actinfilamentes bewegt. Da die Actinfilamente über sogenannte Z-Scheiben am Zytoskelett verankert sind, kommt es im Zuge des synchronen Gleitens vieler Myosinfilamente zu einer schließlich makroskopisch sichtbaren sowie je nach Muskelquerschnitt kraftvollen Verkürzung eines Muskels. Ausgehend vom unterschiedlichen Aufbau ihrer Gleitfilamente unterscheidet man quergestreifte Skelettmuskulatur von glatter Muskulatur, zum Beispiel der Hohlorgane [Benninghoff und Drenckhahn 1994].

\subsubsection{Uktrastruktureller Aufbau der Myofibrillen}

Die charakteristische Querstreifung der Skelettmuskulatur besteht aus 1,5 $\mu$ m breiten anfärbbaren Banden, die sich von hellen Banden unterscheiden lassen. Die dunklen anfärbbaren Banden sind im Polarisationsmikroskop doppelbrechend, genannt anisotrop. Daher bezeichnet man sie als A-Bande. Die helleren, nicht doppelbrechenden werden als isotrop bezeichnet, woraus der Begriff I-Banden hervorgeht. Auf der Mitte einer I-Bande liegt eine Zwichenscheide, Z-Scheibe, welche die I-Bande in zwei Hälften teilt. Der Terminus Sarkomer umfasst den Abschnitt einer Myofibrille, also die Einheit von Actin- und Myosinfilamenten zwischen zwei Z-Scheiben. Folglich besteht ein Sarkomer aus einer A-Bande und zwei ihr benachbarten I-Banden. Mittig von einer ABande liegt die Mittelzone (M-Zone). Den etwas aufgehellten Bereich bezeichnet man als H-Zone (von Hensen-Zone). Sowohl die Breite der H-Zone wie die der I-Bande hängt vom Kontraktionszustand des Muskels ab. In Ruhestellung beträgt die Breite der H-Zone in etwa 30-50\% der Breite der A-Bande. Im Zustand der maximalen Kontraktion verschwinden die H-Zone und die I-Bande völlig, wohingegen sie im Dehnungszustand des Muskels maximale Werte erreichen [Benninghoff und Drenckhahn 1994]. 
Entscheidend für die Kontaktionsfähigkeit der Myofibrillen ist das Zusammenspiel mit Calcium, welches in einer Konzentration von $10^{-7} \mathrm{~mol} / \mathrm{l}$ in der unerregten Muskelzelle vorhanden ist und im erregten Zustand, aus den Sarkomeren ausgeschüttet, die Kontraktion durch die Bindung an Myosin erst ermöglicht. Ebenfalls unabdingbar für eine normale Kontraktion des Muskels ist das Magnesium. Beide Elektrolyte können im Serum bestimmt werden und sind daher ein wichtiger Marker für die Einschätzung, ob eine gesunde Funktionsweise im Skelettmuskel stattfinden kann. [Silbernagel et al. 2014]

Ein anderer etablierter Parameter für die Beurteilung des Zustandes der Skelettmuskulatur ist das Enzym Kreatinkinase, welches maßgeblich am Energiestoffwechsel in der Muskelzelle beteiligt ist, wobei es eine Phosphatgruppe auf das Adenosindiphosphat überträgt und somit Adenosintriphosphat als Energieträger generiert. Die Konzentration dieses Enzyms wird klinisch vor allem eingesetzt um einzuschätzen, ob ein Muskelzerfall stattfindet, dabei werden verschiedene Isoformen für Skelettmuskel, Gehirn und Herz unterschieden [Silbernagel et al. 2014].

\subsubsection{Extrazellulärmatrix des Skelettmuskels}

Ein Muskel wird insgesamt stets von einer Muskelfaszie umhüllt, die aus straffem Kollagen besteht. Dieses kollagene Bindegewebe liegt gitterartig auf dem Muskel und erlaubt dadurch Quer- und Längsdehnungen. Die Elastizität dieses Systems lässt im Alter nach, wodurch ebenfalls das Verletzungsrisiko zunimmt [Gao et al. 2008]. Bei vielen Muskeln ist diese oberflächlichste Muskelfaszie vom darunterliegenden Epimysium getrennt, wodurch sie in der Lage ist, Führungsschienen, sogenannte Faszienlogen, für dazugehörige Muskeln zu bilden. Das Epimysium strahlt in die Tiefe in Form von Bindegewebsblättern, die das Perimysium darstellen und einige Millimeter dicke Muskelfaserbündel (Sekundärbündel) umhüllen. Weiterhin gliedert das Perimysium die Sekundärbündel in Primärbündel, die durchschnittlich 250 Muskelfasern bei einer Dicke von etwa $1 \mathrm{~mm}^{2}$ darstellen. Innerhalb der Primärbündel umhüllt retikuläres Bindegewebe einzelne Muskelfasern. Dieses retikuläre Bindegewebe bezeichnet man als Endomysium [Benninghoff und Drenckhahn 1994]. 


\subsubsection{Klassifizierung der Muskelfasern}

Prinzipiell können sämtliche Skelettmuskelfasern in intra- oder extrafusal unterteilt werden. Intrafusale Fasern bilden sogenannte Muskelspindeln (Fusi neuromusculares) und sind in weitaus geringerer Zahl als die extrafusalen Fasern über den Muskel verteilt. Diese intrafusalen Fasern sind 5-20 $\mu \mathrm{m}$ dick und verbinden zwei wichtige Aufgaben: Die Sensitivitätseinstellung der Muskelspindeln mittels Längen- und Spannungsänderung sowie die Wahrnehmung der Längenänderung eines Muskels und Weiterleitung ins Zentrale Nervensystem im Rahmen des Muskeldehnungsreflexes. Allerdings ist nur der extrafusale Fasertyp zur schnellen, binnen Sekundenbruchteilen stattfindenden Kontraktion und anschließender Erschlaffung in der Lage. Diese Abfolge wird als Zuckung (englisch twitch) bezeichnet. Solche extrafusalen Zuckungsfasern werden in der Regel von einer motorischen Nervenfaser über eine motorische Endplatte innerviert [Benninghoff und Drenckhahn 1994]. Entscheidend für die Innervation des Skelettmuskels ist die Aufzweigung einer motorischen Nervenfaser innerhalb des Muskels auf mehrere Muskelfasern. Die funktionelle Einheit aus einer motorischen Nervenfaser und aller durch sie versorgten Muskelfasern bezeichnet man als „motorische Einheit“. Dabei bestimmt die Anzahl der von einer Nervenfaser innervierten Muskelfasern die Fähigkeit des Muskels zur Abstufbarkeit seiner Kraft. Je weniger Muskelfasern eine Nervenfaser erreicht, umso höher die Feinmotorik, die dieser Muskel ausüben kann. Im Gegensatz zum Herz oder glatter Muskulatur ist ein Übergreifen der Erregung von einer Muskelfaser auf eine andere im Skelettmuskel nicht zu beobachten [Silbernagel et al. 2014].

Die extrafusalen Zuckungsfasern lassen sich wiederum in langsam (Typ-1) und schnell zuckende (Typ-2) Muskelfasern unterteilen. Typ-1-Muskelfasern sind von ihrer Enyzmausstattung her auf Dauerleistung ausgelegt und daher langsam ermüdend. Sie verbrauchen für dieselbe Krafterzeugung wie Typ-2-Fasern nur ein Drittel der Menge an ATP und übernehmen vor allem Halte- und Stützfunktionen im Organismus. Hingegen sind Typ-2-Muskelfasern zu schnellen, kraftvollen Kontraktionen in der Lage, deren Kontraktionsgeschwindigkeit zwei- bis viermal so groß ist wie die von Typ-1-Fasern. Ihrer Funktion entsprechend sind die langsamen Typ-1-Fasern vor allem auf aerobe oxidative und somit mitochondriale ATP-Synthese angewiesen, da die anaerobe Glykolyse zu schnell erschöpft wäre. Hierzu besitzen die Typ-1-Muskelfasern viele Fetttropfen als Energiespeicher, zudem einen hohen Anteil an Sauerstoff-bindendem Protein Myoglobin, das im Zytosol vorliegt. Dieser hohe Myoglobingehalt lässt den Muskel im Gegensatz zum Typ-2-dominanten Muskel rot erscheinen. Die Typ-1-Fasern werden daher auch rote Muskelfasern genannt. Ihrer hohen Ermüdungsresistenz ist ferner der hohe Gehalt an Mitochondrien sowie den sarkoplasmatischen $\mathrm{Ca}^{2+}$-Pumpen (SERCA) geschuldet. Im Gegensatz dazu imponieren die schnell-zuckenden Typ-2Fasern mikroskopisch weiß, da sie weitaus weniger Myoglobin in ihrem Zytosol besitzen. 


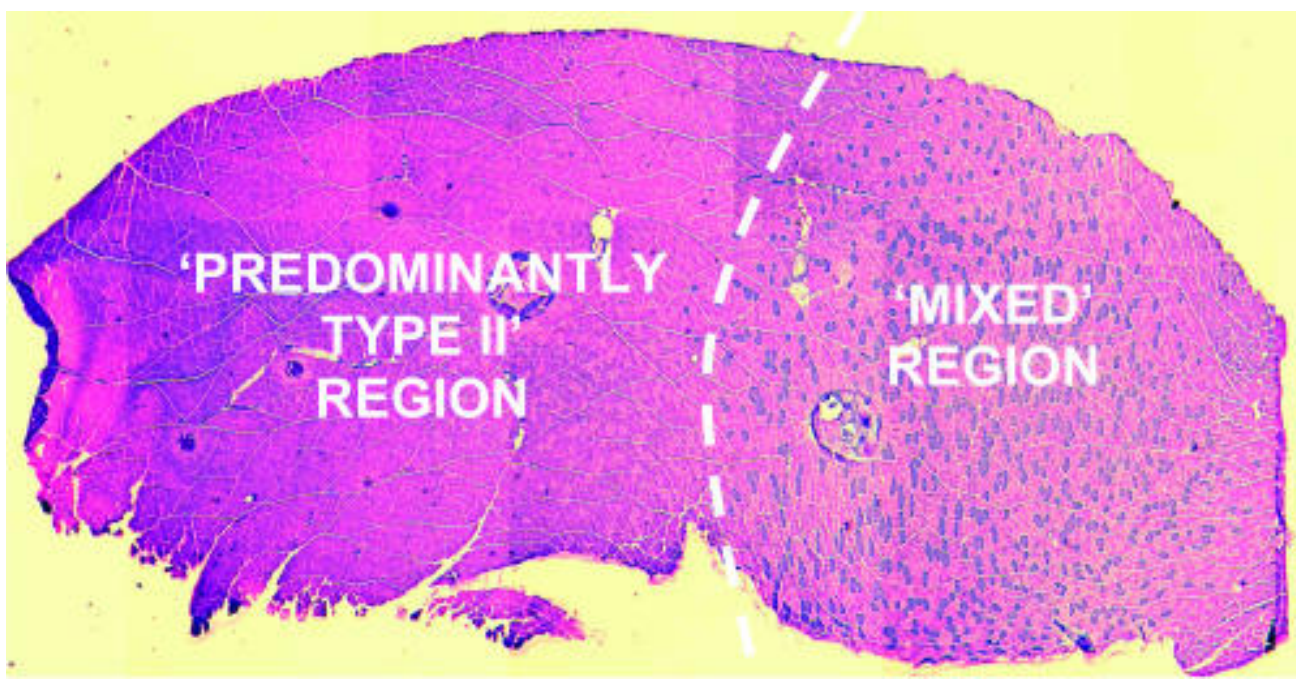

Abbildung 1: weiße, hellere versus rote, dunklere Muskelfasertypen innerhalb eines M. Gastrocnemius einer Ratte, aus [Rossiter et al. 2005] mit freundlicher Genehmigung von John Wiley \& Sons Inc.

Typ-2-Fasern können im Gegensatz zu Typ-1-Fasern ihren kurzzeitigen Energiebedarf durch anaerobe Glykolyse decken. Aus diesem Grund speichern sie möglichst viel Glykogen. Mitochondrien benötigen sie im Vergleich zu Typ-1-Fasern deutlich weniger. Bei der anaeroben Glykolyse fällt Laktat an, welches anschließend über das Blut in die Leber gelangt, wo es zur Neusynthese von Glukose genutzt wird, die dann wiederum übers Blut dem Muskel zur Verfügung gestellt wird (Cori-Zyklus) [Löffler und Pertrides 2007]. Wichtig im Hinblick auf später beschriebene Färbemethoden (siehe 2. Material und Methoden) ist die höhere Aktivität des Isoenzyms Myosin-ATPase in den Typ-2Fasern im Vergleich zu den Typ-1-Fasern. Man unterscheidet weiterhin langsamere Typ2A-Fasern, die zusammen mit Typ-1-Fasern einen Großteil aller Bewegungen ausführen, von schnellen Typ-2B-Fasern, die erst bei starker Muskelarbeit aktiviert werden. Typ2A-Fasern stellen dabei eine Zwischenstufe dar, was unter anderem den Mitochondriengehalt angeht. In der Mehrzahl aller Muskeln kommen Typ-1- und Typ-2-Fasern ungefähr gleich häufig vor. Anders ist die Verteilung bei Muskeln, die vorwiegend der Haltearbeit dienen wie der M. tibialis anterior. Hier kann ein Verhältnis von Typ-1 zu Typ-2 von 66\% Typ-1:34\% Typ-2 gemessen werden [Benninghoff und Drenckhahn 1994]. Ebenfalls entsprechend ihrer Funktion besitzen Muskeln, die vor allem der Schnellkraft dienen, mehr weiße Typ-2-Muskelfasern. Ein Beispiel hierfür ist der Musculus gastrocnemius. 


\subsection{Anpassung des Skelettmuskels an körperliches Training}

Untrainierte Muskeln haben ein recht ausgewogenes Verhältnis von Typ-1- zu Typ-2Muskelfasern, mit Ausnahme solcher Muskeln in denen die anatomische Aufgabe per se die Dominanz eines Fasertyps bedingt. Neben der muskelspezifischen Verteilung von Typ-1- zu Typ-2-Muskelfasern ist für den individuellen Verteilungstyp die Genetik eines Individuums ausschlaggebend. Jedoch kann durch körperliches Training bei jedem Menschen eine Veränderung hinsichtlich seines Verteilungstyps von Muskelfasern erreicht werden. Leistungssportler verfügen deshalb über ein Faserverteilungsprofil, das ihrer Sportart entspricht. Bei Ausdauersportlern liegt vorwiegend eine Typ-1-, bei Sprintern und Kraftsportlern eher eine Typ-2-Dominanz vor. Voraussetzung für eine Anpassung des Muskels ist, dass durch das absolvierte Training ein genügend großer Reiz auf den Muskel ausgeübt wird, der somit erst trainingswirksam ist. Im Rahmen nahezu aller, willkürlicher Kontraktionen eines Muskels werden zuerst langsame motorische Einheiten rekrutiert, weil diese von kleinen $\alpha$-Motoneuronen mit niedriger Reizschwelle innerviert werden. Sofern die Belastung groß genug ist und länger andauert, werden zusätzlich schnelle Typ-2-Einheiten hinzugeschaltet. Ein solches Rekrutieren der größten und schnellsten Fasern geschieht erst bei durchschnittlich 90\% der Maximalkraft. Man bezeichnet dies als Hennemann-Größenordungsprinzip [Dickhuth et al. 2010]. Ein solcher, trainingswirksamer Reiz wird als „Overload“ bezeichnet. Setzt man Menschen einem 24-wöchigen Schnellkrafttraining aus, kommt es $\mathrm{zu}$ einem deutlichen Anstieg seiner Typ-2-Muskelfasern. Diese Änderung der Faserzusammensetzung ist reversibel und kehrt nach mehrwöchiger Ruhe wieder in seinen Ursprungszustand zurück. Abgesehen vom sogenannten Muskelfasershift kommt es zu einer veränderten Proteinexpression.

Dies konnte im untersuchten M. gastrocnemius nachgewiesen werden [Hoff et al. 2013]. Schon nach wenigen Monaten Ausdauertraining ist ein Anstieg verschiedener Enzyme zu verzeichnen, die insbesondere dem Energiestoffwechsel dienen. Dazu gehört die Succinyldehydrogenase, ebenso die Phosphofruktokinase. Dank dieses Effekts auf die Expression von muskelfaserspezifischen Isoenzymen, lässt sich eine Zuordnung von bestimmten Enzymen zu einem Fasertyp vornehmen. Phosphofruktokinase und Citratsynthase sind dabei stärker in Typ-2-Fasern vertreten, während 3-HydroxyacylCoA Dehydrogenase mehr in Typ-1-Fasern exprimiert wird. Außerdem konnten verschiedene Untereinheiten der $\mathrm{Na}^{+}-\mathrm{K}^{+}$-ATPase vermehrt in Typ-1-Muskelfasern nachgewiesen werden [Thomassen et al. 2013].

Neben den genannten Anpassungsvorgängen an das Training findet zudem eine zunehmende Kapillarisierung innerhalb des Muskels statt. So konnte beispielsweise gezeigt werden, dass sechsmonatiges aerobes Ausdauertraining eine Zunahme der Kapillarisierung bewirkt [Prior et al. 2014]. Die daraus resultierende gesteigerte Durchblutung dient dem schnelleren Transport von Nährstoffen, vor allem Sauerstoff 
und Glukose zum Muskel. Ein wesentlicher Einfluss auf die Muskelfaserdicke kann durch Maximalkrafttraining erreicht werden. Dieser Effekt kann bereits nach vierwöchig erfolgtem Krafttraining bei zuvor Untrainierten Individuen beobachtet werden, wodurch der Muskelfaserquerschnitt um durchschnittlich 20\% zunimmt [Mitchell et al. 2013]. Der Muskel unterliegt somit in Faserprofil, Faserdicke, Kapillarisierung und Enzymausstattung seinen an die jeweilige Belastung angepassten Schwankungen.

\subsection{Veränderungen des Muskels im Alter}

Mit zunehmendem Alter kommt es im Organismus zu anthropometrisch messbaren Veränderungen in seiner gesamten Komposition von Bestandteilen. Der Grund dafür liegt in einer Störung der Homöostase, bestehend aus muskelkatabolen und muskelanabolen Einflussfaktoren. Dieses Gleichgewicht stellt dabei einen Knotenpunkt im bioenergetischen System des Organismus dar. Eine negative Beeinflussung zugunsten der katabolen Faktoren bewirkt im Alter eine Reduktion der aktiven Zellmasse, somit von Muskulatur. Diese wird ersetzt durch Fettgewebe. Diese altersbedingte Reduktion an Muskelmasse bezeichnet man als Sarkopenie. Entscheidend für die Betroffenen ist die einhergehende Abnahme an Lebensqualität durch Kraftverlust in Aktivitäten des Alltags. Diese Einbuße an Maximalkraft konnte mit etwa 10\% weniger Schnelligkeit einer Kontraktion und etwa 26\% weniger Maximalkraft von 72-Jährigen im Vergleich zu 25Jährigen nachgewiesen werden [Thompson et al. 2014].

Die Sarkopenie betrifft prinzipiell beide Muskelfasertypen, wobei besonders die schnellen Typ-2-Fasern betroffen scheinen. Das Ausmaß der Progression an Sarkopenie hängt sowohl vom ursprünglichen Vorhandensein der Muskulatur, als auch von Lebensstilfaktoren ab. Im Durchschnitt liegt der jährliche Verlust an Muskelmasse ab dem 50. Lebensjahr bei 1-2\%. Die wesentlichen, diesen Prozess beeinflussenden Faktoren stellen Ernährung und körperliche Aktivität dar. Die Ernährung sollte dabei kalorisch maßvoll und proteinreich sein. Einhergehend sollte Kraft- und Ausdauertraining erfolgen, um einen positiven Effekt zu erzielen. Einen größeren Einfluss auf Muskelmasse und damit auf die Sarkopenie stellt das Krafttraining im Vergleich zum Ausdauertraining dar. Anders als alternde Kraftsportler haben gleichalte Ausdauersportler nur wenig mehr Muskelmasse als untrainierte Gleichaltrige [Dickhuth et al. 2010]. Eine Zunahme an Skelettmuskulatur wirkt einerseits direkt der Sarkopenie entgegen, andererseits beeinflusst eine Zunahme an Muskulatur verschiedene pathologische Stoffwechsellagen positiv. Hierzu gehören vor allem der Lipidhaushalt sowie der Blutzuckerspiegel zusammen mit der Insulinsensitivität. 


\subsection{Osteoporose Definition und Einteilung}

Im Rahmen der Konsensuskonferenz, 1993 in Hongkong wurde Osteoporose als eine Systemerkrankung des Skeletts definiert, ausgezeichnet durch die Merkmale Verminderung der Knochenmasse, Störung der knöchernen Mikroarchitektur einhergehend mit einer Erniedrigung der Knochenfestigkeit bei gleichzeitiger Zunahme des Frakturrisikos (Consensus Development Conference 1993). Sind im Krankheitsverlauf bereits osteoporosebedingte Frakturen aufgetreten, spricht man von manifester Osteoporose. Somit stellt die Osteoporose eine zunächst internistische Erkrankung des Knochenstoffwechsels mit weitreichenden Folgen für die Lebensqualität der Betroffenen dar.

Weiterhin kann die Osteoporose in eine primäre und eine sekundäre Form eingeteilt werden. Die primäre ist dabei zahlenmäßig mit etwa $90 \%$ weit überlegen. Zur primären Osteoporose gehören sowohl der osteoklastenvermittelte Typ-I, bei dem es sich um die postmenopausale Osteoporose handelt, als auch der Typ-II (senile Osteoporose). Beim Typ-I ist vor allem das Trabekelsystem des Knochens betroffen, wodurch es zu den typischen Wirbelkörperfrakturen kommt. Die Typ-II-Osteoporose betrifft stärker den kortikalen Knochen, weshalb hier eher proximale Femurfrakturen oder distale Unterschenkelfrakturen auftreten [Schiltenwolf und Hollo 2014]. Sekundäre Osteoporose betrifft nur etwa 5-10\% aller Osteoporosefälle, wobei diese die Folge einer anderen Grunderkrankung darstellt. Hinzu kommen unbeeinflussbare Faktoren, wie das Alter und Genetik, sowie beeinflussbare Faktoren, wie Ernährung, Bewegung, Hyperkortisolismus, Diabetes und viele andere endokrinologische Erkrankungen.

\subsubsection{Epidemiologie der Osteoporose}

Im Rahmen der Bone Evaluation Study (BEST) [Hadji et al. 2013] wurden die Daten eines großen gesetzlichen Kostenträgers in Deutschland, der Techniker Krankenkasse von 2006-2009 ausgewertet. In diese Studie wurden Versicherte mit der Diagnose Osteoporose, solche mit osteoporosebedingten Frakturen und Versicherte, die Medikamente gegen Osteoporose verordnet bekommen hatten, aufgenommen, sofern sie über 50 Jahre alt waren. Die errechneten Daten wurden anschließend auf Gesamtdeutschland extrapoliert. Heraus kam eine Prävalenz von Osteoporose in Deutschland von $14 \%$ im Kollektiv der über 50-Jährigen insgesamt, mit einer geschlechtsspezifischen Verteilung von $26 \%$ bei Frauen zu $6 \%$ bei Männern. Die Inzidenz der gleichen Altersgruppe betrug 2,1\%. Auf Deutschland bezogen kommt man so auf 885.000 Neuerkrankungen pro Jahr. Dabei erlitten 52\% der Betroffenen 
Frakturen. Die daraus entstehenden Kosten belaufen sich auf $5540 €$ pro Versichertem zulasten der Gesetzlichen Krankenkassen hierzulande. Von den Frakturkosten betrugen $714 €$ osteoporosespezifische Kosten pro Versichertem. Wiederum hochgerechnet auf Deutschland ergibt dies eine Belastung für das Gesundheitssystem in Höhe von 4,5 Mrd. € pro Jahr [Hadji et al. 2013]. Stürze sind dabei mit 90\% der häufigste Grund für Femurfrakturen, wobei die Osteoporose entscheidend für die Instabilität des Knochens ist [Grisso et al. 1991].

Osteoporosebedingte Frakturen treten typischerweise in einem Alter zwischen 50 und 80 Jahren mit einer Inzidenz von $1 \%$ bei Frauen und $0,7 \%$ bei Männern auf. In Deutschland wird sich laut Hochrechnungen des Statistischen Bundesamtes bis zum Jahr 2050 die Inzidenz von Femurfrakturen verdoppeln. Dies ist auch der demografischen Entwicklung geschuldet.

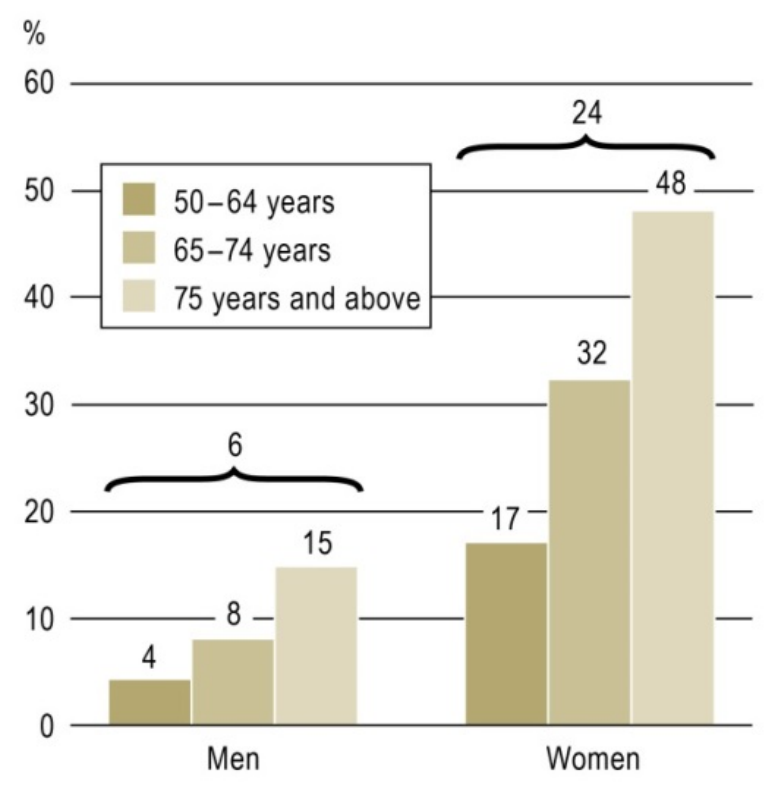

Abbildung 2: Prävalenz der Osteoporose in Deutschland aus [Hadji et al. 2013] mit freundlicher Genehmigung des Deutschen Ärzteverlages

\subsubsection{Sarkopenie und Osteoporose}

Wie oben beschrieben, bedingt die Osteoporose eine verminderte Stabilität und damit erhöhte Bruchanfälligkeit von Knochen. Vor allem hüftgelenksnahe Femur- und Wirbelkörperfrakturen werden dabei von Stürzen verursacht. Die Skelettmuskulatur spielt hinsichtlich des Sturzrisikos eine entscheidende Rolle. Kommt es, wie unter 1.4 beschrieben, zur altersbedingten Sarkopenie, einhergehend mit der Osteoporose, stellt 
dies für den Patienten eine besonders ungünstige Kombination von Risikofaktoren hinsichtlich einer sturzbedingten Fraktur dar. Die Sarkopenie führt nicht nur zu einem Verlust an Muskelmasse, sondern auch zu einer damit verbundenen Abnahme von Kraftund Geschicklichkeit. Des Weiteren führt die Sarkopenie zu einer verminderten Balancefähigkeit und Haltungsstabilität. Hierdurch sind Reflexe zur Haltungsstabilität, wie der Beuge- Streckreflex ebenfalls beeinträchtigt, wodurch es wiederum zu mehr Stürzen kommen kann. Diese Aspekte können allerdings durch die Rumpfmuskulatur stabilisierende, vor allem isometrische Übungen verbessert werden [Pata et al. 2014].

Es existiert eine endokrine Achse zwischen Muskel und Knochen, bestehend aus Insulinlike Growth Factor 1, den Interleukinen-6, -7, -15, Osteoglycin und anderen Stoffen, die vom Muskel auf den Knochen wirken, zudem Substanzen, die vom Knochen gebildet, den Muskel beeinflussen: Sclerostin und Osteocalcin. Offensichtlich ist diese Homöostase bei Osteoprose gestört, sodass der Muskel atrophiert und insuffizient wird. In verschiedenen Studien konnte gezeigt werden, dass sich der Muskel im Rahmen der Osteoporose verändert: Die Anzahl der Muskelfasern, deren Dicke und Kapillarisierung ist vermindert [Terracciano et al. 2013]. Typ-2-Muskelfasern sind ebenfalls im Verhältnis zu Typ-1-Muskelfasern reduziert [Tarantino et al. 2013]. Ein insuffizienter Muskel führt zu Haltungsschäden, wobei insbesondere die Kyphosierung der Wirbelsäule ein psychologisches Problem für Patienten darstellt.

\subsubsection{Diagnostik der Sarkopenie}

Der durch die Sarkopenie bedingte Schwund an Muskelmasse kann mittels bildgebender Verfahren wie Computertomographie und MRT diagnostiziert werden. Eher in der Forschung, da aufwendiger, kann dies auch durch Dual-Röntgen-Absorptiometrie (DXA) geschehen, die der Flächendichtebestimmung hinsichtlich Körperzusammensetzung dient. Ebenso selten werden Bio-Impedanz-Analysen (BIA) angefertigt. Es kann darüber hinaus eine Messung des Körperkaliums, bezogen auf das fettfreie Körpergewebe, vorgenommen werden.

Neuere Studien legen nahe, dass es sich bei der im Serum gemessenen Konzentration des Enzyms Kreatinkinase möglicherweise um einen effektiven Marker von Sarkopenie handeln könnte [Palus et al. 2014]. Die Überschreitung eines noch zu definierenden Grenzwertes könnte dabei einen Hinweis auf einen pathologischen Abbauprozess des Muskels geben.

Klinisch unkomplizierter zur Bestimmung der Muskelkraft dient zuerst der Händedruck. Zudem gibt es noch Leistungstests, wie den Timed-get-up-and-go-Test. Dabei wird die Zeit gestoppt, die der Patient benötigt, um aus einem Stuhl aufzustehen, drei Meter zu 
gehen und sich anschließend wieder hinzusetzen. Eine Zeit unter 10 Sekunden gilt als normal. Zwischen 11 bis 19 Sekunden als geringe Mobilitätseinschränkung, über 20 Sekunden als funktionell relevante Mobilitätseinschränkung. Dem Untersucher steht als Leistungstest noch der Stair-climb-Power-Test zur Verfügung, um das anaerobe Kraftausmaß des Patienten abzuschätzen. In der klinischen Praxis erfolgt die Beurteilung der körperlichen Leistungsfähigkeit jedoch vor allem durch die Ermittlung der gewohnten Ganggeschwindigkeit und der Short-Physical-Performance-Battery (SPPB). Liegt die gewohnte Ganggeschwindigkeit unter 0,8 m/s liegt dem ein pathologisches Leistungsdefizit zugrunde [Cruz-Jentoft et al. 2010].

Der SPPB umfasst neben der Ganggeschwindigkeit noch die Parameter statisches Gleichgewicht und Aufstehtest. Hiervon die höchste Relevanz, das heißt Assoziation zur Sarkopenie besitzt der Stair-climb-power-test [Bean et al. 2007]. Die European Working Group on Sarcopenia in Older People (EWGSOP) hat anhand oben genannter Parameter 2010 im Rahmen einer Konsensus Konferenz drei Stadien der Sarkopenie definiert. Das Stadium der prä-Sarkopenie ist durch alleinigen Verlust an Muskelmasse ohne messbare Auswirkungen auf Muskelkraft oder Leistungsfähigkeit bestimmt. Das Stadium Sarkopenie ist durch messbaren Verlust an Muskelmasse, zusammen mit verminderter Muskelkraft oder Leistungsfähigkeit definiert. Im Stadium der schweren Sarkopenie liegt eine verminderte Muskelmasse, einhergehend mit einer deutlich reduzierten Muskelkraft und Leistungsfähigkeit vor [Cruz-Jentoft et al. 2010].

\subsubsection{Therapie der Sarkopenie}

Da Sarkopenie oft zusammen mit Kachexie und Malnutrition auftritt, spielt die Behandlung dieser Nebenfaktoren eine wichtige Rolle. Hierzu empfiehlt sich bei fast allen Patienten mit Sarkopenie eine Substitution von Nährstoffen. Als solche sind in erster Linie zu nennen die Vitamine E und D sowie Proteine insgesamt. Das Vitamin E ist dabei in der Lage, die im Muskelstoffwechsel anfallenden reaktiven Sauerstoffspezies (englisch ROS) unschädlich zu machen. Diese antioxidative Eigenschaft führt zu einem positiven Effekt auf verschiedene Signalwege innerhalb der Muskelzellen [Khor et al. 2014].

Am wirksamsten zur Erhaltung und Verbesserung der Muskelmasse hat sich neben dem Einsatz von anabolen Steroiden die Trias aus proteinreicher Ernährung, Vitamin D Substitution und regelmäßigem Krafttraining erwiesen. Dabei sollten 1-1,2 g pro kg Körpergewicht Proteine pro Tag aufgenommen werden, davon 20-25 g hochwertiges Protein mit jeder Mahlzeit. Vom Vitamin D sollten täglich mindestens 800 IE eingenommen werden, um eine wirksame Anhebung der Serumkonzentration von 
25-Hydroxyvitamin D zu erreichen. Das Krafttraining sollte drei bis fünfmal pro Woche erflogen, mit zeitlich naher Proteinaufnahme [Rizzoli et al. 2014].

Der Einsatz von anabolen Steroiden sollte dabei als eine weitere Möglichkeit in Betracht gezogen werden [Samaras et al. 2014]. Allerdings ist die Indikationsstellung Gegenstand aktueller Studien und deshalb noch umstritten. Die Lebenserwartung von älteren männlichen Patienten mit Sarkopenie unterscheidet sich nicht wesentlich von gesunden Gleichaltrigen. Bei Frauen allerdings kommt es zu einer mit Sarkopenie assoziierten erhöhten Mortalität [Batsis et al. 2014].

\subsection{Baicalein}

Baicalein ist einer der Stoffe, die aus den Wurzeln der Pflanze Scutellaria baicalensis Georgi extrahiert werden können. Die anderen hieraus gewonnen Substanzen sind das Aglycon Baicalin, Wogonosid, dessen Aglycon Wogonin, Oroxylin und Scutellarin. Der weiten Verbreitung des Baikal-Helmkrauts von Sibirien (Baikalsee) bis nach China und Nordamerika entsprechend, wurde es in diesen Gegenden bereits seit Jahrhunderten in traditionellen Naturheilverfahren verwendet. Mittlerweile konnten einige dieser beschriebenen Effekte nachgewiesen werden. Das Anwendungsgebiet ist sehr vielseitig. Die Wirkungen sind dabei sowohl antiproliferativ und apoptosestimulierend, wie auch anti-inflammatorisch. Zudem konnte eine kardio- und neuroprotektive Wirkung nachgewiesen werden, ebenso eine psychisch beruhigende, ähnlich dem Baldrian [Gaire et al. 2014]. Darüber hinaus haben Studien gezeigt, dass Baicalein ebenfalls degenerative Knochenerkrankungen positiv beeinflusst. Untersucht wurde die positive Wirkung zum Beispiel auf Rheumatoide Arthritis [Chen 2011]. Hier spielen eine Vielzahl von Entzündungsmediatoren eine Rolle, die den Knochenabbau stimulieren, wie es auch bei Osteoporose der Fall ist. Kürzlich konnte nachgewiesen werden, dass Baicalein in der Lage ist diese Kaskade $\mathrm{zu}$ durchbrechen, indem es gezielt Interleukin-1 $\beta$, Tumornekrosefaktor- $\alpha$ sowie verschiedene Matrixmetalloproteasen hemmt [Zhang X et al. 2014].

Eine aktuelle chinesische Studie wies einen inhibierenden Effekt des Baicaleins auf Brustkrebszellen nach, indem Baicalein die DDIT4 induziert, die wiederum mTORC1 und damit das Tumorwachstum hemmen [Wang Y et al. 2015]. Baicalein scheint somit einen generell positiv regulierenden Effekt auf das gestörte Zellwachstum zu haben. In verschiedenen Studien konnte gezeigt werden, dass Baicalein in der Leber durch Biotransformation $\mathrm{zu}$ verschiedenen Metaboliten konjugiert wird. Biotransformation kann in zwei Schritte unterteilt werden (I und II) und bedeutet zunächst das Anfügen 
funktioneller Gruppen an das Zielmolekül. Dies sind vor allem Hydroxyl- und Sulfhydrilgruppen. Im Fall des Baicaleins sind bereits drei Hydroxylgruppen am Molekül vorhanden, an die leicht durch Biotransformation II weitere Gruppen angehängt werden können. Diesen Vorgang bezeichnet man auch als Biotransformation II beziehungsweise Konjugation. Die komplette Biotransformation findet in der Leber statt, nachdem Baicalein aus dem Darm oder wie im vorliegenden Versuch aus dem subkutanen Fettgewebe- ins Blut- und anschließend in die Leber gelangt. Die in der Leber durch Konjugation angehängten Stoffgruppen sind vor allem Sulfate und Glucuronide. Siehe Abbildung 3. Erst einige dieser Metaboliten sind als pharmakodynamisch wirksam beschrieben. Welche der aufgezählten Metaboliten hierbei wirksam sind, ist noch nicht abschließend geklärt. Entscheidend für den Abbau der Metaboliten sind sogenannte OATPs (organic anion transport proteins) und MRPs (multidrug resistance proteins), die den Transport der Stoffwechselprodukte in die Galle bewerkstelligen [Zhang L et al. 2011]. Allen Derivaten bis auf Wogonosid gemein ist eine antioxidative Wirkung, die an Linolensäure nachgewiesen wurde [Wozniak et al. 2014]. 


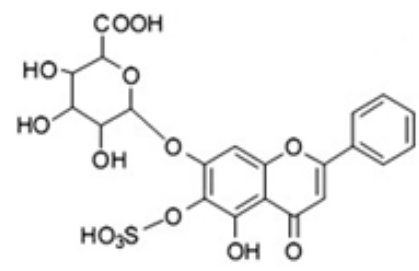

Baicalein-o-glucuronid-o-sulfat
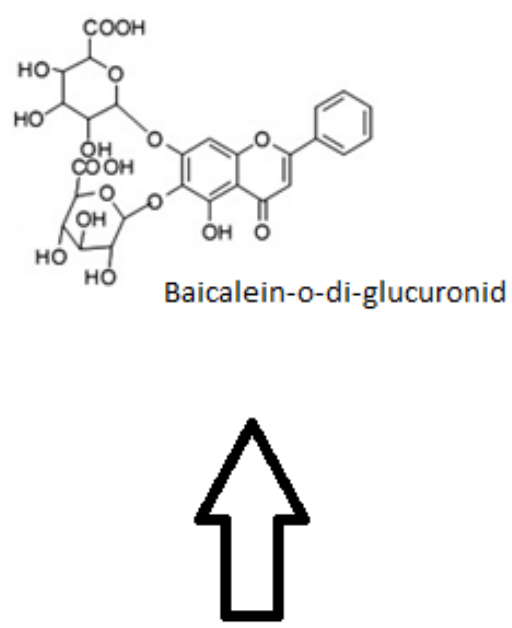<smiles>O=c1cc(-c2ccccc2)oc2cc(O)c(OS(=O)(=O)O)c(O)c12</smiles>

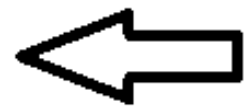

Baicalein-o-sulfat<smiles>COc1c(OC2OC(C(=O)O)C(O)C(O)C2O)cc2oc(-c3ccccc3)cc(=O)c2c1O</smiles>

Methyl-o-baicalein-o-glucuronid

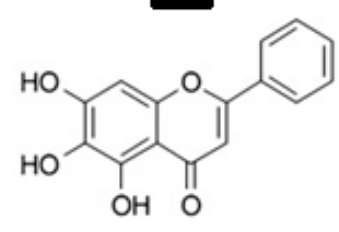

Baicalein<smiles>O=c1cc(-c2ccccc2)oc2cc(O)c(O)c(O)c12</smiles>

Baicalein-o-glucose-o-glucuronid

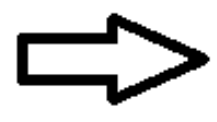<smiles>COc1cc2oc(-c3ccccc3)cc(=O)c2c(O)c1OS(=O)(=O)O</smiles>

Methyl-o-baicalein-o-sulfat<smiles>O=C(O)C1C(O)C(O)C(O)C(Oc2c(O)cc3oc(-c4ccccc4)cc(=O)c3c2O)C1O</smiles>

Baicalein-6-o-glucuronid

Abbildung 3: Baicalein und seine Metaboliten 


\section{Material und Methoden}

\subsection{Versuchstiere}

Bei den Versuchstieren handelte es sich zu Versuchsbeginn um 61 weibliche, drei Monate alte Ratten der Rasse Sprague Dawley von der Firma Winkelmann. Alle Tiere waren mit einem im Nacken implantierten Transponder versehen, sodass jederzeit eine Identifizierung jedes einzelnen Tieres anhand einer individuellen Kennnummer möglich war. Die Tiere wurden über die Dauer des gesamten Versuchs in der Zentralen Tierexperimentellen Einrichtung (ZTE) der Universitätsmedizin Göttingen in Käfigen des Typs Makrolon IV® gehalten. Dabei befanden sich in jedem Käfig drei bis fünf Tiere. Alle drei Tage wurde der Käfig gegen einen desinfizierten ausgewechselt. Trinkwasser wurde täglich in die dafür vorgesehenen Spender nachgefüllt. Gefüttert wurden die Ratten einmal wöchentlich. Dazu wurde wöchentlich eine Ration von 1500 g sojafreiem Futter aufgefüllt und das verbliebene Restfutter gewogen, sodass die pro Woche gefressene Menge bestimmt werden konnte. Außerdem wurden die Tiere wöchentlich gewogen. Die Tiere wurden bei konstanten $20^{\circ} \mathrm{C}$ und einer Luftfeuchtigkeit von ca. 55\% gehalten. Es wurde hierbei auf eine 12-Stunden-hell-dunkel Rhythmik geachtet. Die im Rahmen des Forschungsprojektes durchgeführten Tierversuche wurden von der Bezirksregierung Braunschweig (Aktenzeichen G 14/1530) genehmigt.

\subsection{Versuchsablauf}

Zu Beginn des Versuchs wurden 61 Tiere in fünf Gruppen eingeteilt. Eine Woche nach Ankunft der Tiere wurden vier der fünf Gruppen beidseitig ovariektomiert, damit diese Ratten daraufhin eine Osteoporose entwickelten. Acht Wochen später wurde bei allen Ratten eine Osteotomie mit Plattenosteosynthese der Tibia durchgeführt. Peri- und postoperativ starben elf Ratten, sodass fortan das Gesamtkollektiv 50 Versuchstiere betrug (siehe Tabelle 1: Aufteilung Tiere und Behandlung). In der Annahme, dass die ovariektomierten Ratten acht Wochen nach Ovariektomie unter einer Osteoporose mit einhergehender Sarkopenie litten, wurde ab diesem Zeitpunkt mit der Baicaleintherapie begonnen. Ab dem ersten postoperativen Tag nach Osteotomie für insgesamt vier Wochen wurde den dafür vorgesehenen Ratten die jeweilige Dosierung Baicalein täglich subkutan appliziert. Die insgesamt 30 Tiere, die Baicalein verabreicht bekamen, wurden in drei Gruppen von jeweils zehn Tieren aufgeteilt. Die erste Gruppe bekam für die nächsten vier Wochen Baicalein $1 \mathrm{mg} / \mathrm{kg} \mathrm{KG}$; die nächste Gruppe $10 \mathrm{mg} / \mathrm{kg}$ KG Baicalein und die letzte Gruppe 100 mg/kg KG Baicalein. Zur besseren Auswertung der 
Knochenheilung nach Versuchsende bekamen die Versuchstiere zusätzlich zur Baicaleintherapie zu bestimmten Zeitpunkten verschiedene Farbstoffe verabreicht. Am 15. Behandlungstag wurde allen Ratten $90 \mathrm{mg} / \mathrm{kg}$ KG Xylenol Orange (XO) appliziert, am 20. Behandlungstag der Farbstoff Calcein Grün (CG) in einer Dosierung von $10 \mathrm{mg} / \mathrm{kg}$ KG. Zudem wurde den Ratten am 29. Behandlungstag der Farbstoff Alizarin Komplexon (AK), $30 \mathrm{mg} / \mathrm{kg}$ KG, verabreicht. Schließlich wurden alle Ratten durch Dekapitation getötet.

Tabelle 1: Aufteilung der Tiere und Behandlung

\begin{tabular}{|c|c|c|c|}
\hline Gruppe & Behandlung & $\begin{array}{c}\text { Anzahl Tiere zu } \\
\text { Beginn }\end{array}$ & $\begin{array}{c}\text { Anzahl Tiere zum } \\
\text { Ende }\end{array}$ \\
\hline NON-0VX & keine & 12 & 10 \\
\hline OVX & Ovariektomie & 12 & 10 \\
\hline Baicalein1 & $\begin{array}{c}\text { Baicalein 1 mg/kg } \\
\text { KG/Tag }\end{array}$ & 12 & 10 \\
\hline Baicalein2 & $\begin{array}{c}\text { Baicalein } 10 \mathrm{mg} / \mathrm{kg} \\
\mathrm{KG} / \mathrm{Tag}\end{array}$ & 12 & 10 \\
\hline Baicalein3 & $\begin{array}{c}\text { Baicalein } 100 \mathrm{mg} / \mathrm{kg} \\
\text { KG/Tag }\end{array}$ & 12 & \\
\hline
\end{tabular}




\subsubsection{Ovariektomie}

Die Ovariektomie fand im OP der Zentralen Tierexperimentellen Einrichtung der Universitätsmedizin Göttingen statt. Die Tiere wurden zunächst im OP-Gebiet kurz hinter dem Rippenbogen bis zum Hinterlauf rasiert. Anschließend wurde den Tieren ein 3:1 Gemisch von Ketamin-Dormitor 0,1 ml/100g KG intraperitoneal injiziert und sie damit anästhesiert. Nun wurde der OP Bereich mit Betaisodona®-Lösung desinfiziert. Die Haut wurde mit Skalpell und Schere inzidiert und die Adnexe freipräpariert und dargestellt.

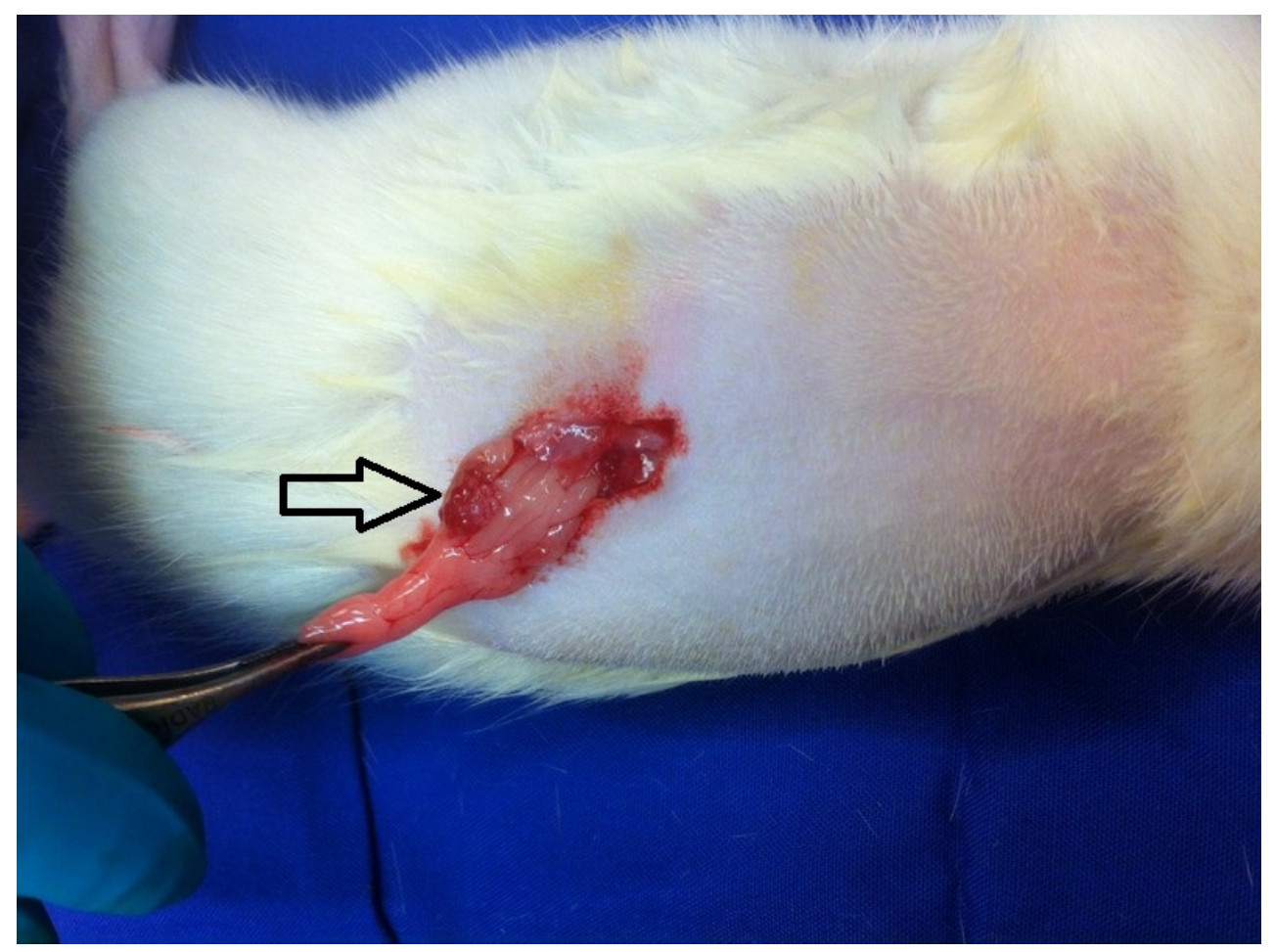

Abbildung 4: freipräparierte Adnexe; Pfeil markiert das Ovar

Das dargestellte Ovar konnte anschließend auf Höhe der Tuba uterina mitsamt zu- und abführenden Gefäßen ligiert werden. Die ligierte Adnexe wurde nun mit einem Skalpell abgetrennt. Schließlich konnte die etwa zwei Zentimeter lange OP-Wunde verschlossen werden. 


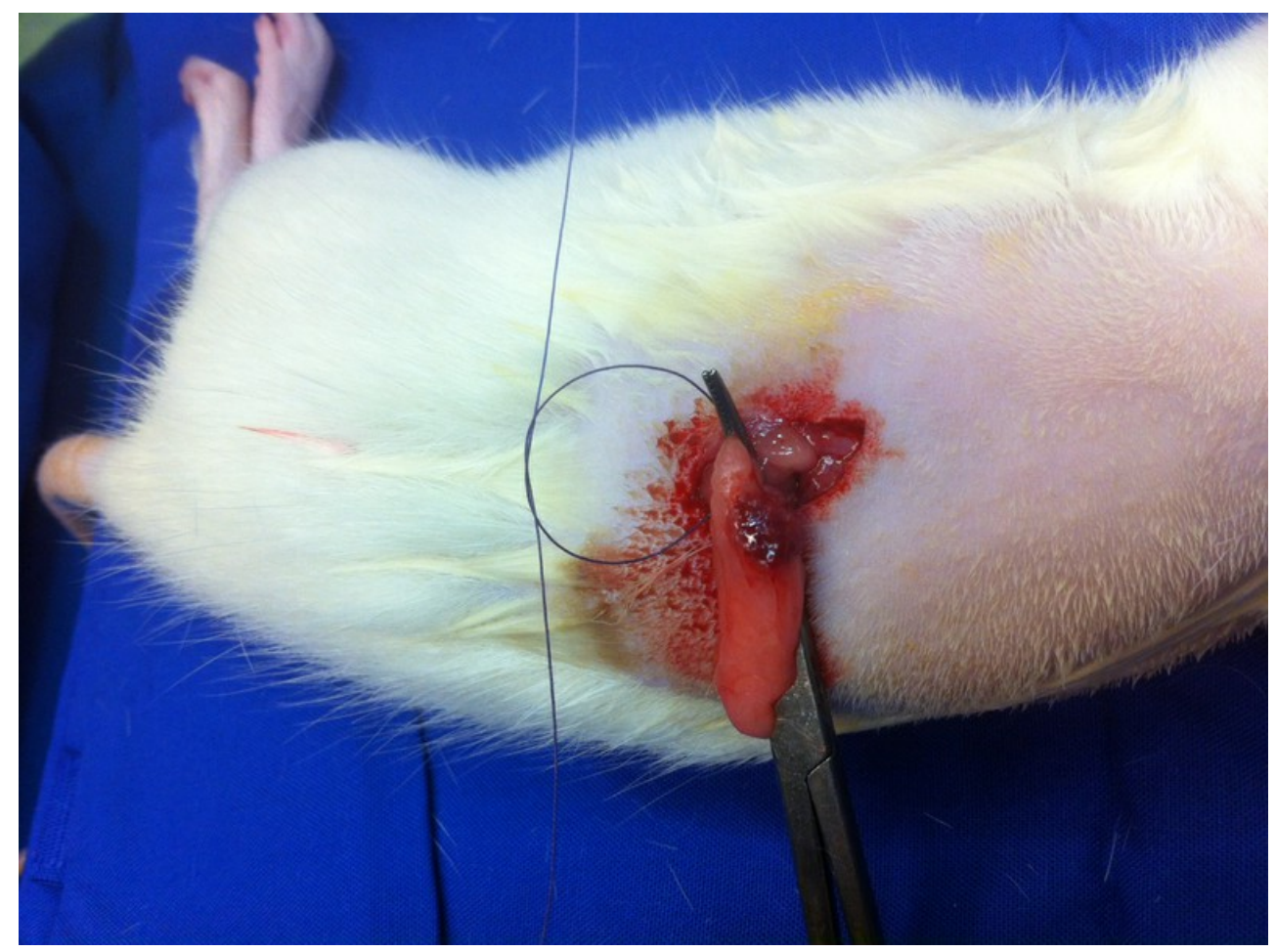

Abbildung 5: Ligatur der Adnexe

Hierzu wurde zuerst die Muskulatur mittels Einzelknopf eines Vicrylfaden vernäht. Anschließend mit etwa $5 \mathrm{~mm}$ langen Metallklammern die Cutis verschlossen. Insgesamt war darauf zu achten, dass die Ratten nicht zu lange auf dem OP-Tisch verblieben, um eine Unterkühlung $\mathrm{zu}$ vermeiden. Hierzu wurden sie anschließend auf einer Wärmematte dicht beieinander gelegt. Zudem wurden sie bis zum Ende der Narkose hinsichtlich ihrer Kreislauffunktion beaufsichtigt. Zum Flüssigkeitsausgleich wurde ein Depot von $3 \mathrm{ml}$ physiologischer Natriumchloridlösung subkutan verabreicht. Trotz dieser Vorsichtsmaßnahmen verstarben perioperativ der Ovariektomie und späteren Osteotomie elf Tiere

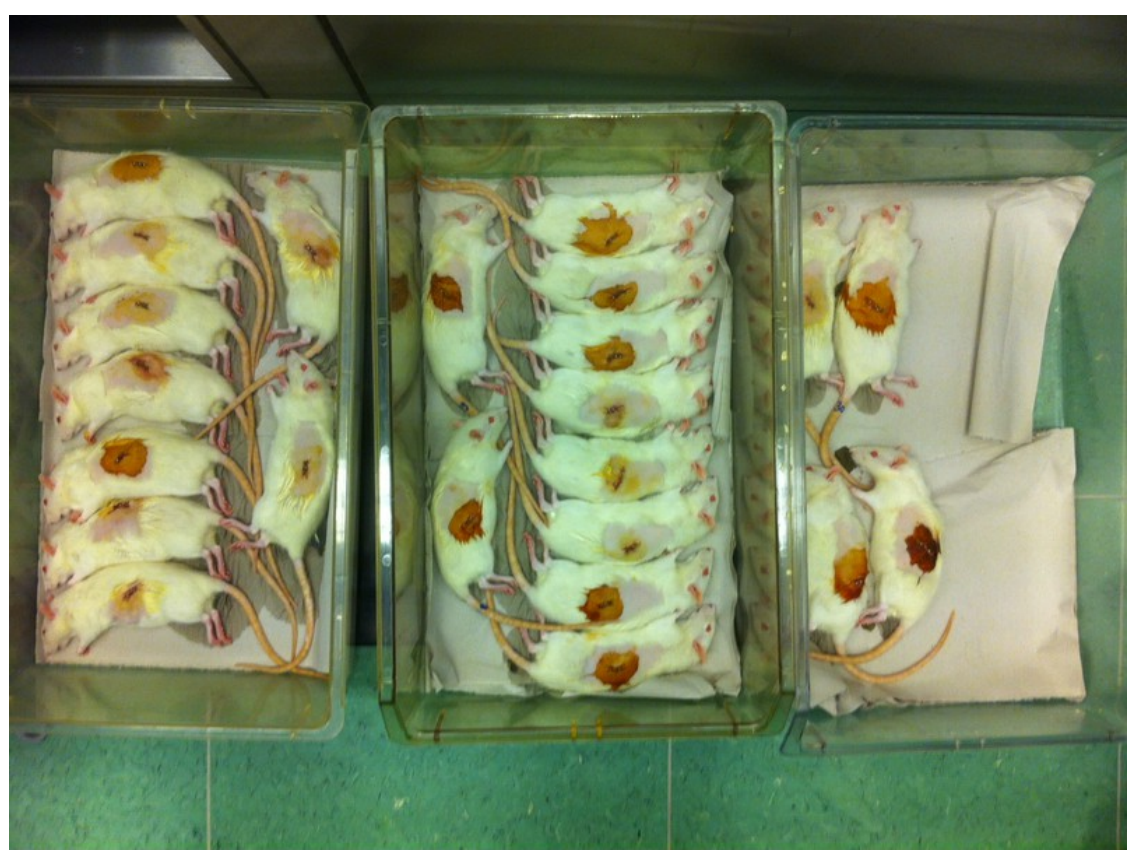

Abbildung 6: Ratten postoperativ 


\subsubsection{Osteotomie}

Bestandteil eines anderen Versuchs war es, den Einfluss von Baicalein auf die Frakturheilung auszuwerten. Hierzu wurde allen Ratten acht Wochen nach Ovariektomie die osteotomierte Tibia mittels Plattenosteosynthese versorgt und die Knochenheilung unter Baicalein ausgewertet und im Rahmen anderer Dissertationen bearbeitet. Zudem wurde den Ratten im Rahmen der Arbeiten zur Knochenanalyse sogenannte 4-Fluorochrome subkutan appliziert, sodass neugebildete Knochensubstanz markiert wurde. In der vorliegenden Arbeit wird auf diesen Arbeitsschritt nicht weiter eingegangen.

\subsubsection{Baicalein-Applikation}

Die Versuchstiere hatten spätestens acht Wochen nach Ovariektomie eine manifeste Osteoporose mit einhergehender Sarkopenie [Kim et al. 2014]. Ab diesem Zeitpunkt, das heisst einen Tag nach Osteotomie, wurde den vorgesehenen Tieren Baicalein der Firma Sigma verabreicht. Um das Baicalein als Flüssigkeit applizieren zu können, musste es zuvor in $100 \%$ Dimethylsulfoxid (DMSO), einem organischen Lösungsmittel aus der Gruppe der Sulfoxide, gelöst werden. Die Kontrollgruppen NON-OVX und OVX bekamen allein das DMSO gespritzt, um einen eventuellen Effekt des DMSOs sichtbar zu machen.

Zur Verabreichung wurden die Ratten in 3 Gruppen zu je 10 Tieren aufgeteilt. Eine Gruppe bekam Baicalein in einer Dosierung von $1 \mathrm{mg} / \mathrm{kg} \mathrm{KG}$, eine Gruppe Baicalein $10 \mathrm{mg} / \mathrm{kg} \mathrm{KG}$ und eine Gruppe Baicalein 100 mg/kg KG. Diese Konzentration bezogen auf das Körpergewicht entsprach einem Volumen von 0,6 ml Baicaleinlösung für jede Ratte. Bei der Verabreichung war darauf zu achten täglich zur gleichen Tageszeit zu spritzen.

Gespritzt wurde mit $1 \mathrm{ml}$ Spritzen Omnifix® und Sterican ${ }^{\circledR}$ Kanüle 0,45 mm x 25 mm, beides von der Firma Braun. Zum Spritzen wurde immer ein Tier aus dem Käfig entfernt und mit einer Hand zwischen den Vorderläufen und einer Hand am Schwanz auf einer weichen Unterlage fixiert. Die gespritzten Ratten aus einem Käfig wurden in einen zweiten bereitgestellten Käfig des gleichen Typs gesetzt bis alle Ratten eines Käfigs gespritzt waren. Das Spritzen fand in einem separaten Raum neben dem Haltungsraum im ZTE statt. Die Ratten wurden während der Behandlung schonend in abgedeckten Käfigen gehalten. 


\subsection{Muskelpräparation}

Nach vierwöchiger Baicaleinbehandlung erfolgte die Tötung der Versuchstiere durch Dekapitation. Diese erfolgte in zuvor eingeleiteter $\mathrm{CO}_{2}$-Gas-Narkose. Außerdem wurde allen Ratten der Uterus entnommen und gewogen, zum Beweis der erfolgreichen Ovariektomie.

Es waren nun zur Auswertung zu präparieren: der Musculus gastrocnemius, Musculus soleus und Musculus longissimus. Von allen Muskeln war randomisiert eine Körperseite, links oder rechts zu präparieren. Die Knochen Tibia, Femur, sowie fünf Wirbelkörper wurden ebenfalls entnommen, jedoch als Gegenstand anderer Arbeiten. Die Präparation begann mit einem Hautschnitt in Höhe der Tibia und Abtrennung der oberflächlichen Muskeln bis hinab auf den M. gastrocnemius mit Hilfe einer spitzen Schere. Der so freipräparierte M. gastrocnemius konnte dann an seinem distalen Sehnenansatz zusammen mit dem Ansatz des tiefer liegenden M. soleus mit einem Skalpell durchtrennt werden. Nun wurde der M. gastrocnemius mit einer Pinzette angehoben, woraufhin der darunterliegende M. soleus zum Vorschein kam.

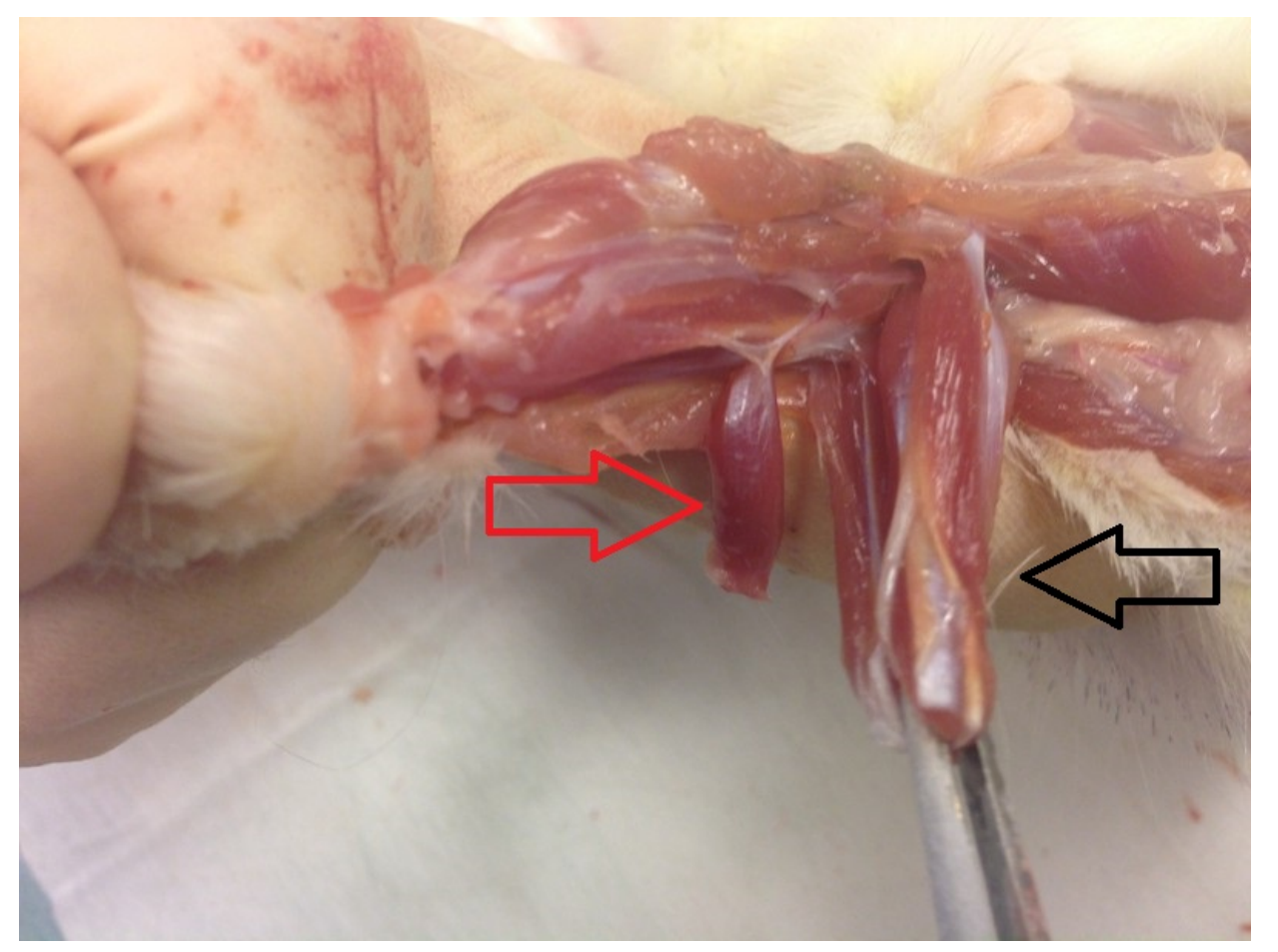

Abbildung 7:
Präparation
Unterschenkel
roter Pfeil
M.soleus;
schwarzer Pfeil
M.gastrocnemius

Dieser wurde mit einer Pinzette weiter freipräpariert. Anschließend wurden beide Muskeln zusammen an ihrem proximalen Ursprung abgetrennt. Die entnommenen Muskeln wurden daraufhin gewogen und deren Gewicht dokumentiert. Bevor diese beiden Muskeln in flüssigem Stickstoff eingefroren wurden, war der M. gastrocnemius 
noch auf der Hälfte im Querschnitt zu durchtrennen, was das spätere Schneiden in der Mitte zu erleichtern half.

Zur Präparation des M. longissimus wurde mit der Schere die Haut am Rücken der Ratten vom Os sacrum bis zu den Schulterblättern inzidiert. Nach Abtrennung der oberflächlichen Muskeln konnte man den M. longissimus oberhalb seines Ursprungs am Os sacrum mit dem Skalpell absetzen und unter Zug durch die Pinzette mit Hilfe des Skalpells in seinem Verlauf von Wirbelsäule und Rippen bishin zum letzten Halswirbel der Ratte scharf freipräparieren.

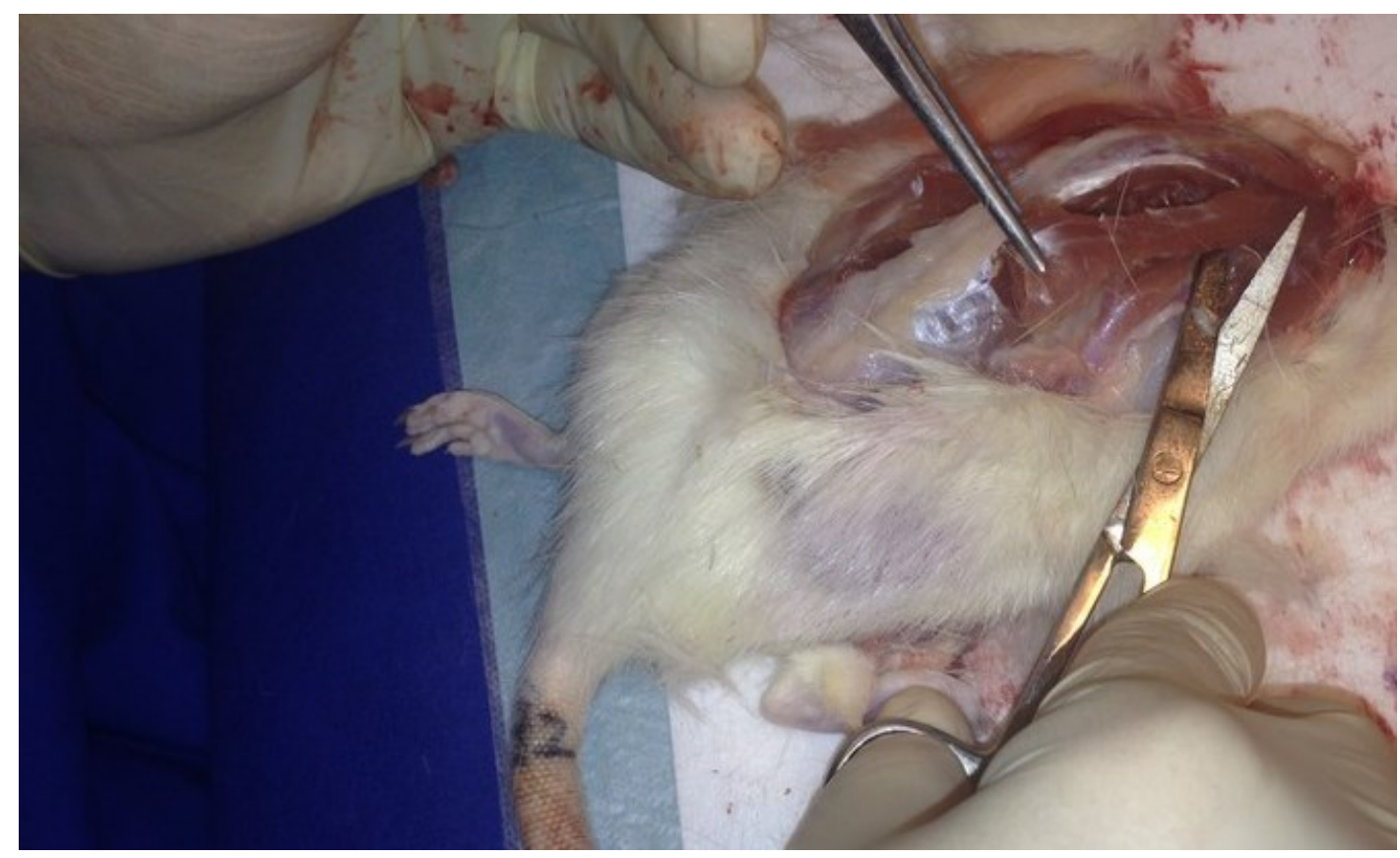

Abbildung 8: präparierter M. longissimus: Pinzette hält caudalen Teil, Schere fasst kranialen Teil des Muskels.

Nach etwa 4-5 cm wurde dieser Muskel kranial auf Höhe der Vorderläufe abgetrennt. Auch dieser Muskel wurde einseitig zur Enzymanalyse verwende sowie das Exemplar der Gegenseite zur histologischen Auswertung entnommen. Alle zur histologischen Auswertung verwendeten Muskeln wurden mit Alufolie umwickelt und beschriftet. 


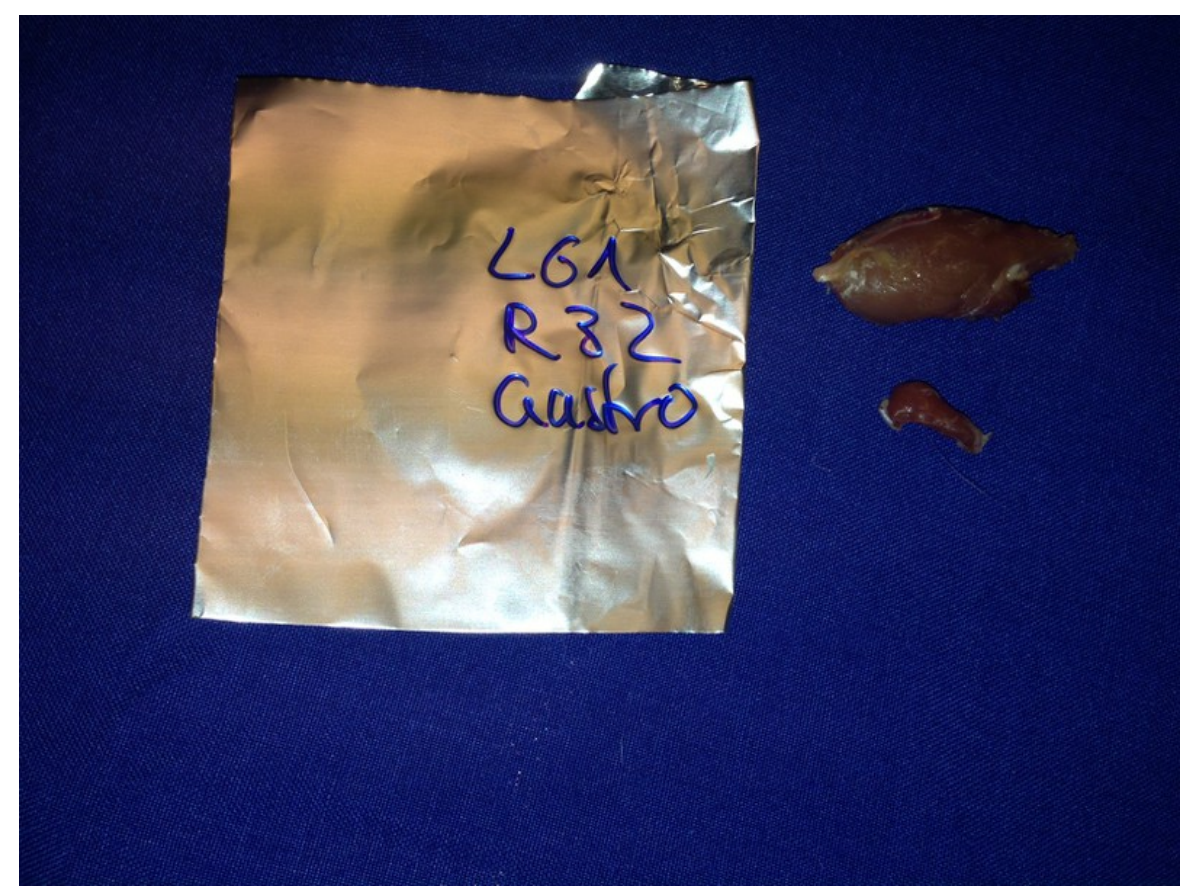

Abbildung 9: entnommene Muskeln gastrocnemius und soleus

Anschließend wurden die verpackten Muskeln in flüssigem Stickstoff bei $-80{ }^{\circ} \mathrm{C}$ aufbewahrt. Am Ende jedes der drei Tötungstage wurden sie im Labor sortiert und bis zur späteren Auswertung in der Kühltruhe eingefroren.

\subsection{Anfertigen der mikroskopischen Schnitte}

Zur späteren mikroskopischen Auswertung mussten zunächst Schnitte der Muskeln auf Objektträgern angefertigt werden. Hierzu wurde das Mikrotom des Instituts für Nutztierwissenschaften benutzt. Es handelte sich um das Modell CM 1900 Cryostat der Firma Leica-Microsystems, Nussdorf, Deutschland. An diesem Gerät ist das Mikrotom in eine Kühlkammer eingebaut, welches das Fertigen von Gefrierschnitten ermöglicht. Diese Kühlkammer kann an der Stelle des Mikrotoms auf $-35^{\circ} \mathrm{C}$ heruntergekühlt werden. Zum Anfertigen, der für diesen Versuch benötigten Schnitte, wurde am Mikrotom direkt eine Temperatur von ca. $-20^{\circ} \mathrm{C}$ eingestellt. Die Dicke der Schnitte kann zwischen 1 und $60 \mu \mathrm{m}$ eingestellt werden. Für diesen Versuch waren Schnitte in einer Dicke von $12 \mu \mathrm{m}$ anzufertigen. Die ebenfalls in der Kühlkammer erfolgende Fixierung der Proben an vorgesehenen Platten mittels gefrierendem Wasser erfolgte bei ca. $-18^{\circ} \mathrm{C}$. Die jeweils an den verschiedenen Orten innerhalb der Kühlkammer herrschenden Temperaturen konnten außen am Gerät (siehe Abbildung 11: Mikrotom) eingestellt und variiert werden. 


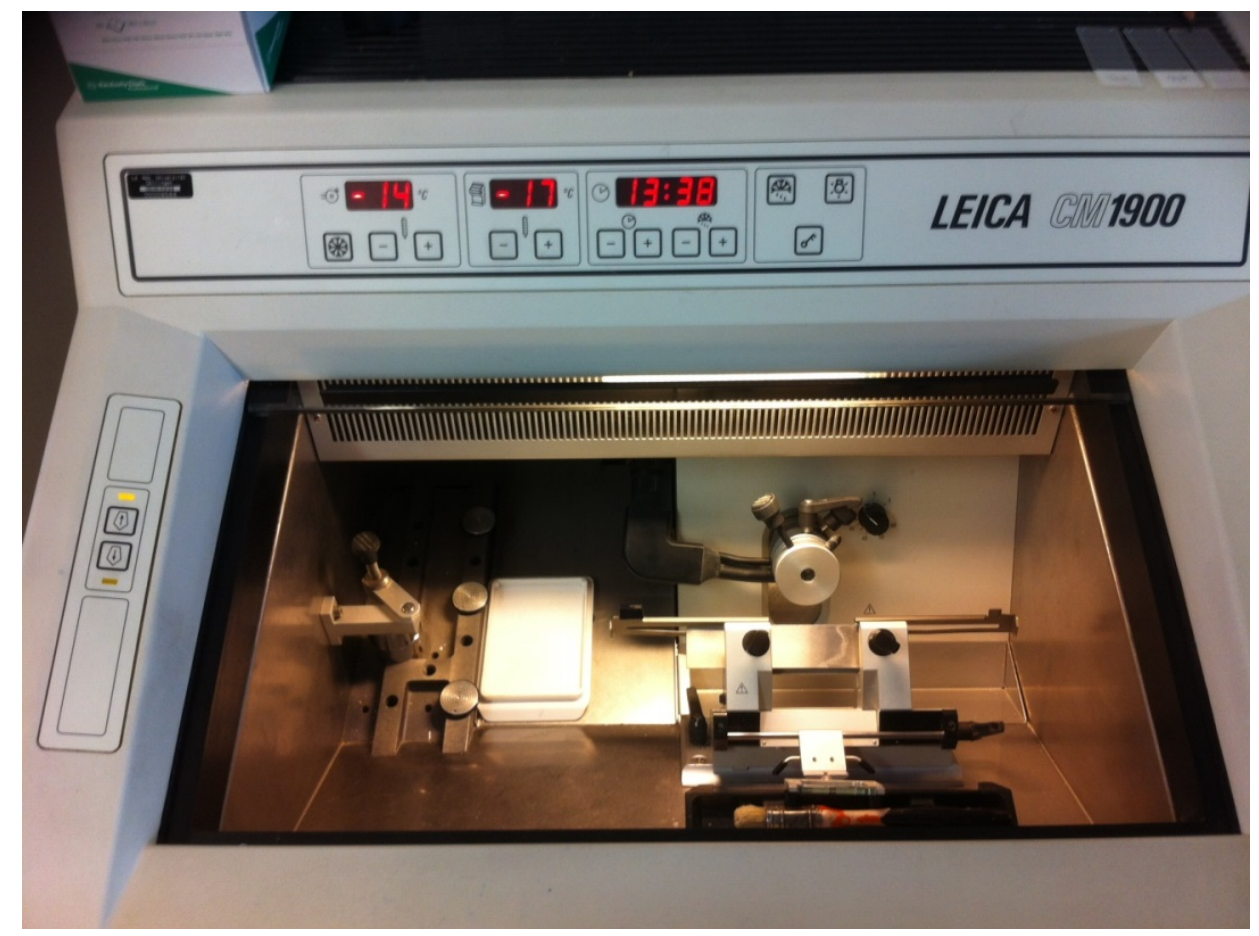

Abbildung 10: Mikrotom CM 1900

Das Anfertigen der Schnitte begann mit der Fixierung eines Teils des präparierten Muskels von etwa 1,5 cm Größe und eventuell vorherigem Zuschneiden mit dem Skalpell. Wichtig war, darauf zu achten, dass der zu schneidende Muskel quer angeschnitten und dafür bereits quer auf der Platte fixiert wird. Der so fixierte Muskel wurde nun zum Schneiden in die dafür vorgesehene Halterung am Mikrotom eingeschraubt und langsam maschinell oder zur Feinjustierung mithilfe der Handkurbel an die Klinge angenähert. Anschließend wurde eine Vielzahl von zunächst sehr kleinen Schnitten durch Drehen der Handkurbel vorgenommen, bis die Schnittfläche groß genug war, um einen Eindruck unter dem Mikroskop darüber zu gewinnen, ob man den Muskel in der korrekten Ebene angeschnitten hatte, sodass die quer angeschnittenen Muskelfasern in ihrer typischen Anordnung sichtbar wurden. War dies der Fall, konnten weitere Schnitte angefertigt werden, bis zwei Objektträger pro Muskel mit je vier bis fünf Schnitten voll waren. Auf diese Weise wurden von allen Mm. longissimi und gastrocnemii zusammen 200 Objektträger mit Schnitten angefertigt, sowie insgesamt 100 Objektträger von allen Mm. soleii. Diese wurden zunächst etwa eine Stunde getrocknet und anschließend bis zur Färbung im Institut für Nutztierwissenschaften bei $-20^{\circ} \mathrm{C}$ eingefroren aufbewahrt. 


\subsection{Anfärben der Schnitte}

Zur Auswertung der angefertigten Schnitte war es nötig, diese anzufärben. Das Färben fand im Labor der Unfallchirurgie statt. Von den zwei pro Muskel gefertigten Objektträgern mit Schnitten, wurde je Objektträger eine Färbung angefertigt, sodass für jeden Muskel zwei verschiedene Färbungen zur Auswertung zur Verfügung standen. Bei den Färbungen handelte es sich um eine ATPase-Färbung kombiniert mit Diaphorase nach Horak-Methode Halle, sowie um eine Amylase-PAS für Kapillarfärbung nach Horak 1983 [Komrakova et al. 2009].

Die ATPase-Färbung dient dabei zur späteren Unterscheidung zwischen glykolitischen und oxidativen Muskelfasern. Die PAS-Kapillarfärbung dient der Darstellung von Kapillaren zur nachfolgenden Quantifizierung von Kapillaren innerhalb des Muskels.

\subsubsection{ATPase-Färbung kombiniert mit Diaphorase}

Will man eine lichtmikroskopisch sichere Unterscheidung von roten Typ-1- und weißen Typ-2-Muskelfasern vornehmen, gelingt dies nur durch die Anwendung eines histochemischen Spezialverfahrens und dem verbundenen Nachweis verschiedener Enzyme [Benninghoff und Drenckhahn 1994]. Genauer gesagt, macht man sich das unterschiedliche pH-Optimum des Isoenzyms Myosin-ATPase, das sowohl in Typ-1-, wie auch in Typ-2-Muskelfasern vorkommt, zu Nutze. Bei neutralem bis mäßig alkalischem pH-Wert ist die Aktivität der Myosin-ATPase der Typ-2-Fasern deutlich stärker als die der Typ-1-Fasern. Die Typ-2-Fasern lassen sich in diesem $\mathrm{pH}$-Milieu gut anfärben. Das in den roten Typ-1-Fasern exprimierte Isoenzym der Myosin-ATPase hat hingegen sein pH-Optimum in einem sauren Milieu von $\mathrm{pH}$ 4,3. Dieser unterschiedlichen Aktivitätsprofile bedient man sich im Rahmen der angewandten Färbemethode mittels ATPase. Zusätzlich kombiniert man hier die ATPase-Färbung mit der Diaphorasefärbung. Diaphorasen stellen mitochondriale Enzyme dar. Somit sind es Markerenzyme für rote, mitochondrienreiche Typ-1-Muskelfasern. 


\subsubsection{Färbeprotokoll ATPase-Färbung}

1. Fixierung

1 Minute

Die Färbung begann mit der Herstellung der Fixierlösung. Sie enthielt Paraformaldehyd, Calciumchloriddihydrat, Saccharose und Aqua dest. und wurde nach pH-Wert Einstellung zwischen 6,3 und 6,6 für eine Minute auf die Objektträger aufgegossen.

2. Aqua dest.

10 Minuten

Danach wurden die in Küvetten gestellten Objektträger für zweimal fünf Minuten in Aqua dest. getaucht.

3. Diaphoraseinkubation

60 Minuten

Anschließend wurden die Objektträger in hierfür vorgesehene feuchte Plastikkammern gestellt und auf den Trägern Diaphorase-Inkubationslösung, bestehend aus NADHDinatriumsalz, Phosphatpuffer, Nitro-blaues Tetrazoliumchlorid und Aqua dest, aufgebracht. In diesem Zustand wurden sie 60 Minuten bei $37^{\circ} \mathrm{C}$ inkubiert.

4. Aqua dest.

15 Minuten

Nach Entfernung aus dem Inkubator wurden die Objektträger wieder in Küvetten gestellt und mit Aqua dest. übergossen.

5. Saure Vorinkubation

15 Minuten

Die Aqua dest. wurde abgegossen und auf die Küvetten eine Lösung zur sauren Vorinkubation geschüttet. Zur Herstellung dieser Lösung benötigt man CalciumchloridStammlösung, Eisessig und Aqua dest. Der pH wurde kurz vor Verwendung durch Zugabe von Salzsäure oder Natriumhydroxyd unter pH-Meter Beobachtung auf 4,2 eingestellt.

6. Tris-Calciumchloridlösung

2 Minuten

Diese Lösung wurde vor Ort hergestellt aus Calciumchloridstammlösung, Aqua dest. und Tris, steht für Tris-Aminomethan, das als schwach basische Verbindung gute organische Pufferfunktion besitzt.

7. ATPase-Inkubation

30 Minuten

Der Kern dieser Färbemethode wurde aus Kaliumchlorid, ATP, Glycinpuffer und Calciumchloridstammlösung hergestellt. Der pH-Wert dieser Lösung wurde auf 9,4 wiederum durch Zugabe von Salzsäure und Natriumhydroxyd eingestellt. Nach Hinzugabe in die Küvetten, wurden diese für 30 Minuten in den Inkubator gestellt. 
Nach Entfernung aus dem Inkubator wurden die Küvetten dreimal mit CalciumchloridWaschlösung übergossen, die aus Calciumchloriddihydrat und Aqua dest. angefertigt wurde.

9. Kobaltchloridlösung

2 Minuten

Diese Lösung aus Kobaltchlorid und Aqua dest. war wegen seiner kanzerogenen Wirkung unter dem Abzug herzustellen und zu verwenden. Und für insgeamt zwei Minuten auf die Küvetten auzubringen.

10. Aqua dest.

dreimal 45 Sekunden

Die Küvetten waren nach Abschütten der Kobaltchloridlösung dreimal mit Aqua dest. zu spülen.

11. Ammoniumsulfidlösung

2 Minuten

Anschließend wurden sie für zwei Minuten mit Ammoniumsulfidlösung aus Ammoniumsulfid und Aqua dest. übergossen.

\section{Leitungswasser}

10 Minuten

Nun wurden die Objektträger in Küvetten für 10 Minuten unter fließendem Leitungswasser gespült.

13. Aqua dest.

5 Minuten

Zuletzt wurde in die Küvetten Aqua dest. eingefüllt. Im Anschluss daran wurden die Objektträger einzeln aus den Aqua dest.-haltigen Küvetten entnommen, ein wenig von der Unterseite abgetrocknet und auf eine trockene Unterlage aufgebracht. Dort wurden sie mit dem wässrigen Eindeckmittel Aquatex® der Firma Merck beträufelt, um daraufhin vorsichtig die Deckgläschen aufzubringen. Hierbei war darauf zu achten, dass sich keine Luftblasen unter den Deckgläschen innerhalb des Präparates bildeten. Die so fixierten Präparate wurden zum Trocknen des Klebers auf einer trockenen Unterlage für etwa drei Tage ausgebreitet. Nach etwa drei Tagen konnten sie mit einem feuchten Schwamm von überschüssigem Kleber und anheftender Unterlage gereinigt werden. Zur weiteren Auswertung wurden die Objektträger nach Färbung und Muskel sortiert in vorgesehenen Kästen aufbewahrt. 


\subsubsection{Amylase-PAS für Kapillarfärbung}

Zur späteren Quantifizierung der Kapillaren innerhalb eines Muskels, ist es nötig, diese zunächst anzufärben. Dies gelingt mithilfe der Periodsäure-Schiff-Reaktion (englisch periodic-acid-Schiff PAS). Das Prinzip dieser Reaktion beruht auf der Fähigkeit von Periodsäure als starkes Oxidationsmittel $\mathrm{zu}$ fungieren und somit Glycolgruppen im Muskelpräparat zu nebeneinanderliegenden Aldehydgruppen zu oxidieren. Hilfreich ist die vorherige Aufspaltung der Glycolgruppen durch das Hinzugeben des Enzyms Amylase. Die Anfärbung dieser Gruppen geschieht durch anschließende Anlagerung von Schiff-Reagenz, die Fuchsinschweflige Säure enthält. Die Anlagerung des farblosen Schiff-Reagenz an die Aldehydgruppen mit der daraus entstehenden Schiffschen Base bewirkt die daraus resultierenden rötlich anfärbenden Eigenschaften im Präparat. Auf diesem Weg kann vor allem glykogenhaltige extracelluläre Substanz angefärbt werden. Beispielsweise Kollagen und Basalmembranen wie sie in Gefäßen vorkommen [Baum 2008].

\subsubsection{Färbeprotokoll Amylase-PAS-Kapillarfärbung}

\section{Fixierlösung}

60 Minuten

Die Objektträger wurden zuerst für eine Stunde in einer Fixierlösung aus Ethanol, Chloroform und Essigsäure bei $4{ }^{\circ} \mathrm{C}$ aufbewahrt.

\section{Aqua dest.}

zehnmal spülen

Anschließend wurden die in Küvetten gestellten Objektträger insgesamt zehnmal mit destilliertem Wasser abgespült.

3. Amylase

25 Minuten

Nun wurden die Küvetten mit, in Aqua dest. gelöster, Amylase übergossen und für 25 Minuten bei $37^{\circ} \mathrm{C}$ inkubiert.

4. Aqua dest.

zehnmal spülen

Die inkubierten Küvetten konnten im Anschluss entleert und zehnmal mit destilliertem Wasser gespült werden.

5. Perjodsäure

30 Minuten

Zur Oxidation der Glycolgruppen wurde nun die Perjodsäure in die Küvetten abgefüllt und 30 Minuten bei Raumtemperatur reagieren lassen. 
6. Aqua dest.

zehnmal spülen

Im Anschluss wurden die Küvetten wiederum mit destilliertem Wasser zehnmal abgespült.

7. Schiff-Reagenz.

ca. 10 Minuten

Um die entstandenen Aldehydgruppen anzufärben, gab man nun zur Anlagerung an diese Gruppen für etwa zehn Minuten das Schiff-Reagenz hinzu. Dabei war auf den Grad der Anfärbung zu achten, um eine zu dunkle Färbung zu vermeiden.

8. Schwefliges Wasser

30 Minuten

Anschließend wurde für 30 Minuten zur Konsolidierung der Anfärbung schwefliges Wasser hinzugefügt.

9. Leitungswasser

10 Minuten

Die angefärbten Objektträger wurden nun für 10 Minuten unter fließendem Leitungswasser ausgespült.

10. Aqua dest.

3 Minuten

Bis zum Aufbringen der Deckgläschen wurden die Objektträger in destilliertem Wasser aufbewahrt, mindestens für drei Minuten. Auf die gefärbten Objektträger wurden wie unter 2.5.2 beschrieben zunächst Deckgläschen fixiert und anschließend getrocknet, sowie ebenfalls bis zur weiteren Auswertung in Kästen aufbewahrt.

\subsection{Auswertung der Schnitte am Mikroskop}

Die gefärbten Schnitte wurden schließlich mit einem Mikroskop unter Zuhilfenahme eines speziellen Programms am Computer ausgewertet. Bei dem Mikroskop handelte es sich um das Modell Eclipse E600 der Firma Nikon sowie bei dem Programm um NISElements AR 4.0, ebenfalls von der Firma Nikon Instruments Europe, Amsterdam, Niederlande.

Untersucht wurde hierbei die unter 1 . beschriebenen Parameter Kapillarisierung und Muskelfaserfläche der verschiedenen Muskelfasertypen sowie deren Verhältnis zueinander. 


\subsubsection{Auswertung der Kapillarisierung}

Die Hälfte der insgesamt etwa 300 Objektträger war mittels Kapillarfärbung gefärbt, wodurch es möglich war, die einzelnen Kapillaren unter dem Mikroskop zu erkennen. Es wurden nun von jedem Muskel zwei Schnitte zur Kapillarauswertung ausgewählt, wobei innerhalb von jedem dieser Schnitte auf einer Fläche von je $0,25 \mathrm{~mm}^{2}$ alle vorhandenen Kapillaren ausgezählt wurden. Ebenfalls wurden auf dieser Fläche die Anzahl aller Muskelfasern ausgezählt, sodass von beiden Schnitten zusammen eine Fläche von insgesamt 0,5 $\mathrm{mm}^{2}$ pro Muskel, hinsichtlich Anzahl der Kapillaren und Anzahl der Muskelfasern ausgezählt werden konnte. Anschließend wurden die mithilfe des Programms erhobenen Zahlen in eine Excel-Datei eingefügt und das Verhältnis von Kapillaren zu Muskelfasern ausgewertet. Auf diese Weise wurde die Kapillarisierung der Muskeln soleus, gastrocnemius und longissimus ausgewertet.

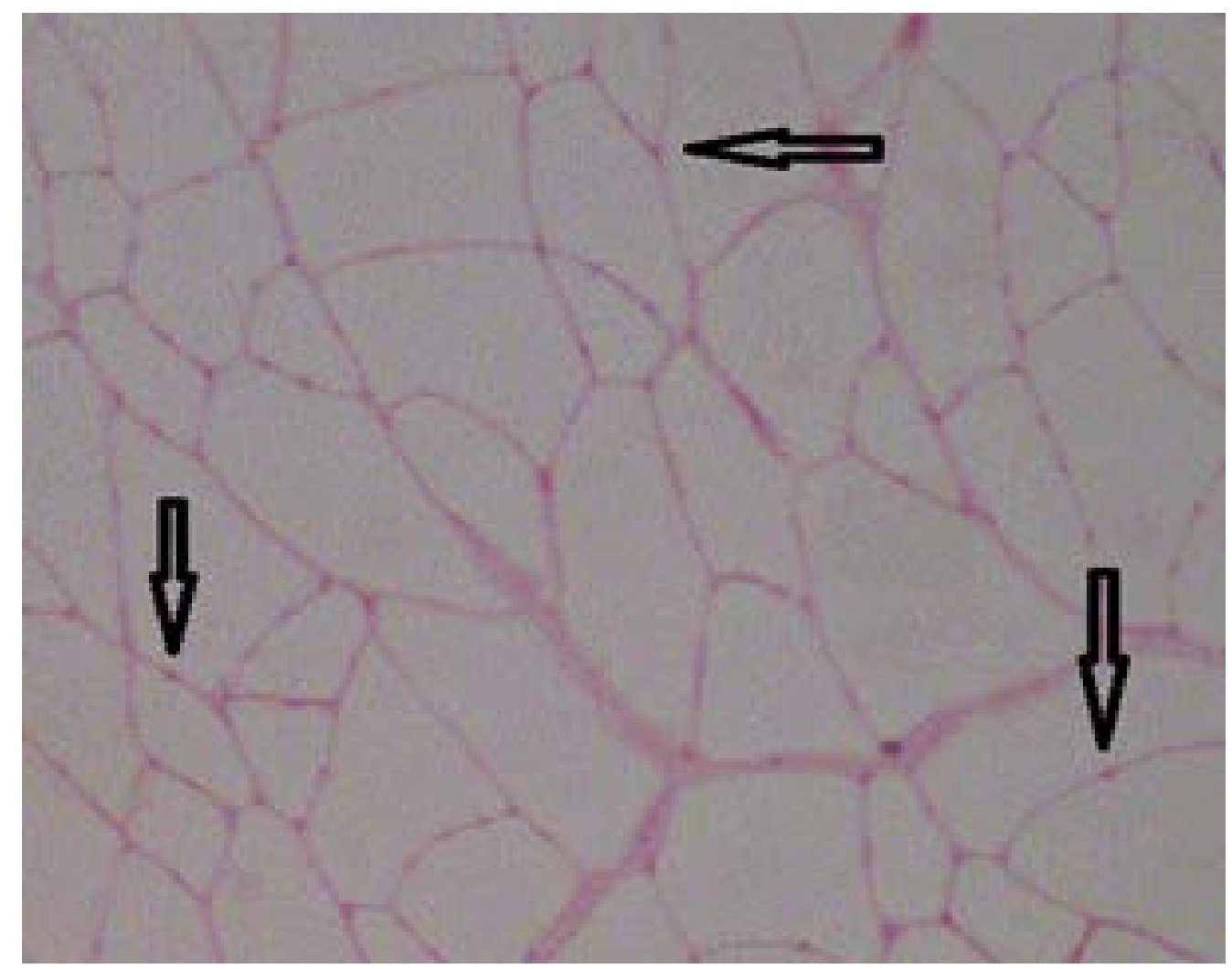

Abbildung 11: Kapillarfärbung eines M. longissimus, mit Pfeilen markierte Kapillaren 


\subsubsection{Auswertung der ATPase-Färbung}

Die ATPase-Färbung diente, wie beschrieben, der Darstellung der unterschiedlichen Muskelfasertypen und deren genaueren Vermessung. Die Qualität der angefertigten Schnitte sowie deren Färbung ermöglichte nicht nur eine Unterscheidung von Typ-1 zu Typ-2, sondern zusätzlich eine Differenzierung von sogenannten intermediären Typ-2BMuskelfasern. Die Auswertung der einzelnen Muskeln war hier unterschiedlich, da die drei vorliegenden Muskeln per se ein unterschiedliches Verhältnis von Typ-1- zu Typ-2Muskelfasern besitzen. Dieses beläuft sich beim M. soleus auf über $90 \%$ zugunsten der Typ-1-Muskelfasern, während beim M. gastrocnemius das Verhältnis stark variieren kann. Aus diesem Grund wurde bei diesen beiden Muskeln auf eine Auswertung des Verhältnisses der Typen zueinander verzichtet. Stattdessen wurden beim M. gastrocnemius auf drei unterschiedlichen Bildausschnitten jeweils 30 Typ-1Muskelfasern, 30 Fasern vom Typ-2A, sowie 30 Fasern vom Typ-2B ausgemessen, das heißt mithilfe des Programms umrandet und anschließend deren Flächen und Durchmesser berechnet. Insgesamt wurden auf diese Weise pro M. gastrocnemius 270 Fasern ausgemessen. Die erhobenen Daten wurden wiederum in Excel-Dateien eingefügt. Da beim M. soleus fast ausschließlich Typ-1-Muskelfasern vorkommen, wurden hier keine Fasertypen unterschieden, sondern pro Muskel auf drei Bildausschnitten jeweils 30 Fasern ausgemessen, sodass 90 Fasern pro M. soleus ausgemessen wurden.

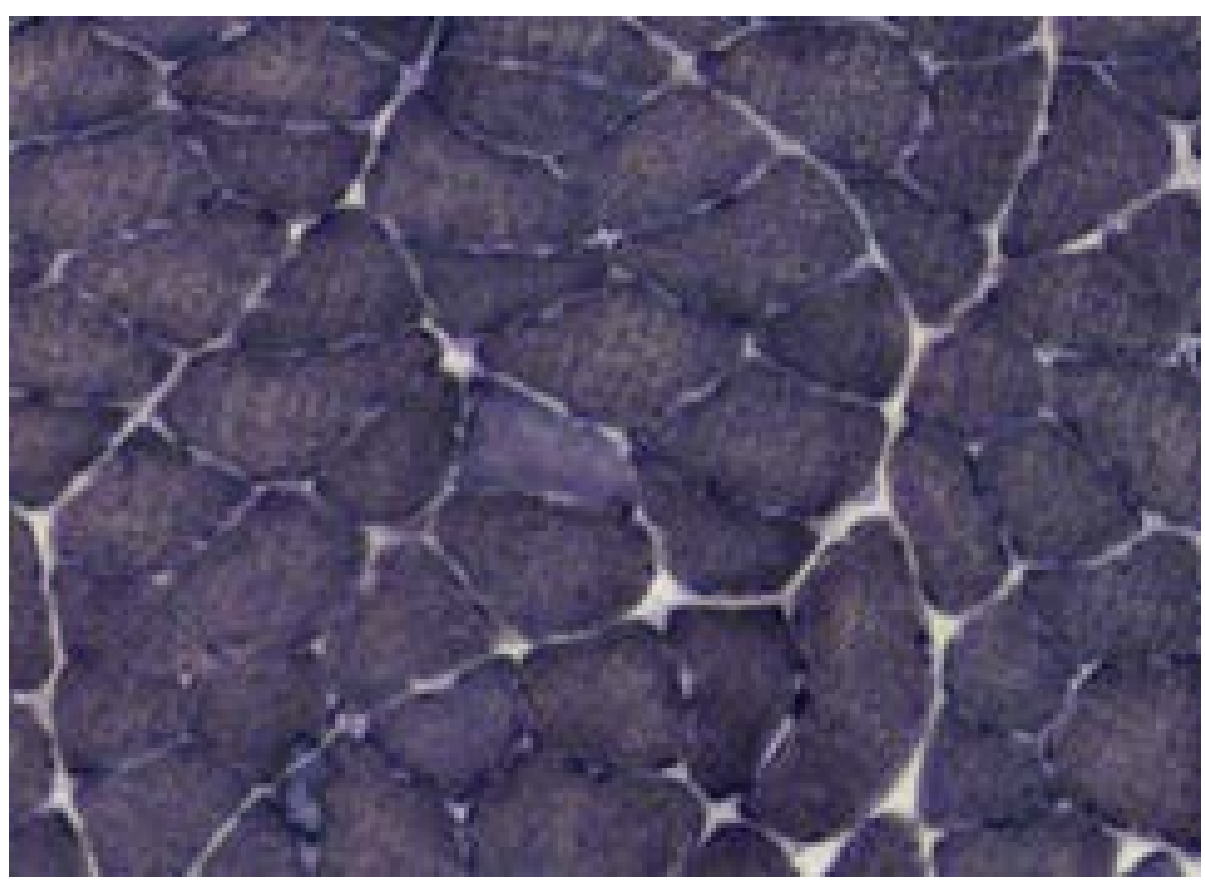

Abbildung 12: ATPase-Färbung M. soleus; keine Zelldifferenzierung 


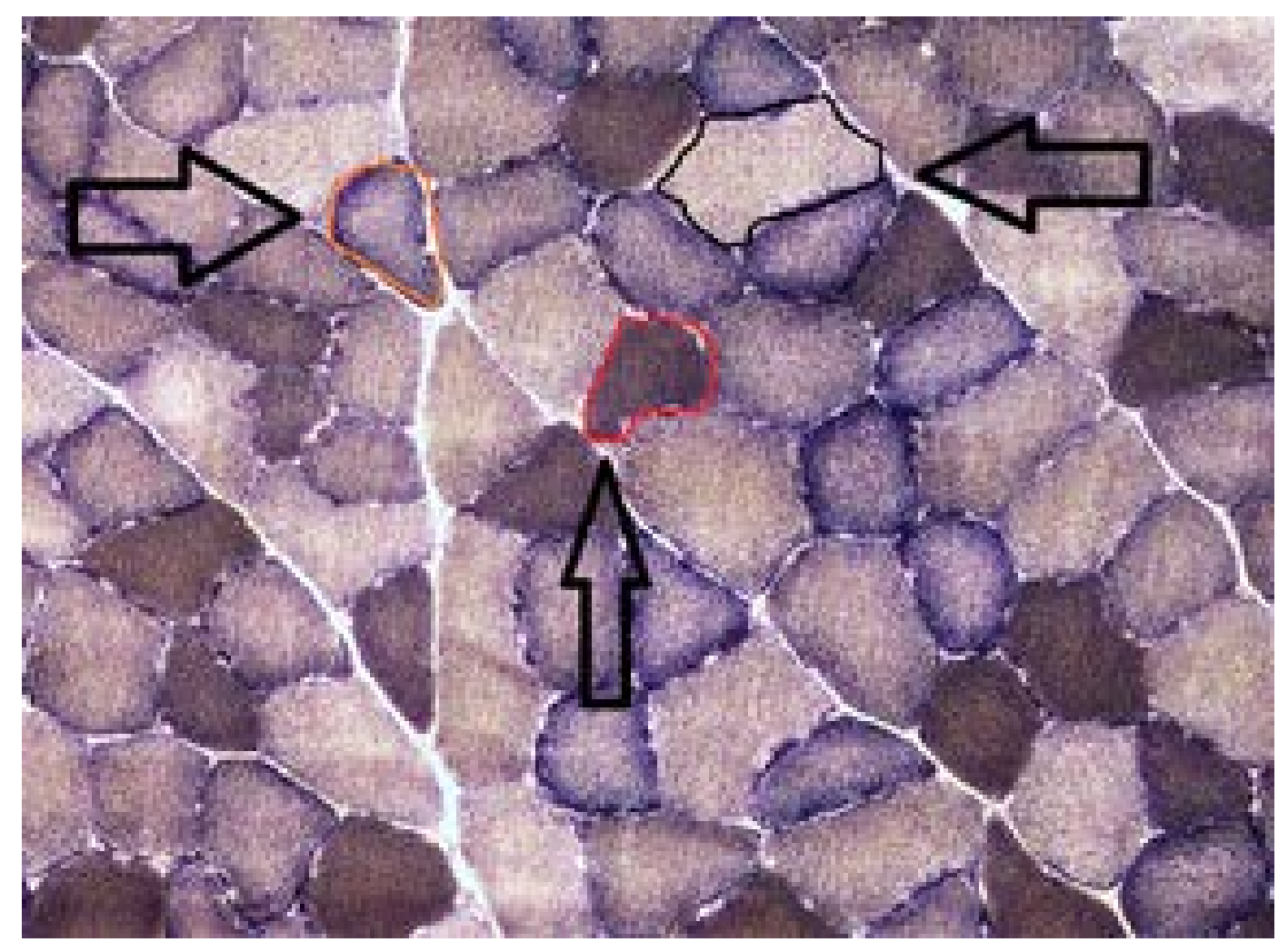

Abbildung 13: ATPase-Färbung M. gastrocnemius; rot umrandet Typ-1, schwarz umrandet Typ-2A, orange umrandet Typ-2B

Die ATPase-gefärbten Schnitte des M. longissimus wurden auf ebenfalls drei unterschiedlichen Bildausschnitten ausgewertet, das heißt jeweils 30 Fasern Typ-1, Typ-2A und Typ-2B ausgemessen, sodass wie beim M. gastrocnemius 270 Fasern pro Muskel ausgemessen wurden. Anschließend wurde noch die Anzahl der verschiedenen Muskelfasertypen auf einer Fläche von $1 \mathrm{~mm}^{2}$ ausgezählt, sowie deren Verhältnis zueinander ermittelt. 


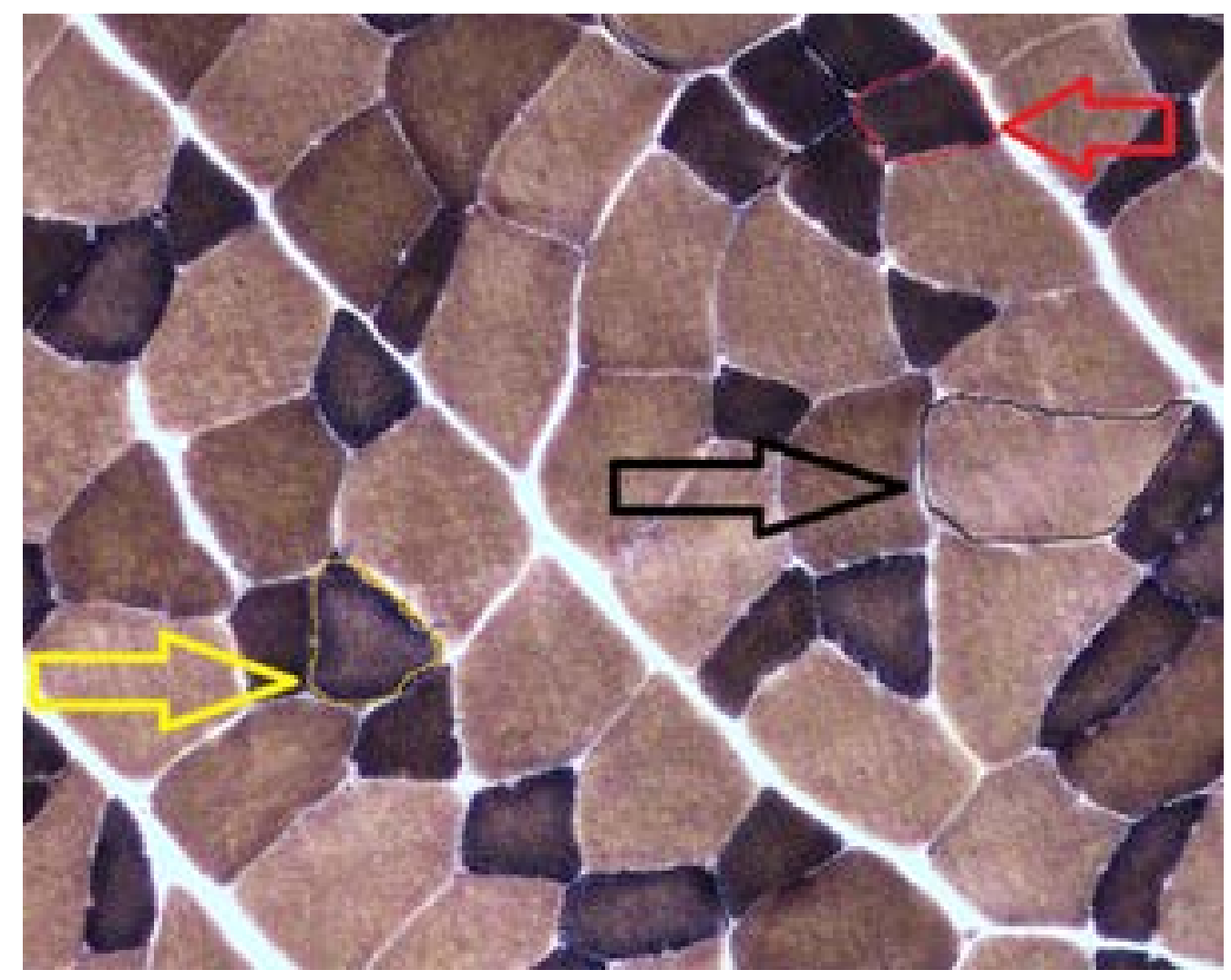

Abbildung 14: ATPase-Färbung M. longissimus; roter Pfeil Typ-1-Faser, schwarzer Pfeil Typ-2A, gelber Pfeil Typ-2B-Faser

\subsection{Erhebung der Serumparameter}

Wie bereits erwähnt, sollten zur Beurteilung der Funktionsfähigkeit und des Zustandes der Muskulatur die Konzentrationen der Parameter Kreatinkinase, Calcium und Magnesium im Serum der Ratten bestimmt werden.

Dies erfolgte nach der Tötung der Ratten durch die Abteilung Klinische Chemie an der Universitätsmedizin Göttingen. Dort verwendete man zur Ermittlung der Kreatinkinase das Creatine Kinase Assay des Architect c16000 Analysiergeräts der Firma Abbott, Wiesbaden zur quantitativen Bestimmung im Serum. Grundlage dieses Verfahrens stellt die von der Kreatinkinase katalysierte Reaktion dar, in der eine Phosphatgruppe auf ADP übertagen wird, sodass ATP entsteht. Durch dieses ATP wird in einer weiteren Reaktion Glukose durch das Enzym Hexokinase zu Glukose-6-Phosphat phosphoryliert. Das Glukose-6-Phosphat wird im Anschluss durch die Glukose-6-PhosphatDehydrogenase oxidiert, wodurch NADP zu NADPH reduziert wird. Somit ist die Menge an gebildetetem NADPH proportional zur anfänglich eingesetzten Menge an Kreatinkinase in der Probe. Letztlich kann das NADPH über einen optischen Nachweis bei $340 \mathrm{~nm}$ Wellenlänge ermittelt werden. 
Das Calcium im Serum wurde ebenfalls durch das Architect c16000 Gerät der Firma Abbott, Wiesbaden ermittelt. Hier wurde das System mit dem Farbstoff Arsenazo III verwendet. Dieses stellt ein Färbemittel zur Anfärbung von Calcium dar.

Auch zur Ermittlung der Magnesiumkonzentration im Serum wurde das Architect c16000 System der Firma Abbott eingesetzt. Grundlage war auch beim Magnesium die Anfärbung durch den Arsenazo Farbstoff und der anschließende optische Nachweis von Arsenazo-Magnesium-Komplex bei einer Wellenlänge von $572 \mathrm{~nm}$. Vorher musste allerdings das in der Probe befindliche Calcium durch einen Chelatbildner komplexiert werden, um eine Störung der Messung durch Calcium zu verhindern.

\subsection{Statistische Auswertung}

Alle zuvor erhobenen Daten wurden zunächst mit dem Programm Excel von Microsoft Office, Redmond, U.S.A. bearbeitet und gespeichert. Zur anschließenden statistischen Auswertung wurde das Programm Prism 5.0 der Firma Graph Pad Software Inc., San Diego, U.S.A. verwendet. Mithilfe dieses Programms konnten die Daten sowohl in tabellarischer Form, als auch in Form von Säulendiagrammen dargestellt werden.

Zur Bestimmung von Signifikanzen im Vergleich der unterschiedlichen Gruppen zueinander sowie der einzelnen Werte innerhalb einer Gruppe konnte im Prism Programm die sogenannte one way analysis of variance (one-way ANOVA) angewandt werden. Im Anschluss daran wurde der Tukey-Kramer post hoch Test verwendet, mit dessen Hilfe man noch genauere Signifikanzen ermitteln konnte. Für beide Tests lag das Signifikanzniveau bei einem p-Wert $<0,05$. 


\section{Ergebnisse}

\subsection{Körpergewichte, Muskelgewichte und Uterusgewichte}

\subsubsection{Körpergewichte}

Das Körpergewicht aller Tiere wurde wöchentlich gemessen. Die Tabelle 2 im Anhang beinhaltet die Mittelwerte der Körpergewichte in Gramm der einzelnen Gruppen zu drei Zeitpunkten während des Versuchs sowie die jeweilige Standardabweichung.

Die statistische Analyse zeigt einen signifikanten Unterschied zwischen den zwei Gruppen NON-OVX und OVX zum Zeitpunkt der Tötung. Zum Versuchsbeginn bestanden keine signifikanten Unterschiede. Dabei ist das Körpergewicht der Tiere aus der OVX Gruppe größer als das der NON-OVX Gruppe, wie das unten stehende Diagramm verdeutlicht. (Tabelle 3, Abb. 15)

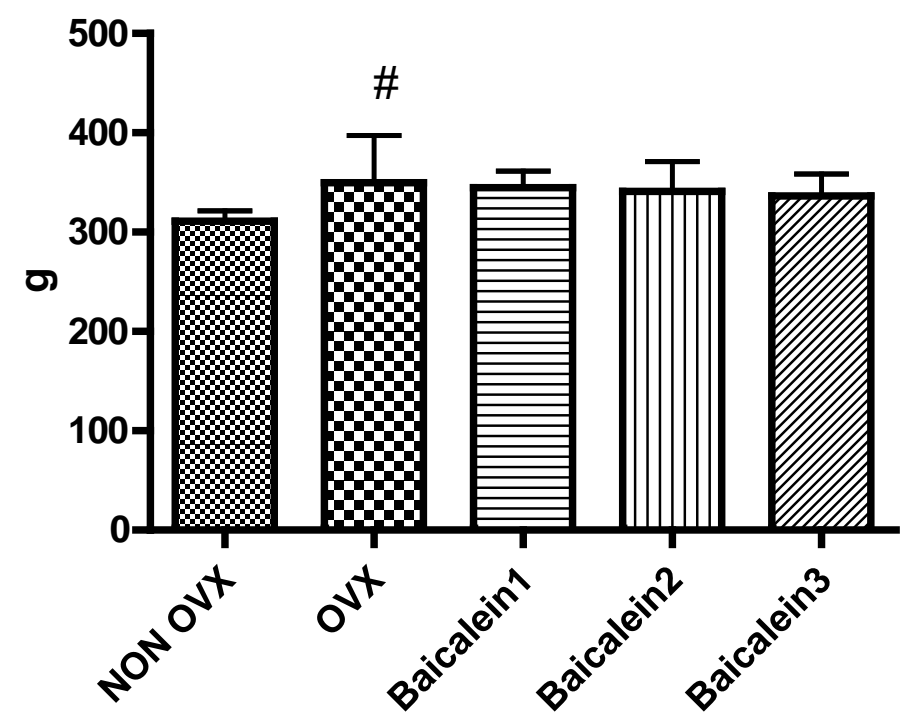

\# signifikant zu NON-OVX

Abbildung 15: Körpergewichte zu Versuchsende 


\subsubsection{Muskelgewichte}

Die Muskeln Gastrocnemius und Soleus wurden unmittelbar nach der Tötung gewogen. In Tabelle 4 und 5, im Anhang sind die Mittelwerte der in toto exstipierten Muskeln der einzelnen Gruppen in Gramm aufgeführt. Folgende Diagramme verdeutlichen die Ergebnisse.

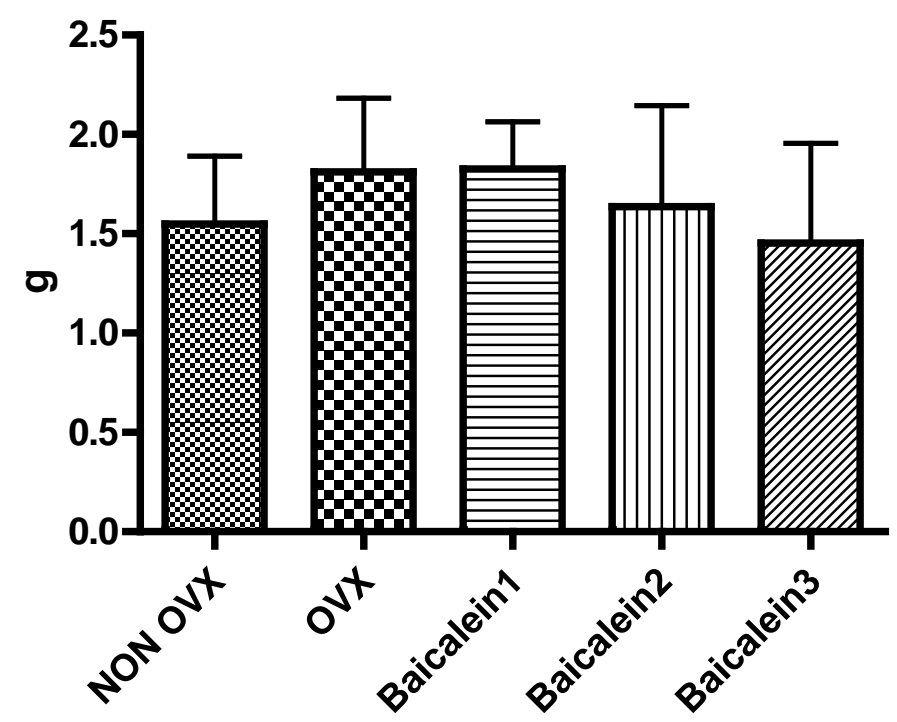

Abbildung 16: Gewichte des M. gastrocnemius

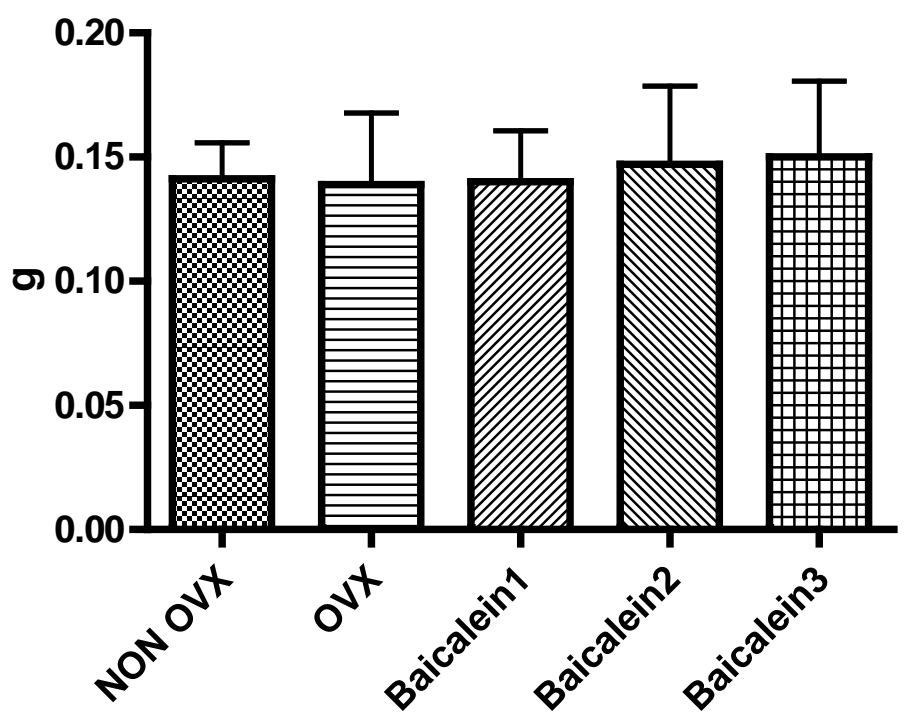

Abbildung 17: Gewichte des M. soleus 
Es liegen zwischen den Gruppen keine Signifikanzen hinsichtlich der Gewichte des M. gastrocnemius oder des M. soleus zwischen den einzelnen Versuchsgruppen vor. (Tabellen 4,5 Abb. 16,17)

\subsubsection{Uterusgewichte}

Die Uteri aller Versuchstiere wurden bei Versuchsende gewogen, um nachzuvollziehen, ob die Ovariektomie erfolgreich war.

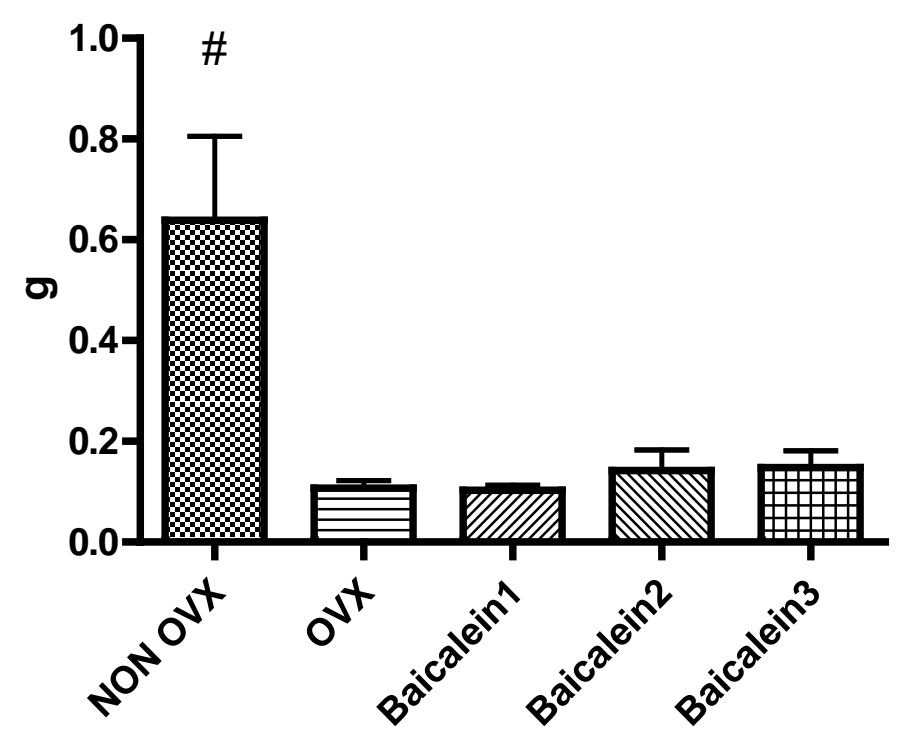

\# signifikant vs. allen übrigen Gruppen

Abbildung 18: Uterusgewichte nach Tötung

Die signifikant größeren Gewichte der NON-OVX-Gruppe im Vergleich zu den ovariektomierten Gruppen: OVX, Baicalein1, 2 und 3 belegen die erfolgreiche Ovariektomie zu Versuchsbeginn mit der daraus resultierenden Uterusatrophie in den jeweiligen Gruppen. (Tabelle 6, Abb. 18) 


\subsection{Verhältnis von Kapillaren zu Muskelfasern}

\subsubsection{Musculus soleus}

Wie unter 1.5.2 beschrieben interessiert bezüglich der Kapillaren im sarkopenisch veränderten Muskel primär die Anzahl von Kapillaren pro Muskelfaser. Aus diesem Grund wurde deren Verhältnis wie unter 2.5.1 Auswertung der Kapillarisierung beschrieben, jeweils auf 0,5 $\mathrm{mm}^{2}$ Muskelgewebe analysiert. Tabelle 7 im Anhang umfasst die Mittelwerte der Verhältnisse von Kapillaren zu Muskelfasern der einzelnen Gruppen. Wie auch im folgenden Text soll MF hier für Muskelfaser stehen.

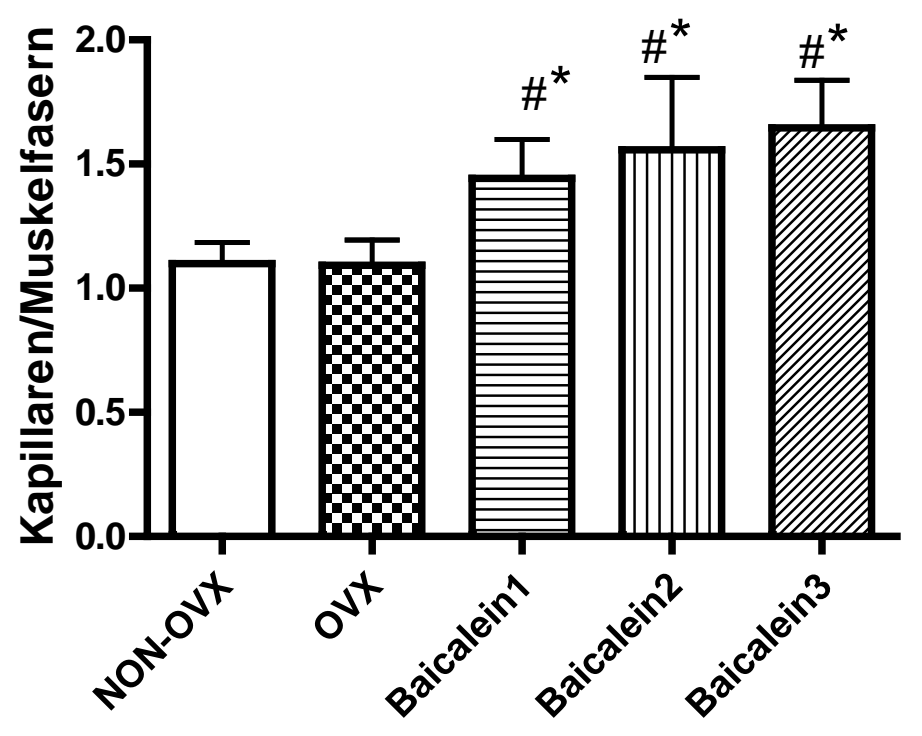

\# signifikant vs. NON-OVX, * signifikant vs. OVX

Abbildung 19: Verhältnis von Kapillaren zu Muskelfasern beim M. soleus

Jede der mit Baicalein behandelten Tiergruppen wies eine signifikant höhere Anzahl von Kapillaren zu Muskelfasern im Vergleich zu den unbehandelten Gruppen auf. Im Einzelnen zeigte die Gruppe mit der höchsten Dosierung den größten Wert auf, die Gruppe mit der zweithöchsten Dosierung den mittleren Wert und die niedrigste Dosisgruppe den kleinsten noch signifikanten Effekt. (Tabelle 7, Abb. 19) 


\subsubsection{Musculus gastrocnemius}

Auch hier wurde das Verhältnis von Kapillaren zu Muskelfasern pro 0,5 mm² Muskelgewebe ausgewertet.

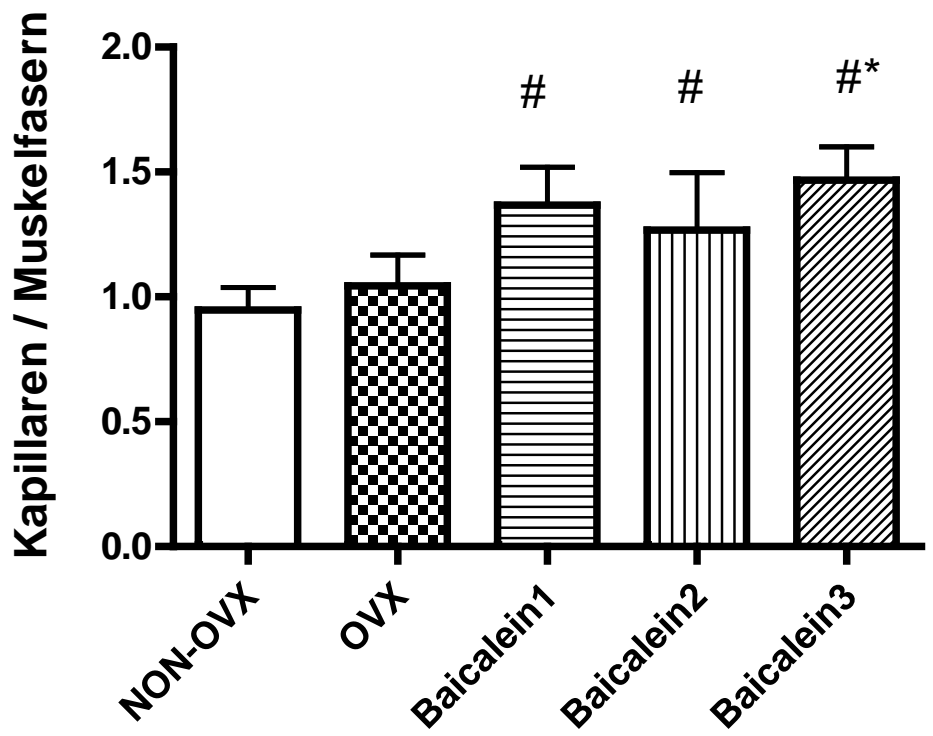

\#signifikant vs. NON-OVX und OVX; *signifikant vs. Baicalein2

Abbildung 20: Verhältnisse von Kapillaren zu Muskelfasern beim M. gastrocnemius

Alle Baicalein-Gruppen zeigten ein signifikant höheres Verhältnis von Kapillaren zu Muskelfasern im Vergleich zu den NON-OVX- und OVX-Gruppen. Ebenfalls signifikant größer ist das Verhältnis von Kapillaren zu Muskelfasern bei der Baicalein3-Gruppe gegenüber der Baicalein2-Gruppe. (Tabelle 8, Abb. 20)

\subsubsection{Musculus longissimus}

Wie bei den vorangegangenen beiden Muskeln wurde das Verhältnis von Kapillaren zu Muskelfasern pro $0,5 \mathrm{~mm}^{2}$ Muskelgewebe bestimmt. Tabelle $8 \mathrm{im}$ Anhang zeigt die dazugehörigen Werte. 


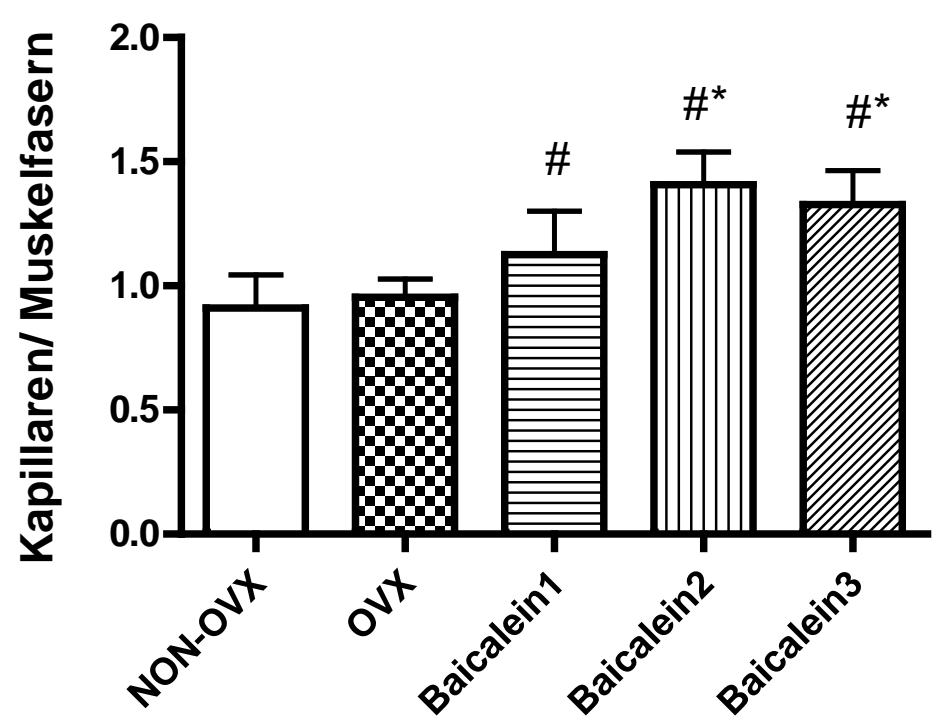

\#signifikant vs. NON-OVX und OVX; *signifikant vs. Baicalein1

Abbildung 21: Verhältnis von Kapillaren zu Muskelfasern beim M. longissimus

Die Gruppen Baicalein1, Baicalein2 und Baicalein3 wiesen allesamt ein signifikant höheres Verhältnis von Kapillaren zu Muskelfasern im Vergleich zu den Gruppen OVX und NON-OVX auf. Die Gruppe Baicalein2 war signifikant größer als die Baicalein1Gruppe, welche wiederum signifikant kleiner war als die Baicalein3-Gruppe. (Tabelle 9, Abb. 21)

\subsection{Muskelfaserdurchmesser und Flächen beim M. soleus}

Wie unter 2.5.2 Auswertung der ATPase-Färbung beschrieben, konnte die Analyse der Muskelfasern, das heißt Messen des Durchmessers und der Flächen nur durch vorheriges Anfärben mittels ATPase-Färbung vorgenommen werden. Hierzu wurden jeweils drei verschiedene Schnittbilder der Muskeln Soleus, Gastrocnemius und Longissimus ausgewertet. 


\subsubsection{Muskelfaserdurchmesser beim M. soleus}

Beim M. soleus wurden pro Versuchstier auf drei Bildausschnitten jeweils 90 Muskelfasern ausgewertet. Wie bereits erwähnt sind hier über 90\% der Muskelzellen vom Typ-1, weshalb keine weitere Differenzierung von Muskelfasertypen vorgenommen wurde.

Tabelle 10 im Anhang zeigt die Mittelwerte der gemessenen Muskelfaserdurchmesser des M. soleus.

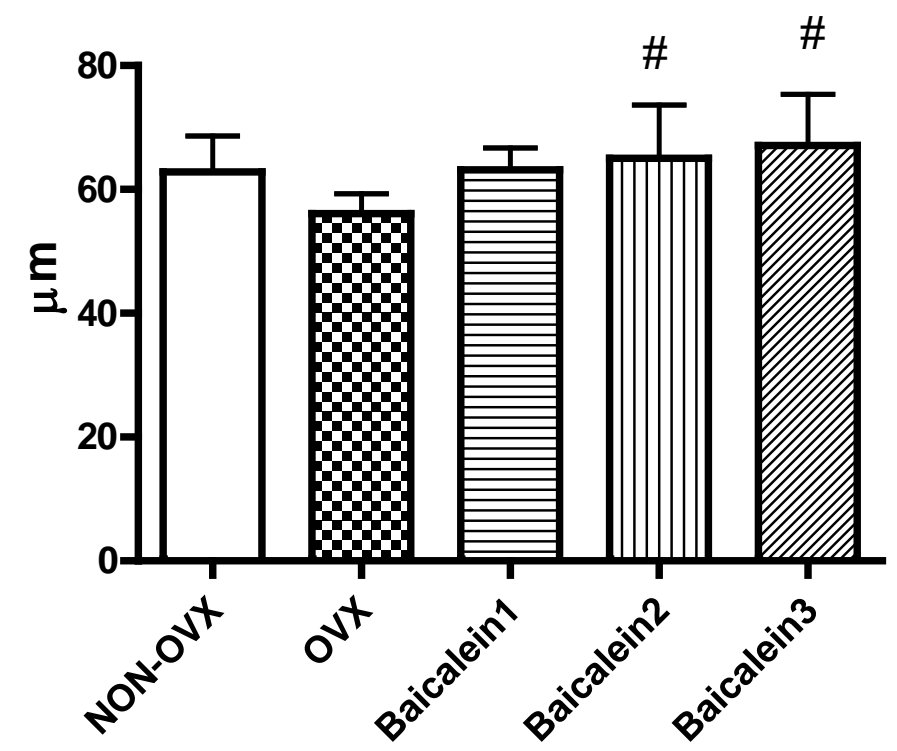

\#signifikant vs. OVX

Abbildung 22: Durchmesser der Muskelfasern M. soleus

Die statistische Anaylse der Muskelfaserdurchmesser ergab beim M. soleus signifikant größere Werte in den Gruppen Baicalein2- gegenüber der OVX-Gruppe sowie der Baicalein3-Gruppe gegenüber der OVX-Gruppe. (Tabelle 10, Abb. 22)

\subsubsection{Flächengrößen des $M$. soleus}

Mithilfe des unter 2. Material und Methoden beschriebenen Computerprogramms wurden die Flächen der Muskelfasern zunächst umrandet, um anschließend berechnet zu werden. So verfahren wurde beim M. soleus auf drei verschiedenen Bildausschnitten, wobei auf jedem Ausschnitt 30 Muskelfasern vermessen wurden, sodass pro Muskel 90 
Muskelfasern, unabhängig von der Differenzierung in verschiedene Muskelfasertypen vermessen wurden. Die Tabelle $11 \mathrm{im}$ Anhang beinhaltet die Mittelwerte der Flächen der einzelnen Versuchsgruppen.

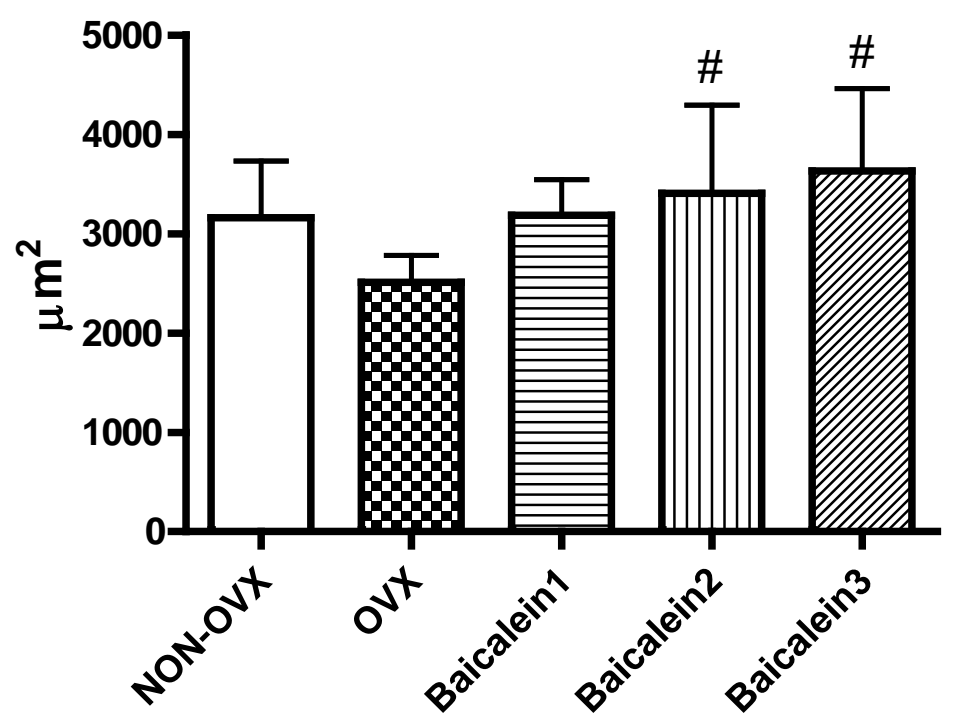

\#signifikant vs. OVX

Abbildung 23: Mittelwerte der Muskelfaserflächen im M. soleus

Die statistische Analyse der Mittelwerte ergab, dass die Baicalein2-Gruppe und die Baicalein3-Gruppe signifikant größere Flächen enthielten als die OVX-Gruppe. (Tabelle 11, Abb. 23)

\subsubsection{Verhältnisse der Muskelfaserdurchmesser zu den Gewichten beim M. soleus}

Um den im vorangegangenen Teil dargestellten Werten von Muskelfaserdurchmesser und Muskelfaserfläche eine höhere Aussagekraft zu verleihen, wurden diese Werte wiederum mithilfe des Statistikprogramms in Relation zum Muskel- und Körpergewicht gesetzt. Beim M. longissimus nur zum Körpergewicht, da dieser Muskel nicht komplett resiziert wurde, sodass kein Muskelgewicht bestimmt werden konnte. 


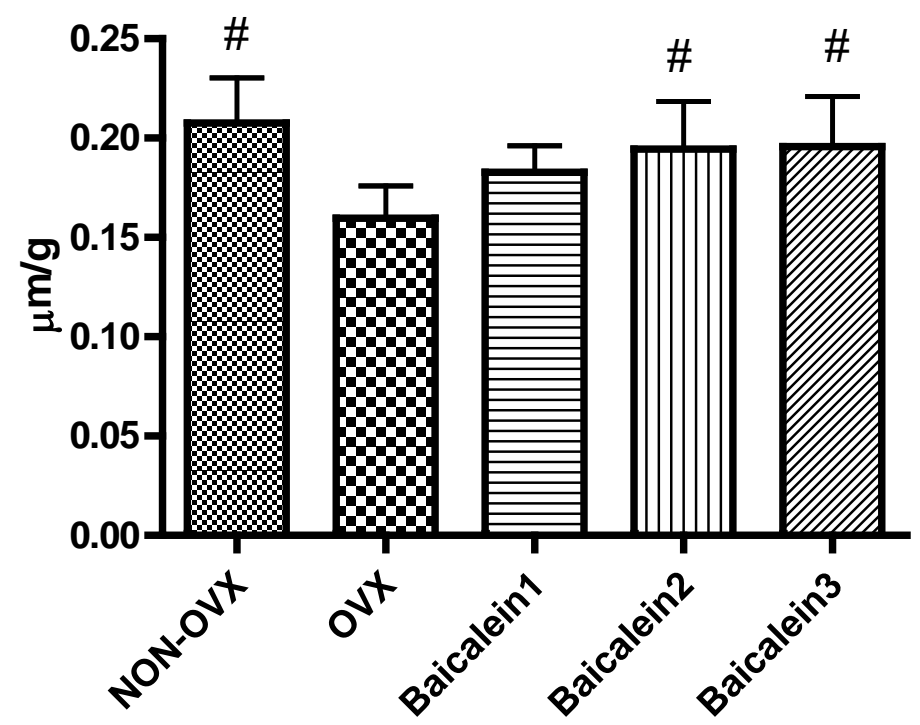

\#signifikant vs. OVX

Abbildung 24: Relation von Muskelfaserdurchmesser zum Körpergewicht beim M. soleus

In Relation zum Körpergewicht waren die Faserdurchmesser der NON-OVX-Gruppe signifikant größer als die der OVX-Gruppe. Außerdem waren die Fasern der Baicalein2Gruppe sowie der Baicalein3-Gruppe signifikant größer als die der OVX-Gruppe. (Tabelle 12, Abb. 24)

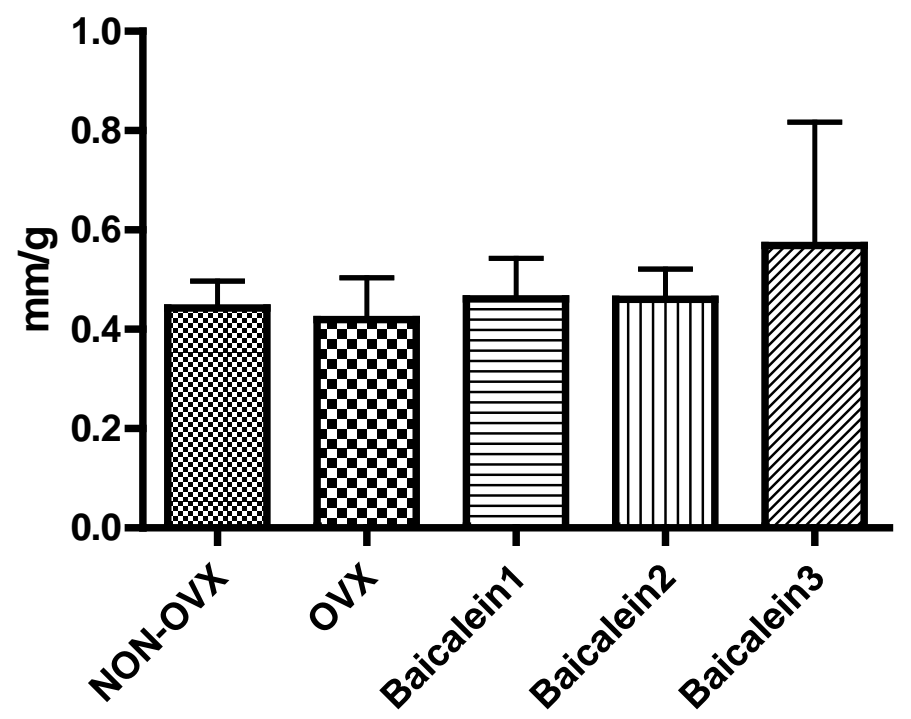

Abbildung 25: Relation von Muskelfaserdurchmesser zum Muskelgewicht beim M. soleus 
Die statistische Auswertung dieser Relationen ergab keine Signifikanzen. (Tabelle 12, Abb. 25)

\subsubsection{Verhältnisse der Muskelfaserflächen zu den Gewichten beim M. soleus}

Ebenso wurden die Flächen der Muskelfasern des M. soleus in Relation, sowohl zum Körpergewicht, als auch zum Muskelgewicht gesetzt. Tabelle 13 im Anhang enthält deren Werte.

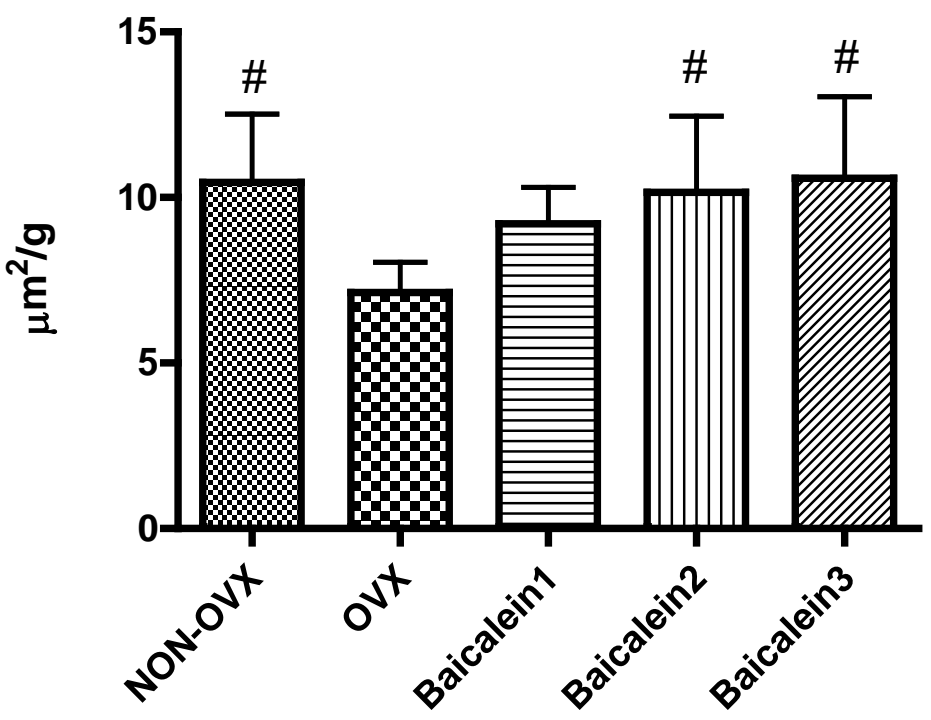

\#signifikant vs. OVX

Abbildung 26: Relation von Muskelfaserfläche zum Körpergewicht beim M. soleus

Es zeigten sich bei der Auswertung dieser Relationen signifikant größere Werte zunächst der NON-OVX- gegenüber der OVX-Gruppe. Außerdem waren die Verhältniswerte der Baicalein2-Gruppe und der Baicalein3-Gruppe signifikant größer als die der OVX-Gruppe. (Tabelle 13, Abb. 26) 


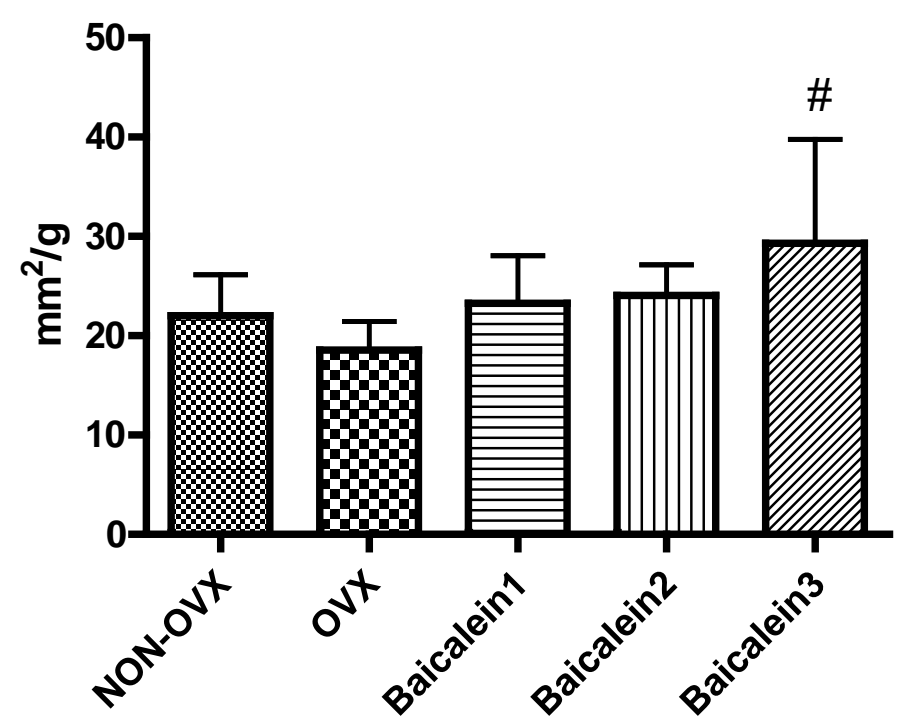

\#signifikant vs. OVX

Abbildung 27: Relation von Muskelfaserfläche zum Muskelgewicht beim M. soleus

Die statistische Analyse dieser Relationen zeigte signifikant größere Werte der Baicalein3-Gruppe gegenüber der OVX-Gruppe. (Tabelle 13, Abb. 27)

\subsection{Muskelfaserdurchmesser und Flächen beim M. gastrocnemius}

\subsubsection{Muskelfaserdurchmesser des M. gastrocnemius}

Anders als beim M. soleus ist das Verhältnis der verschiedenen Muskelfasertypen im M. gastrocnemius sehr inhomogen. Weshalb es hier sinnvoll war, die verschiedenen Typen auszumessen. Hierzu wurden auf drei Bildausschnitten jeweils 30 Fasern vom Typ-1, 30 Fasern vom Typ-2A sowie 30 Fasern des Typs-2B vermessen, das heisst 270 Muskelfasern pro Tier. In Tabelle 13 im Anhang sind die Mittelwerte der einzelnen Gruppen und Muskelfasertypen aufgeführt. 


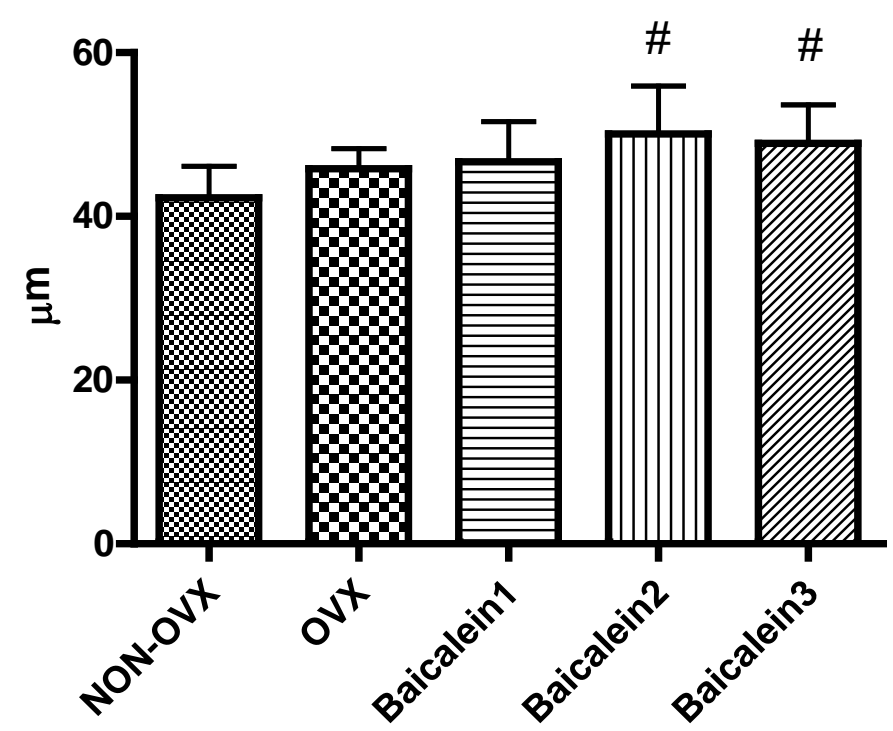

\#signifikant vs. NON-OVX

Abbildung 28: Typ-1-Muskelfaserdurchmesser beim M. gastrocnemius

Statistisch signifikant größer sind die Gruppen Baicalein2 und Baicalein3 gegenüber der NON-OVX-Gruppe. (Tabelle 14, Abb. 28)

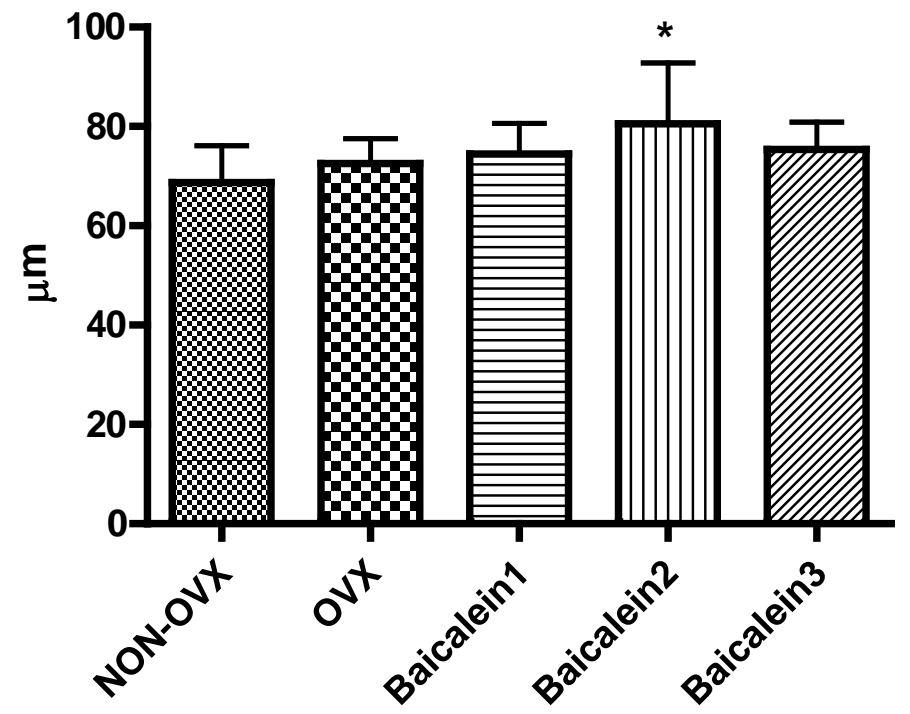

*signifikant vs. NON-OVX

Abbildung 29: Typ-2A-Muskelfaserdurchmesser beim M. gastrocnemius

Bezüglich der Durchmesser der Typ-2A-Muskelfasern waren die Mittelwerte der Gruppe Baicalein2 signifikant höher als die der NON-OVX-Gruppe. (Tabelle 14, Abb. 29) 


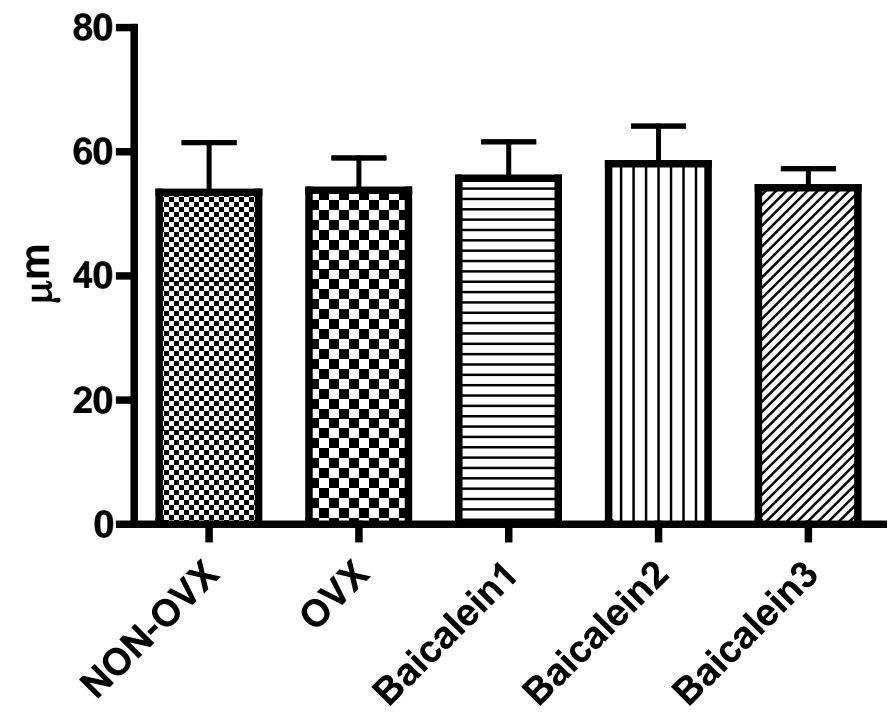

Abbildung 30: Typ-2B-Muskelfaserdurchmesser beim M. gastrocnemius

Es konnten bei den Typ-2B-Muskelfasern keine signifikanten Gruppenunterschiede festgestellt werden. (Tabelle 14, Abb. 30) 


\subsubsection{Flächengrößen des M. gastrocnemius}

Im Gegensatz zur Flächenvermessung beim M. soleus, wurden beim M. gastrocnemius die unterschiedlichen Muskelfasertypen beim Vermessen berücksichtigt. Tabelle $15 \mathrm{im}$ Anhang enthält die Flächenmittelwerte der verschiedenen Fasertypen.

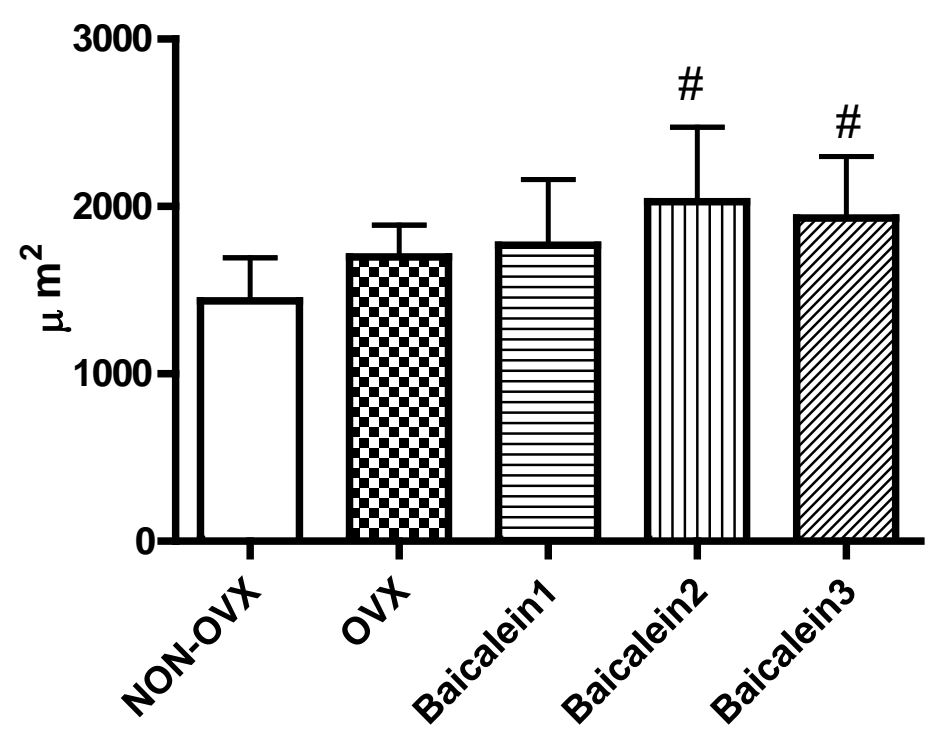

\#signifikant vs. NON-OVX

Abbildung 31: Typ-1-Muskelfaserflächen im M. gastrocnemius

Statistisch signifikant war hierbei der Unterschied zwischen der Baicalein2-Gruppe gegenüber der NON-OVX-Gruppe, sowie der Baicalein3-Gruppe gegenüber der NONOVX-Gruppe. (Tabelle 15, Abb. 31) 


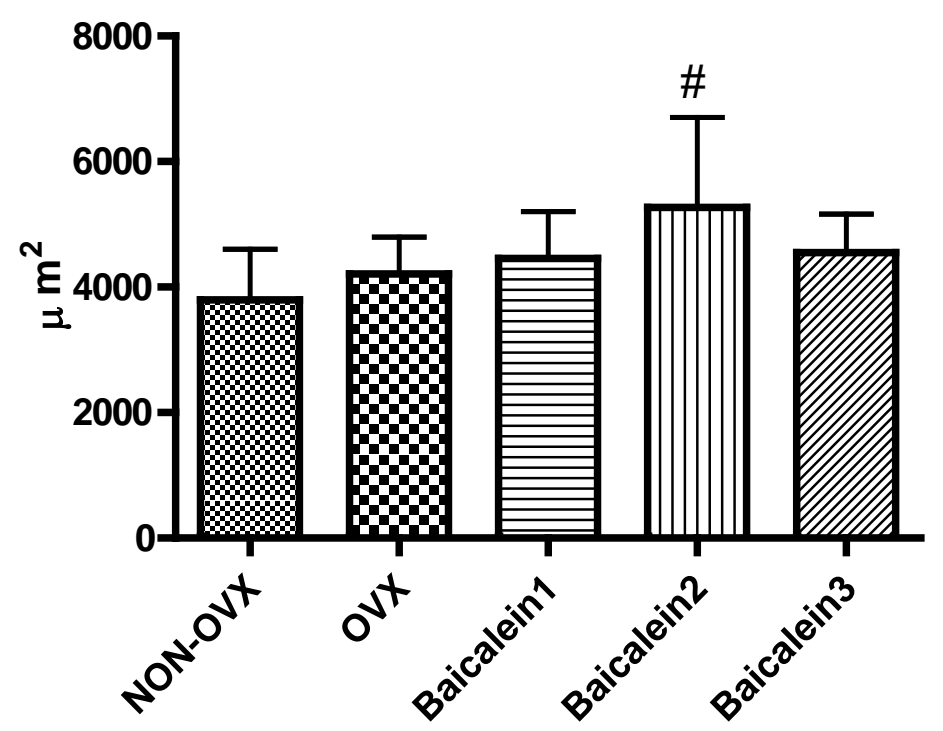

\#signifikant vs. NON-OVX

Abbildung 32: Typ-2A-Muskelfaserflächen im M. gastrocnemius

Es zeigte sich nach statistischer Analyse ein signifikant höherer Mittelwert der Baicalein2-Gruppe gegenüber der NON-OVX-Gruppe. (Tabelle 15, Abb. 32)

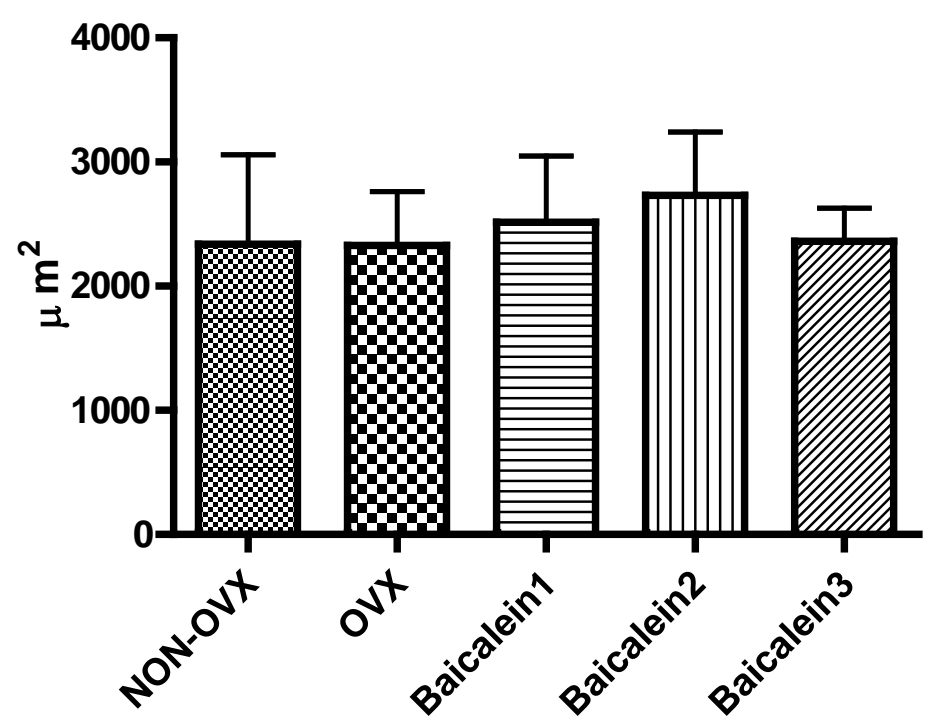

Abbildung 33: Mittelwerte der Typ-2B-Muskelfaserflächen im M. gastrocnemius

Es ließen sich bei den Typ-2B-Flächen keine Signifikanzen feststellen. (Tabelle 15, Abb. 33) 


\subsubsection{Verhältnisse der Muskelfaserdurchmesser zu den Gewichten beim}

\section{M. gastrocnemius}

In ähnlicher Weise wie beim M. soleus wurden auch die Werte des M. gastrocnemius in Verhältnis zu dessen Gewicht sowie zum Körpergewicht der Ratten gesetzt. Allerdings konnten bei diesem Muskel, wie bereits beschrieben, die einzelnen Muskelfasertypen einzeln ausgewertet werden. Tabelle 16 im Anhang enthält die berechneten Verhältniswerte für die Muskelfaserdurchmesser.

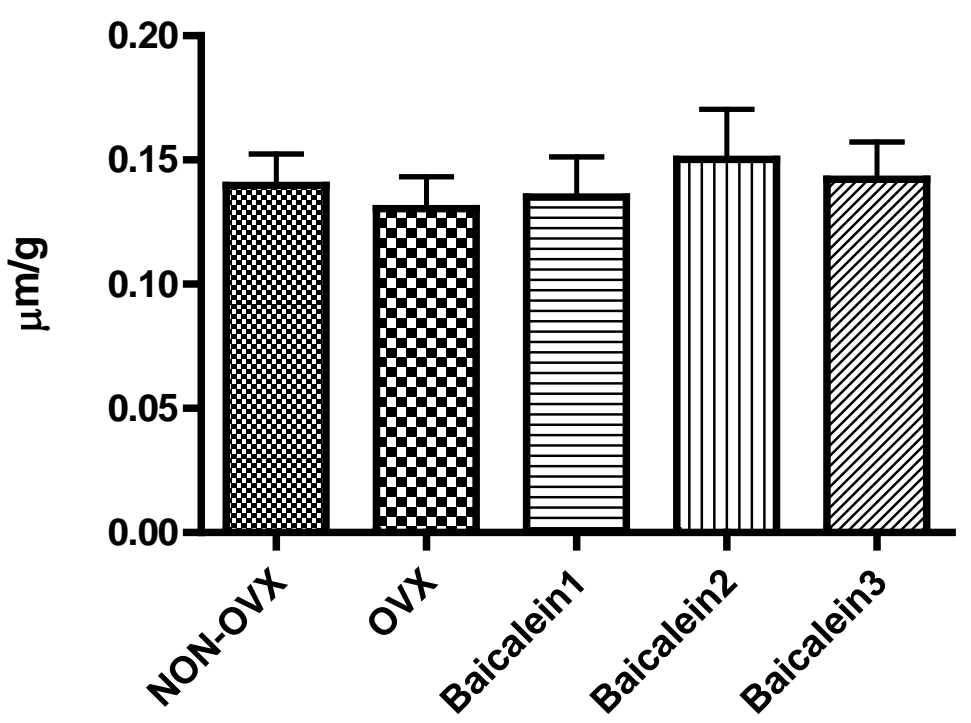

Abbildung 34: Relation von Muskelfaser-Typ-1-Durchmesser zum Körpergewicht beim M. gastrocnemius

Es konnten hierbei keine signifikanten Unterschiede erkannt werden. (Tabelle 16, Abb. 34) 


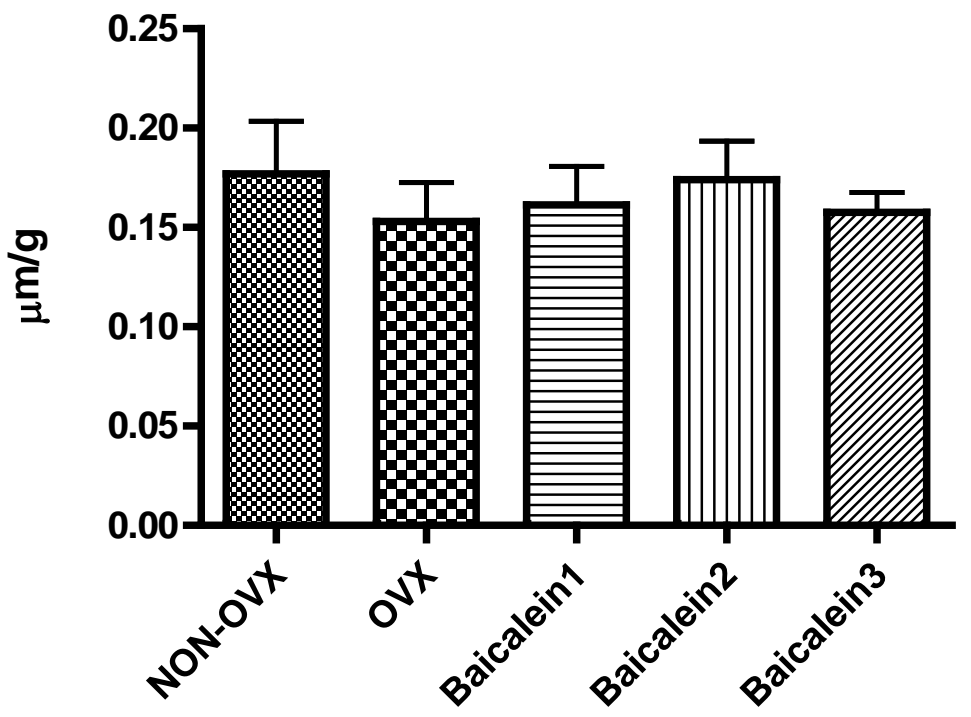

Abbildung 35: Relation von Muskelfaser-Typ-2A-Durchmesser zum Körpergewicht beim M. gastrocnemius

Die Analyse dieser Verhältniswerte ergab keine statistischen Signifikanzen. (Tabelle 16, Abb. 35)

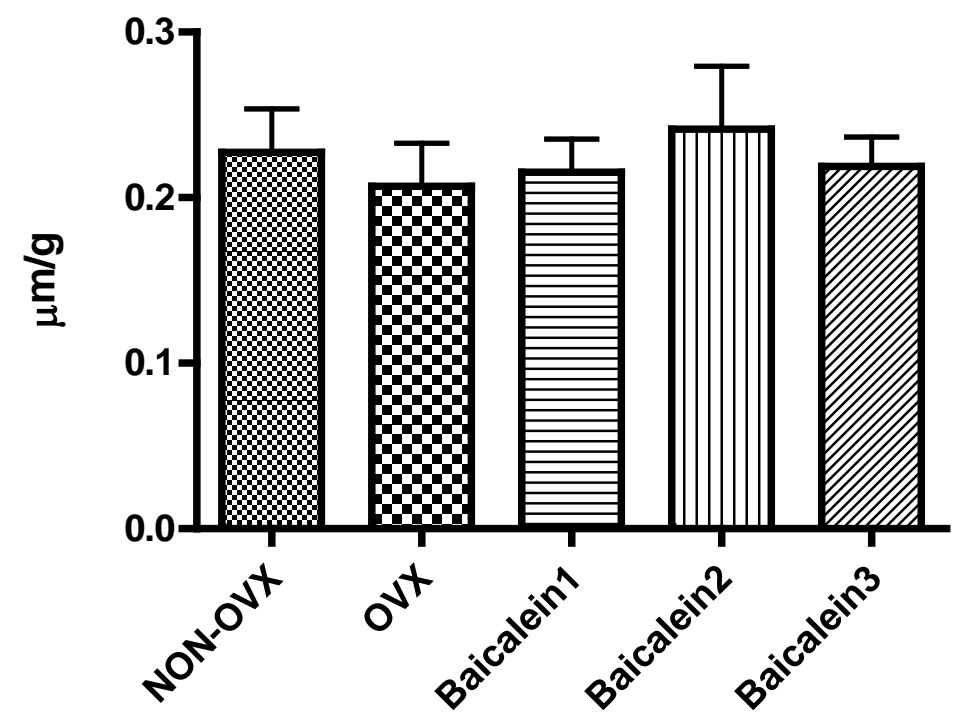

Abbildung 36: Relation von Muskelfaser-Typ-2B-Durchmesser zum Körpergewicht beim M. gastrocnemius

Die statistische Analyse dieser Verhältniswerte wies keine signifikanten Unterschiede auf. (Tabelle 16, Abb. 36) 


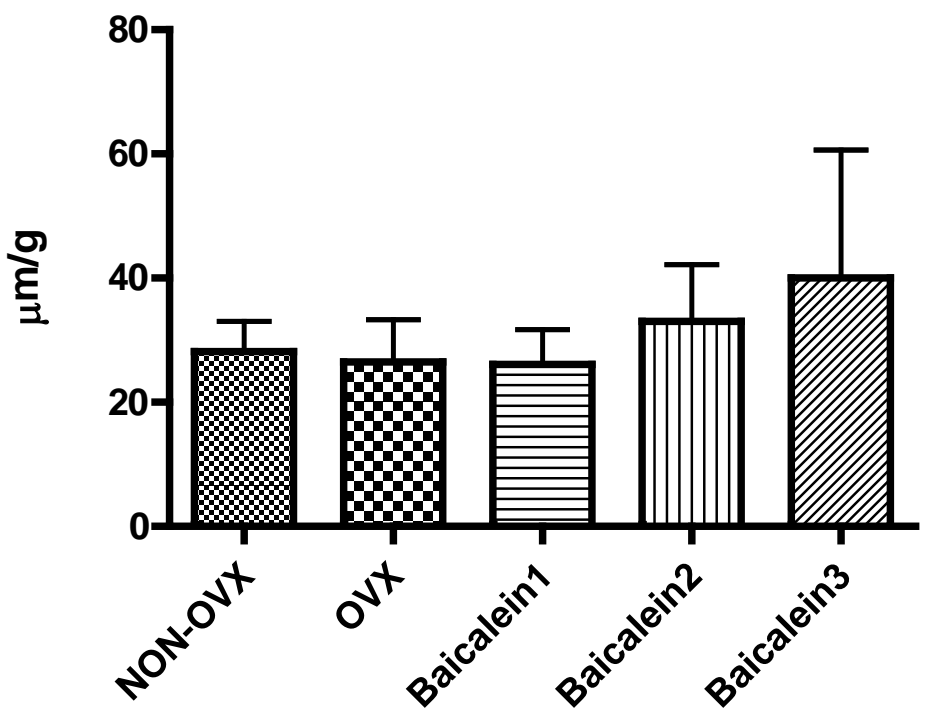

Abbildung 37: Relation von Muskelfaser-Typ-1-Durchmesser zum Muskelgewicht beim M. gastrocnemius

Es konnten bei diesen Verhältnissen keine signifikanten Unterschiede ermittelt werden. (Tabelle 16, Abb. 37)

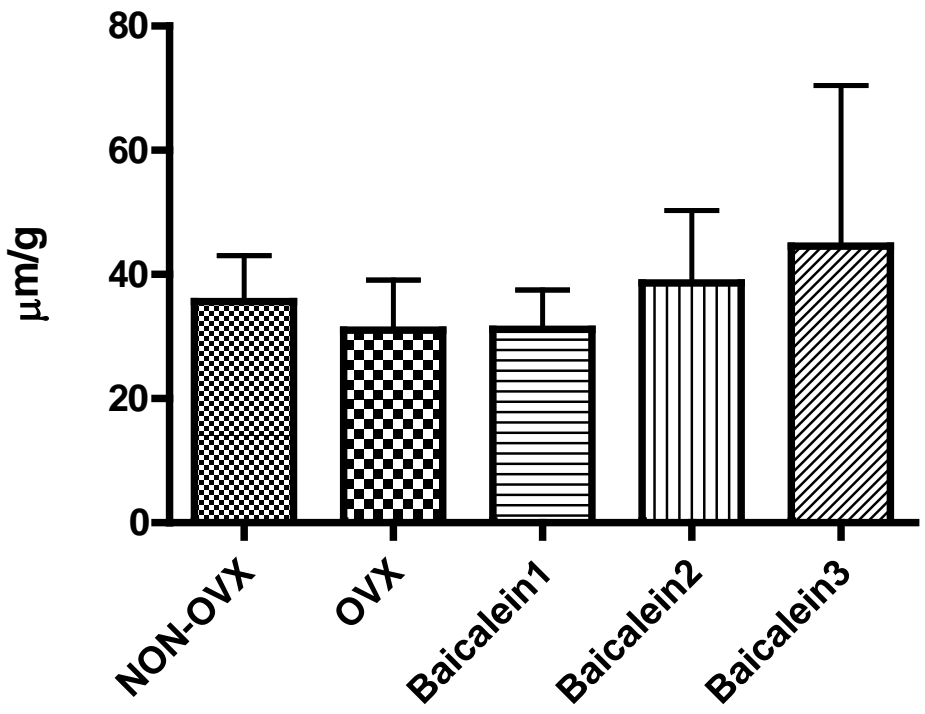

Abbildung 38: Relation von Muskelfaser-Typ-2A-Durchmesser zum Muskelgewicht beim M. gastrocnemius

Die Analyse der vorliegenden Verhältniswerte führte zu keiner statistischen Signifikanz. (Tabelle 16 Abb. 38) 


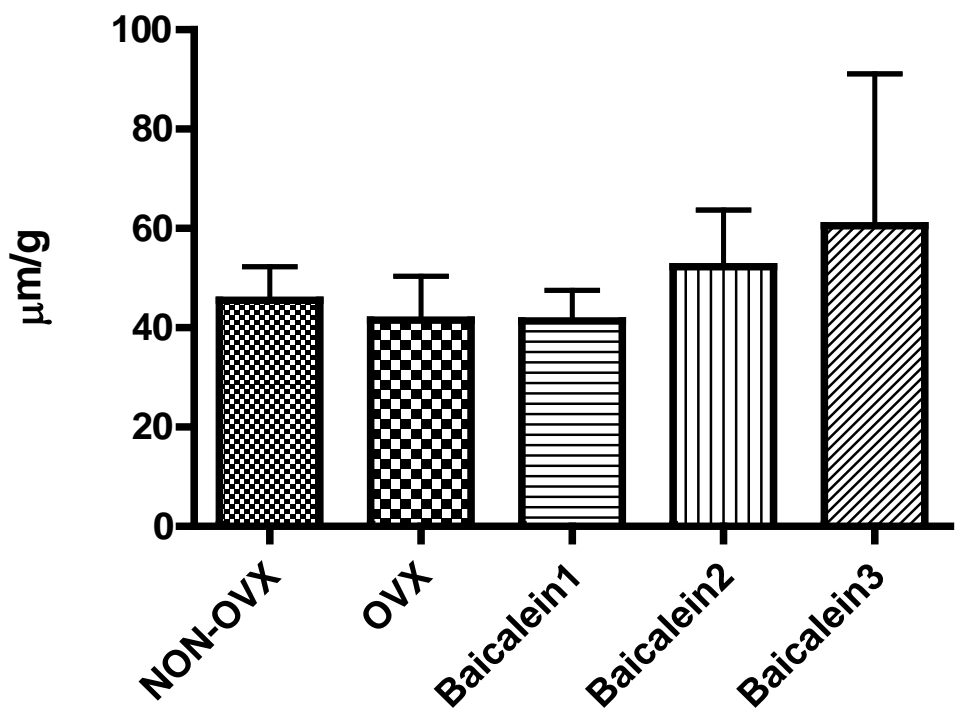

Abbildung 39: Relation von Muskelfaser-Typ-2B-Durchmesser zum Muskelgewicht beim M. gastrocnemius

Es lagen bei den gezeigten Verhältniswerten keine statistisch signifikanten Unterschiede vor. (Tabelle 16, Abb. 39)

\subsubsection{Verhältnisse der Muskelfaserflächen zu den Gewichten beim}

M. gastrocnemius

Ebenso wie die Mittelwerte der Muskelfaserdurchmesser wurden auch die Werte der Muskelfaserflächen in ein Verhältnis zu den Körper- und Muskelgewichten der jeweiligen Versuchstiere gesetzt. Tabelle 17 im Anhang enthält die Mittelwerte dieser Relationen aufgeteilt in die einzelnen Versuchsgruppen. 


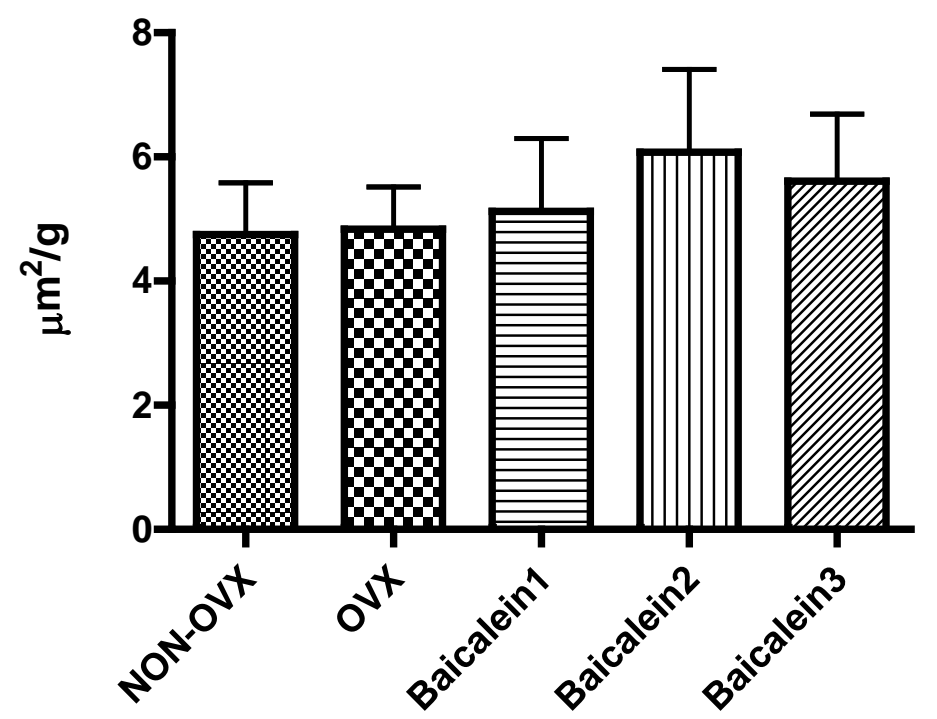

Abbildung 40: Relation von Muskelfaser-Typ-1-Fläche zum Körpergewicht beim M. gastrocnemius

Die dargestellten Verhältnisse erfüllten keine signifikanten Unterschiede zwischen den einzelnen Versuchsgruppen. (Tabelle 17, Abb. 40)

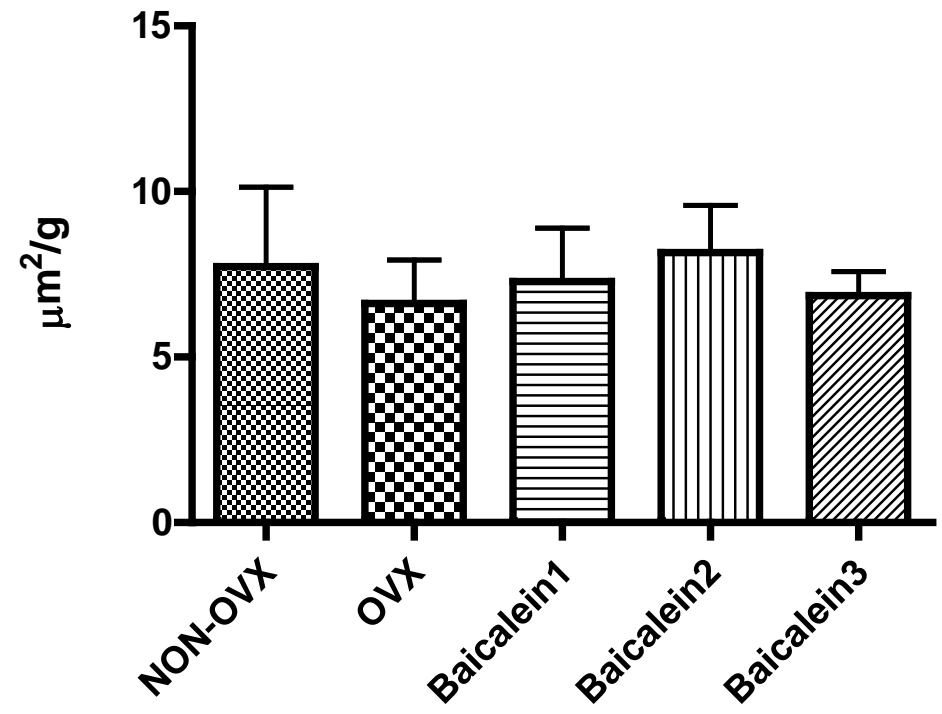

Abbildung 41: Relation von Muskelfaser-Typ-2A-Fläche zum Körpergewicht beim M. gastrocnemius

Die statistische Analyse der Werte zeigte hier keine signifikanten Unterschiede.

(Tabelle 17, Abb. 41) 


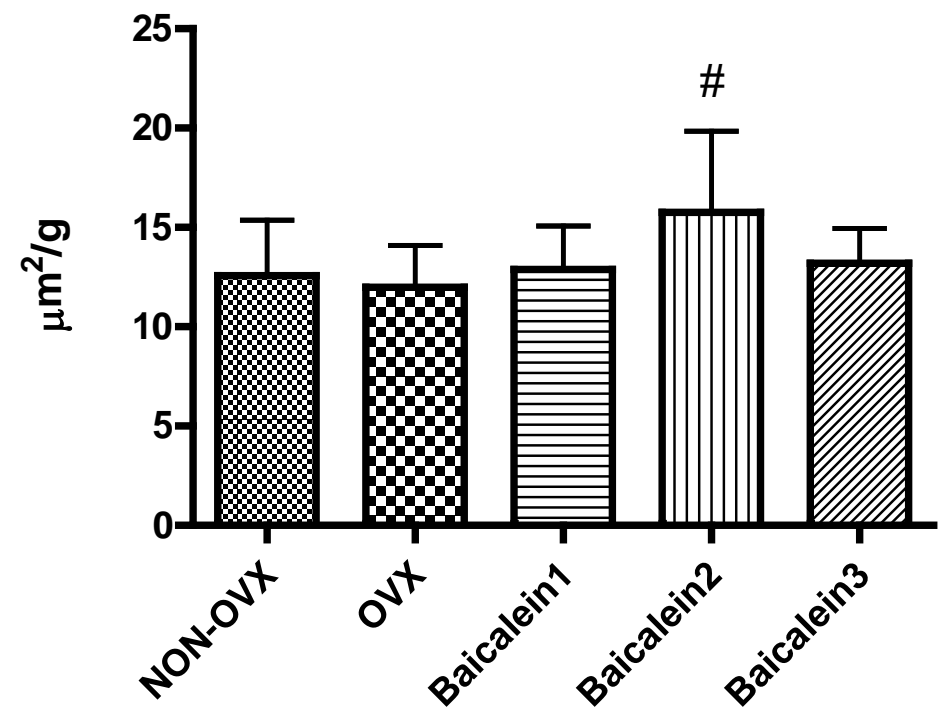

\#signifikant vs. OVX

Abbildung 42: Relation von Muskelfaser-Typ-2B-Fläche zum Körpergewicht beim M. gastrocnemius

Die statistische Auswertung ergab, dass die Verhältniswerte der Baicalein2-Gruppe signifikant größer als die der OVX-Gruppe sind. (Tabelle 17, Abb. 42)

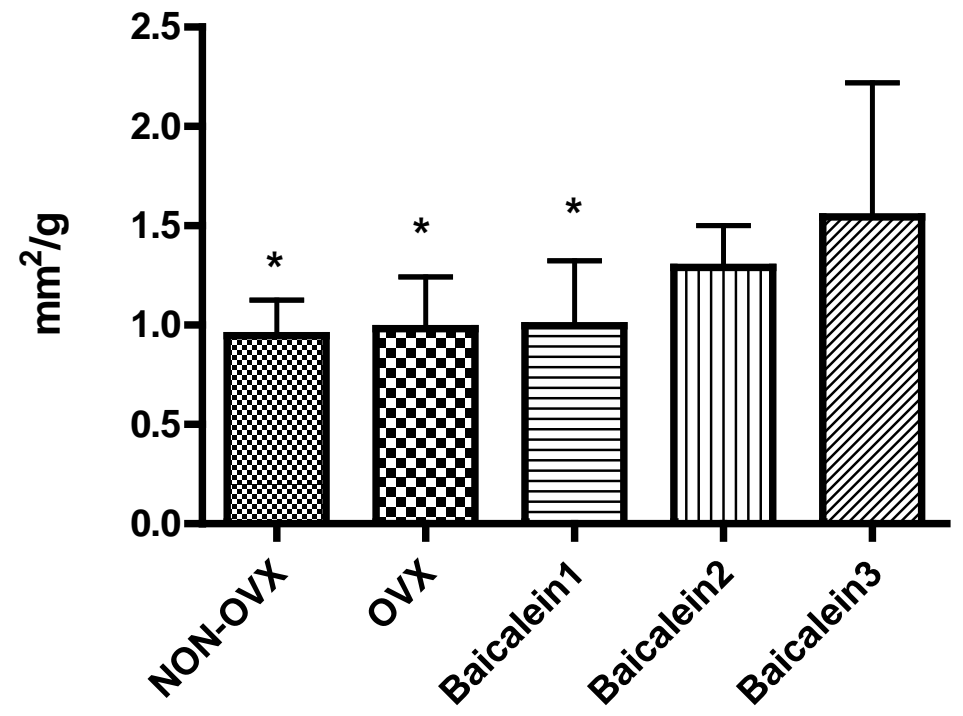

*signifikant vs. Baicalein3

Abbildung 43: Relation von Muskelfaser-Typ-1-Fläche zum Muskelgewicht beim M. gastrocnemius

Laut statistischer Analyse sind die Verhältniswerte der Baicalein3-Gruppe signifikant größer als die Werte der Gruppen NON-OVX, OVX und Baicalein1. (Tabelle 17, Abb. 43) 


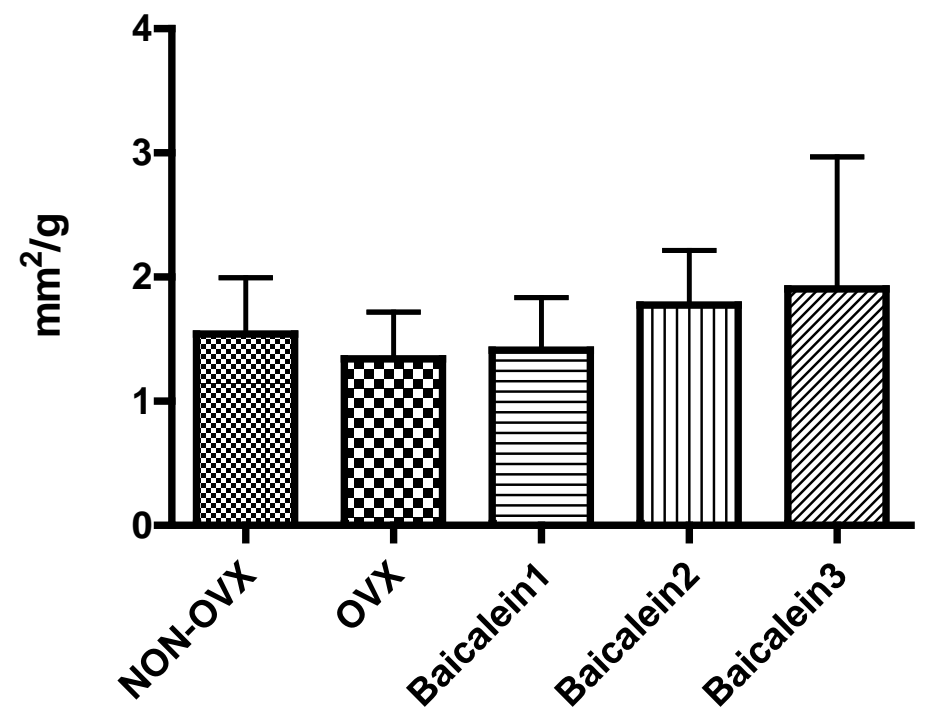

Abbildung 44: Relation von Muskelfaser-Typ-2A-Fläche zum Muskelgewicht beim M. gastrocnemius

Es ließen sich keine statistischen Signifikanzen dieser Verhältniswerte ermitteln. (Tabelle 17, Abb. 44)

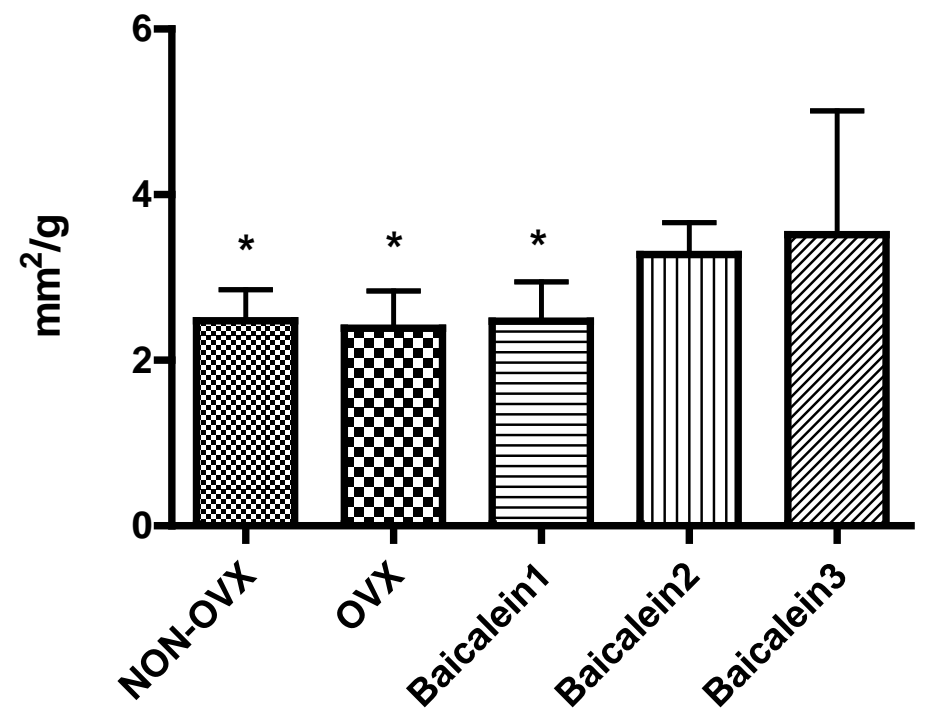

*signifikant vs. Baicalein3

Abbildung 45: Relation von Muskelfaser-Typ-2B-Fläche zum Muskelgewicht beim M. gastrocnemius

Die Verhältniswerte der Baicalein3-Gruppe waren hier signifikant größer im Vergleich zu den Gruppen NON-OVX, OVX und Baicalein1. (Tabelle 17, Abb. 45) 


\subsection{Analyse der Muskelfaserdurchmesser und der Flächen beim M. Iongissimus}

\subsubsection{Analyse der Muskelfaserdurchmesser des M. longissimus}

Wie auch beim M. gastrocnemius konnten beim M. longissimus die drei verschiedenen Muskelfasertypen ausgewertet werden. Es wurden ebenfalls 270 Muskelfasern pro Muskel ausgemessen. In Tabelle 18 im Anhang sind die dazugehörigen Mittelwerte der einzelnen Gruppen und Muskelfasertypen aufgeführt.

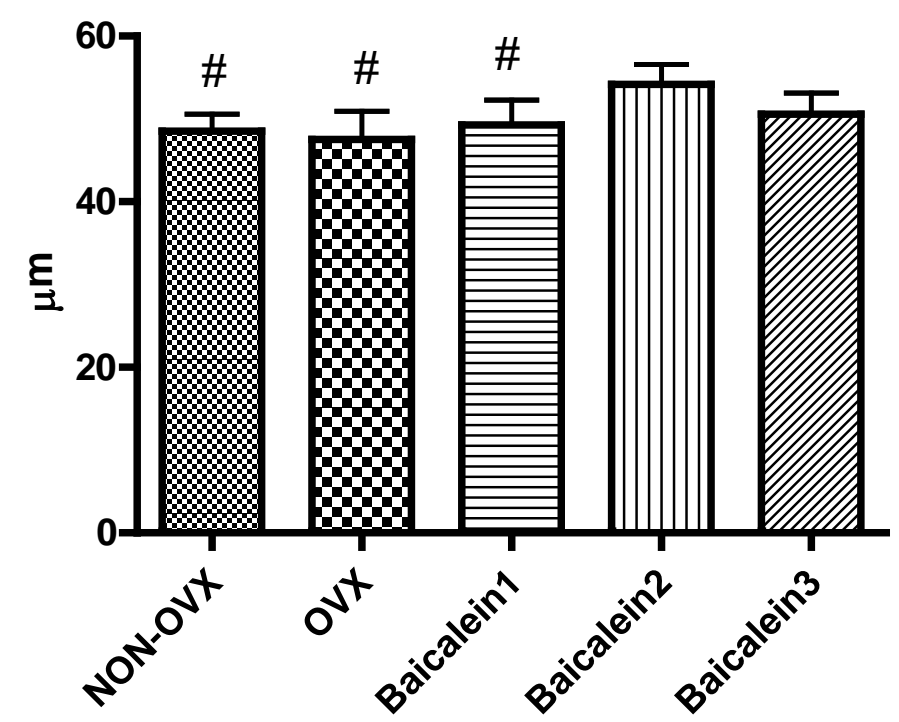

\#signifikant vs. Baicalein2

Abbildung 46: Typ-1-Muskelfaserdurchmesser beim M. longissimus

Die statistische Analyse der Mittelwerte ergab einen signifikanten Unterschied der NONOVX-Gruppe zur Baicalein2-Gruppe. Zudem waren die Werte der Baicalein2-Gruppe signifikant höher gegenüber denen der OVX-, und der Baicalein1-Gruppe. (Tabelle 18, Abb. 46) 


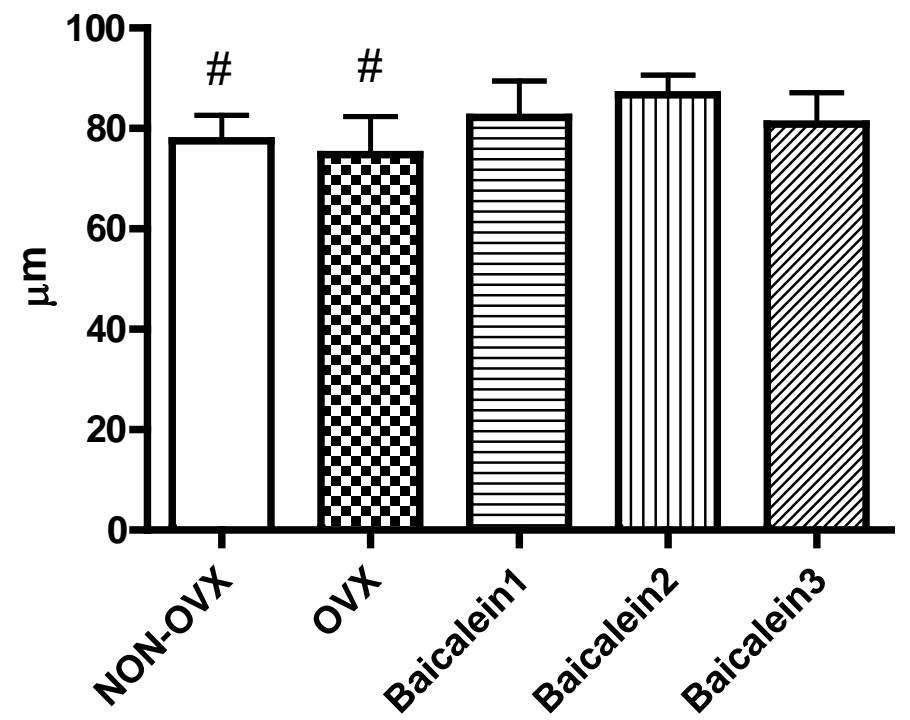

\#signifikant vs. Baicalein2

Abbildung 47: Typ-2A-Muskelfaserdurchmesser beim M. longissimus

Die vorliegenden Mittelwerte der Baicalein2-Gruppe erwiesen sich als signifikant erhöht gegenüber denen der NON-OVX- sowie der OVX-Gruppe. (Tabelle 18, Abb. 47)

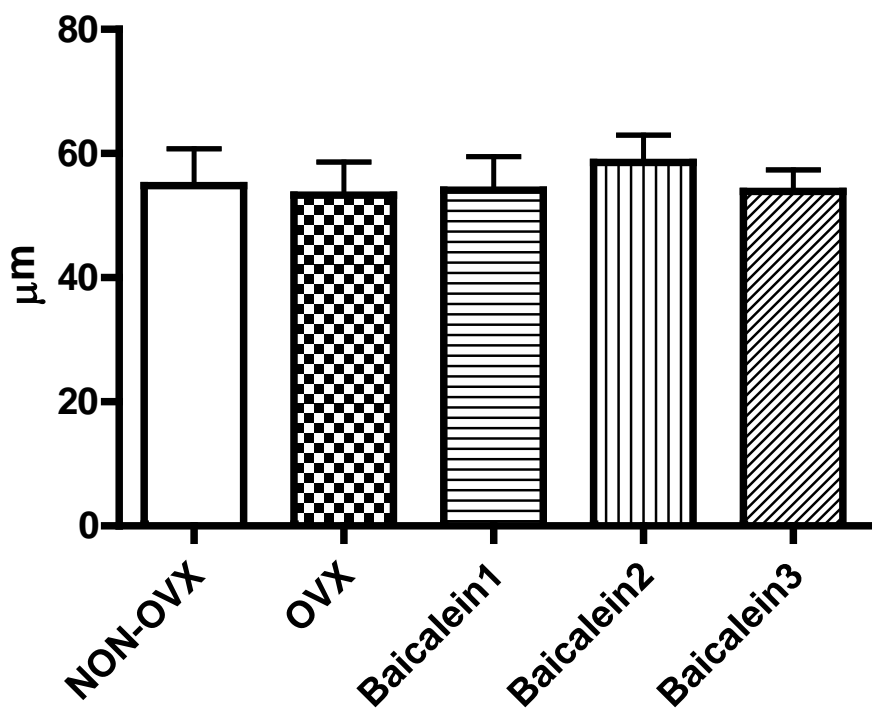

Abbildung 48: Typ-2B-Muskelfaserdurchmesser beim M. longissimus

Es zeigten sich bei den Typ-2B-Muskelfasern keine signifikanten Unterschiede der Durchmesser zwischen den einzelnen Gruppen. (Tabelle 18, Abb. 48) 


\subsubsection{Flächengrößen des $M$. longissimus}

Ähnlich wie beim M. gastrocnemius wurden die Flächen der verschiedenen Muskelfasertypen bestimmt. Tabelle 19 im Anhang zeigt die ermittelten Mittelwerte der einzelnen Versuchsgruppen.

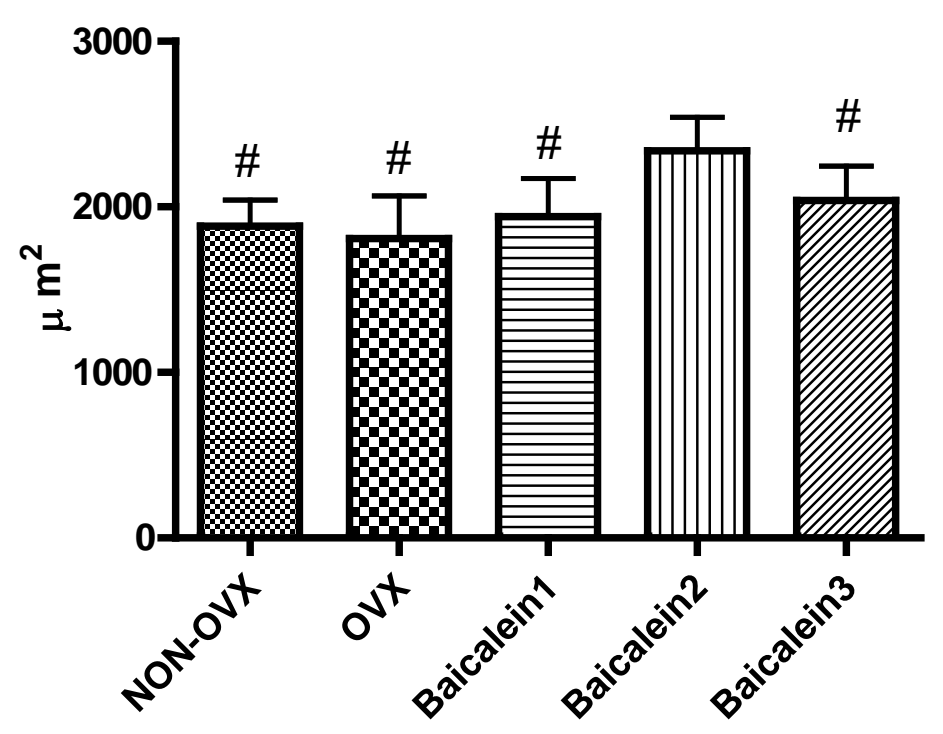

\#signifikant vs. Baicalein2

Abbildung 49: Typ-1-Muskelfaserflächen im M. longissimus

Die statistische Analyse dieser Werte ergab signifikante Unterschiede. So waren die Flächen der Baicalein2-Gruppe größer als die der NON-OVX-Gruppe. Zudem waren die Werte der Baicalein2-Gruppe höher als die der OVX-Gruppe, der Baicalein1-Gruppe und der Baicalein3-Gruppe. (Tabelle 19, Abb. 49) 


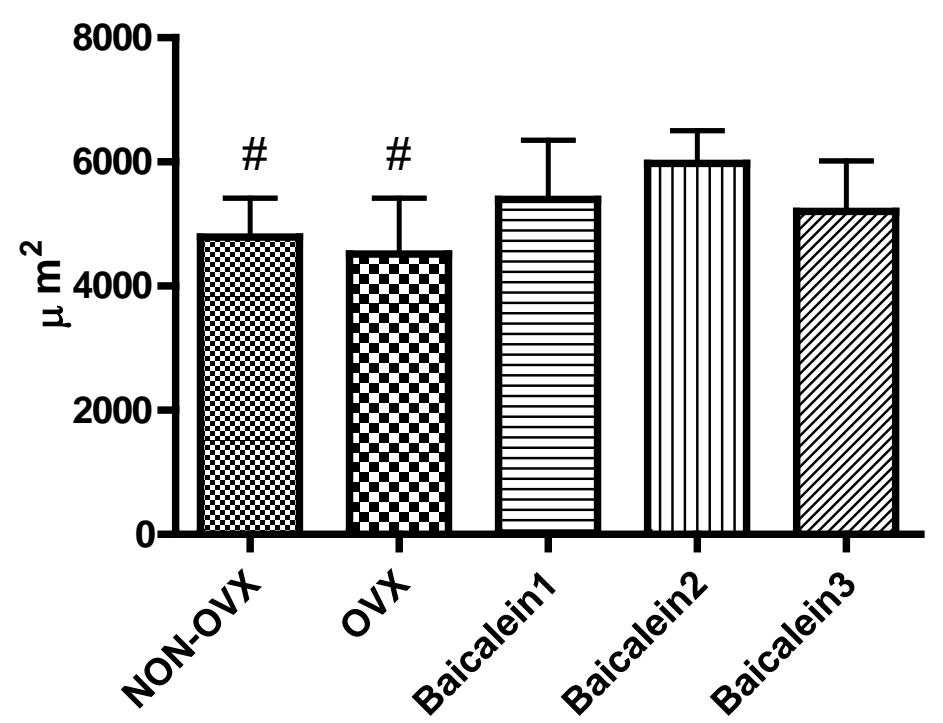

\#signifikant vs. Baicalein2

Abbildung 50: Typ-2A-Muskelfaserflächen im M. longissimus

Es zeigte sich hier ein signifikant größerer Mittelwert der Baicalein2-Gruppe im Vergleich zur OVX-, und NON-OVX-Gruppe. (Tabelle 19, Abb. 50)

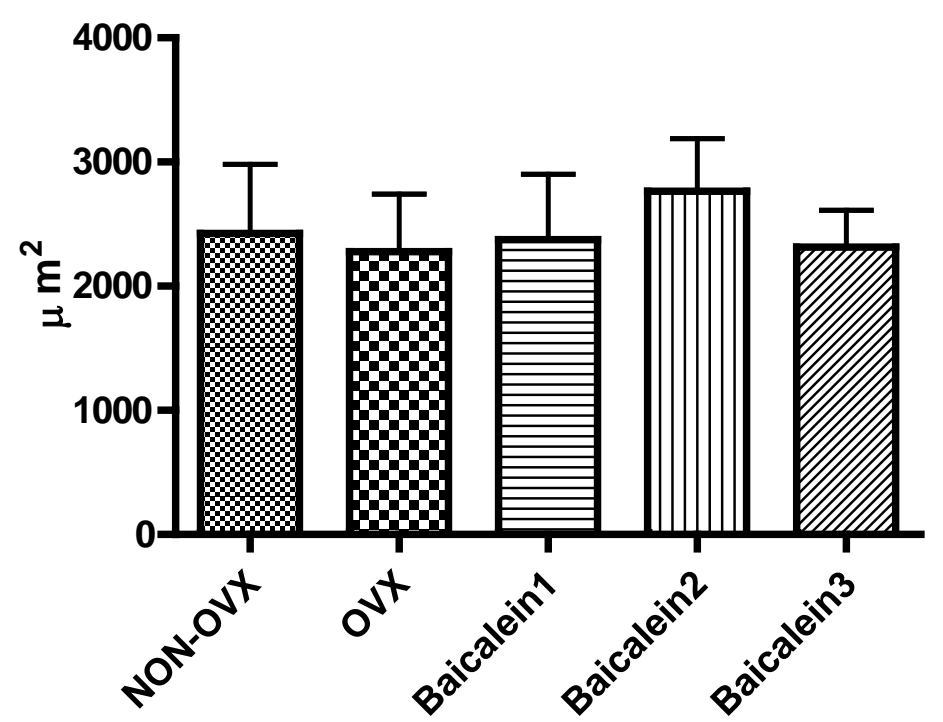

Abbildung 51: Typ-2B-Muskelfaserflächen im M. longissimus

Innerhalb der Typ-2B-Muskelfaserflächen des M. longissimus ließen sich keine Signifikanzen nachweisen. (Tabelle 19, Abb. 51) 


\subsubsection{Verhältnisse der Muskelfaserdurchmesser zu den Gewichten beim}

\section{M. longissimus}

Da der M. longissimus nicht in toto resiziert wurde, konnte dessen Gewicht nicht bestimmt werden. Demzufolge wurden bei diesem Muskel, sowohl Flächen, als auch Durchmesser nur auf das Körpergewicht bezogen. Tabelle 20 im Anhang zeigt die Mittelwerte dieser Verhältnisse hinsichtlich der Muskelfaserdurchmesser.

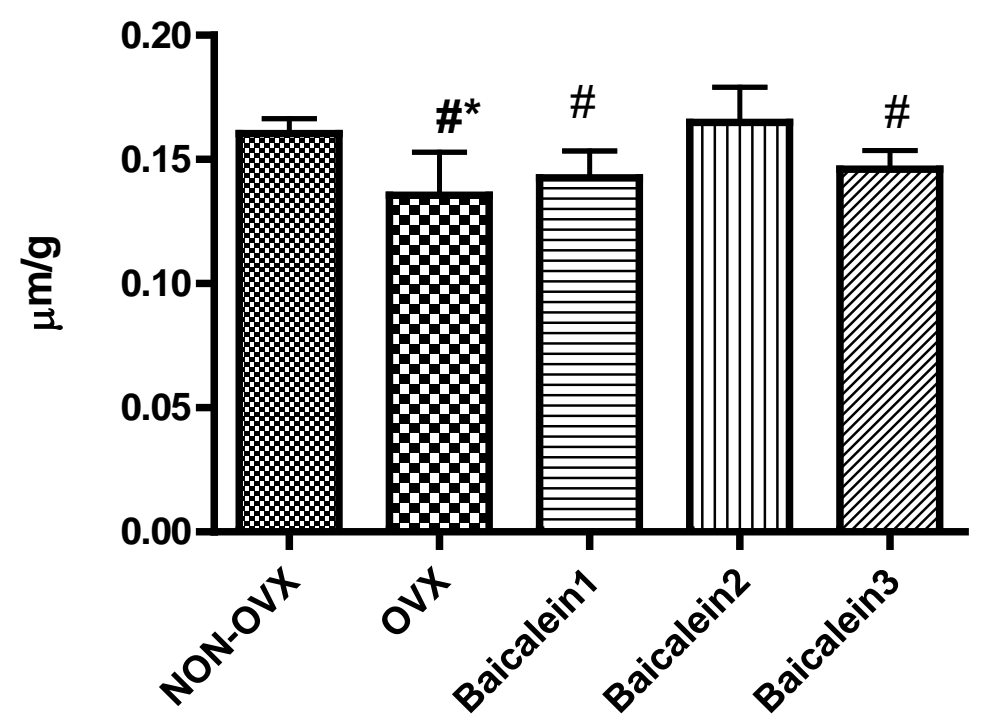

\#signifikant vs. Baicalein2; *signifikant vs. NON-OVX

Abbildung 52: Relation von Muskelfaser-Typ-1-Durchmesser zum Körpergewicht beim M. longissimus

Die Verhältnisse zum Körpergewicht waren in der NON-OVX-Gruppe signifikant größer als die Werte aus der OVX-Gruppe. Zudem lagen die Werte der Baicalein2-Gruppe signifikant über denen der Gruppen OVX, Baicalein1 und Baicalein3. (Tabelle20,Abb. 52) 


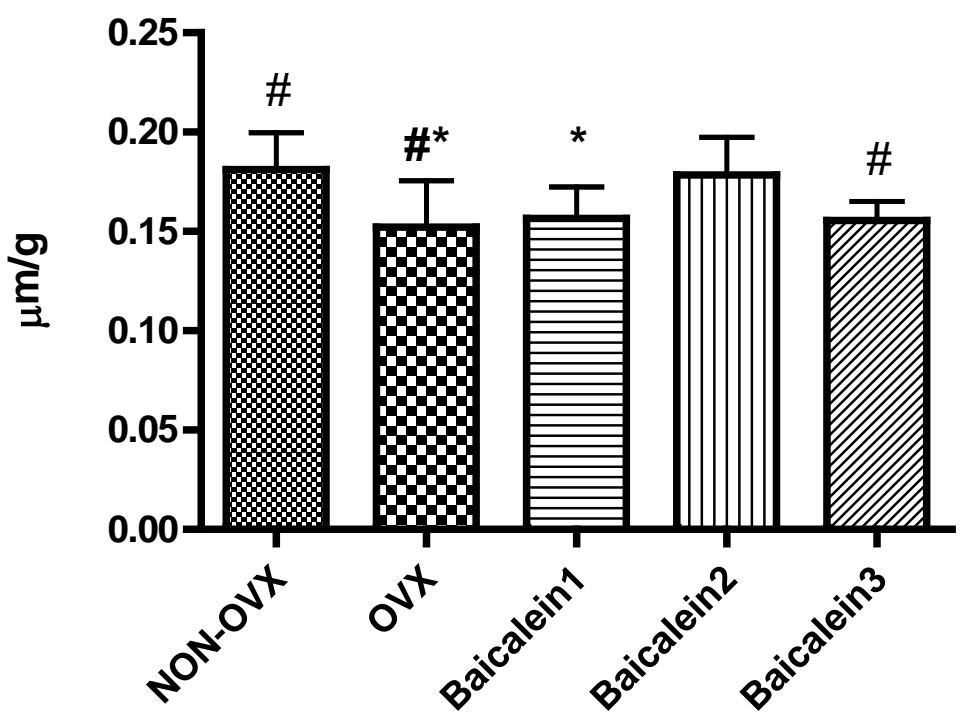

\#signifikant vs. Baicalein2; *signifikant vs. NON-OVX

Abbildung 53: Relation von Muskelfaser-Typ-2A-Durchmesser zum Körpergewicht beim M. longissimus

Die Verhältniswerte der NON-OVX-Gruppe lagen signifikant über denen der OVXGruppe. Ebenso waren die Werte der Baicalein1-Gruppe signifikant größer als die der NON-OVX-Gruppe. Zudem lagen die Werte der Baicalein2-Gruppe signifikant über denen der OVX-Gruppe, sowie die NON-OVX- über der Baicalein3-Gruppe. (Tabelle 20, Abb. 53)

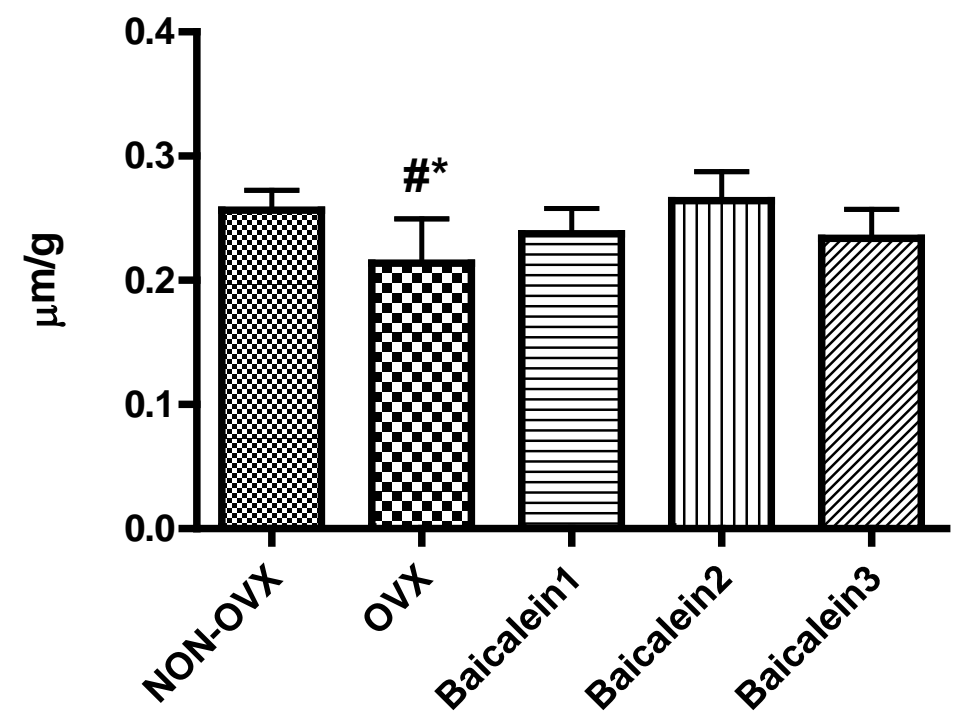

\#signifikant vs. Baicalein2; *signifikant vs. NON-OVX

Abbildung 54: Relation von Muskelfaser-Typ-2B-Durchmesser zum Körpergewicht beim M. longissimus 
Die Werte der Gruppe NON-OVX waren signifikant größer als die Werte der OVXGruppe, sowie die Verhältniswerte der Baicalein2-Gruppe signifikant größer gegenüber der OVX-Gruppe. (Tabelle 20, Abb. 54)

\subsubsection{Verhältnisse der Muskelfaserflächen zu den Gewichten beim M. longissimus}

Es wurden hierbei die ermittelten Muskelfaserflächen in Relation zum Körpergewicht der Ratten gesetzt. Tabelle 21 im Anhang enthält diese Werte.

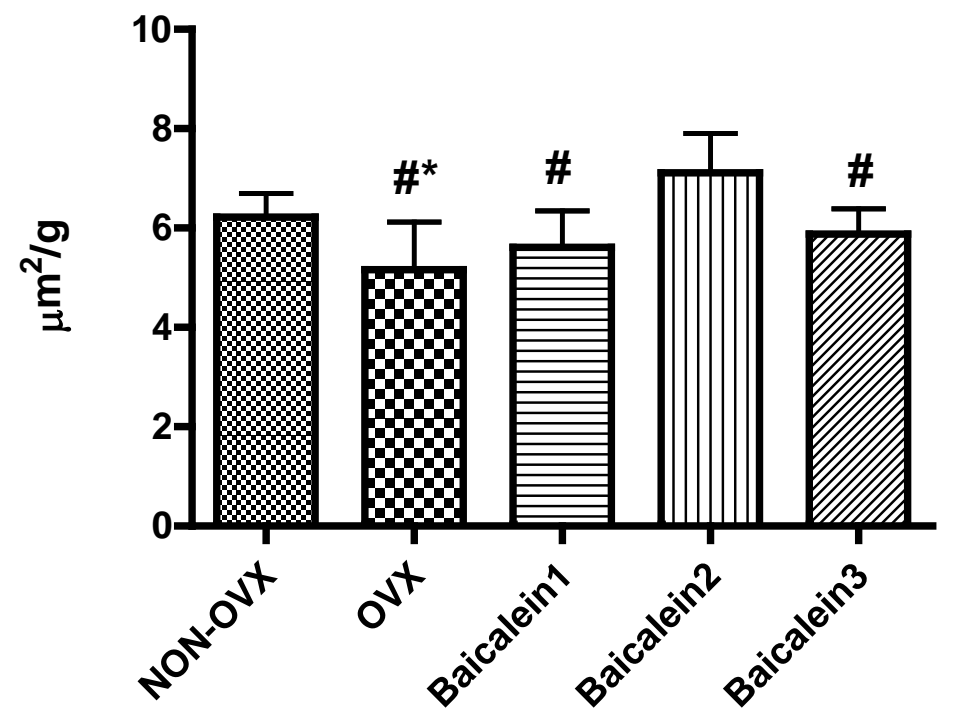

\#signifikant vs. Baicalein2; *signifikant vs. NON-OVX

Abbildung 55: Relation von Muskelfaser-Typ-1-Fläche zum Körpergewicht beim M. longissimus

Es zeigt sich bei diesen Werten eine Signifikanz von NON-OVX- zu OVX-Gruppe. Die Baicalein2-Gruppe verfügt ferner über signifikant größere Mittelwerte als die OVXGruppe, die Baicalein1- sowie die Baicalein3-Gruppe. (Tabelle 21, Abb. 55) 


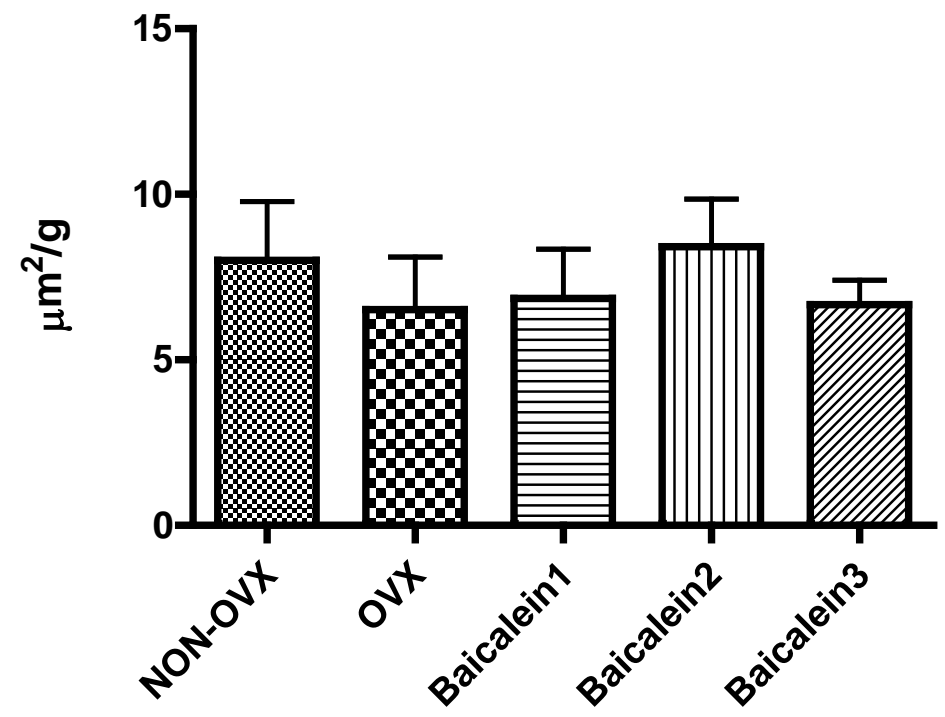

Abbildung 56: Relation von Muskelfaser-Typ-2A-Fläche zum Körpergewicht beim M. longissimus

Die statistische Analyse führte zu keinen Signifikanzen. (Tabelle 21, Abb. 56)

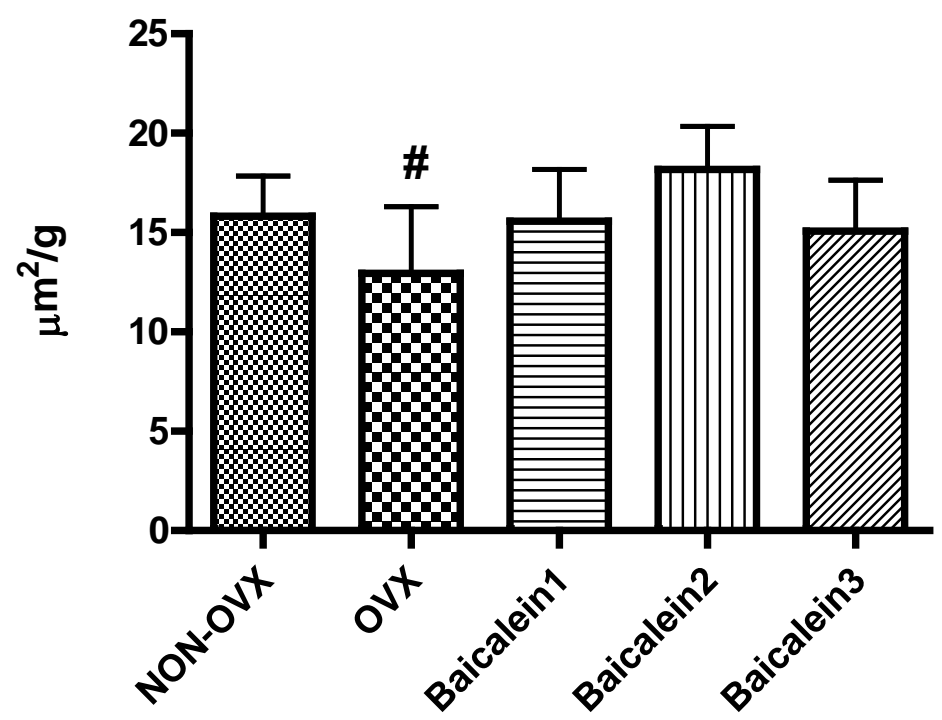

\#signifikant vs. Baicalein2

Abbildung 57: Relation von Muskelfaser-Typ-2B-Fläche zum Körpergewicht beim M. longissimus

Es ergab sich aus diesen Werten, dass die Baicalein2-Gruppe signifikant größere Mittelwerte im Vergleich zur OVX-Gruppe aufwies. (Tabelle 21, Abb. 57) 


\subsubsection{Verhältnisse der Muskelfasertypen im M. longissimus}

Aufgrund der inhomogenen Verteilung der Muskelfasertypen im M. longissimus war eine Bestimmung der Verhältnisse der Typen zueinander sinnvoll. Hierzu wurden auf einer Fläche von $1 \mathrm{~mm}^{2}$ die verschiedenen Fasertypen ausgezählt und anschließend deren Verhältnis zueinander berechnet. Tabelle 22 im Anhang beinhaltet die Verhältnisse der Anzahlen von verschiedenen Fasertypen der einzelnen Gruppen zueinander.

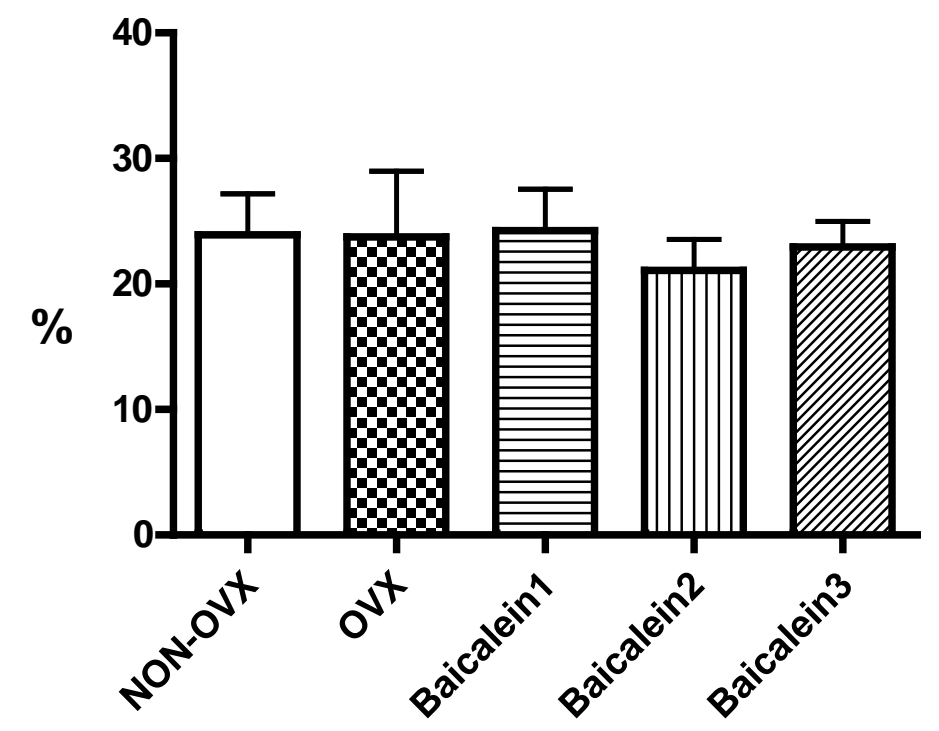

Abbildung 58: Verhältnis von Typ1-Muskelfasern zur Summe aller Fasern im M. longissimus in Prozent an gesamten Fasern auf $1 \mathrm{~mm}^{2}$

Die Verhältnisse von Typ-1 zur Summe aller Muskelfasern zeigten keine statistischen Signifikanzen zwischen den verschiedenen Gruppen auf. (Tabelle 22, Abb. 58) 


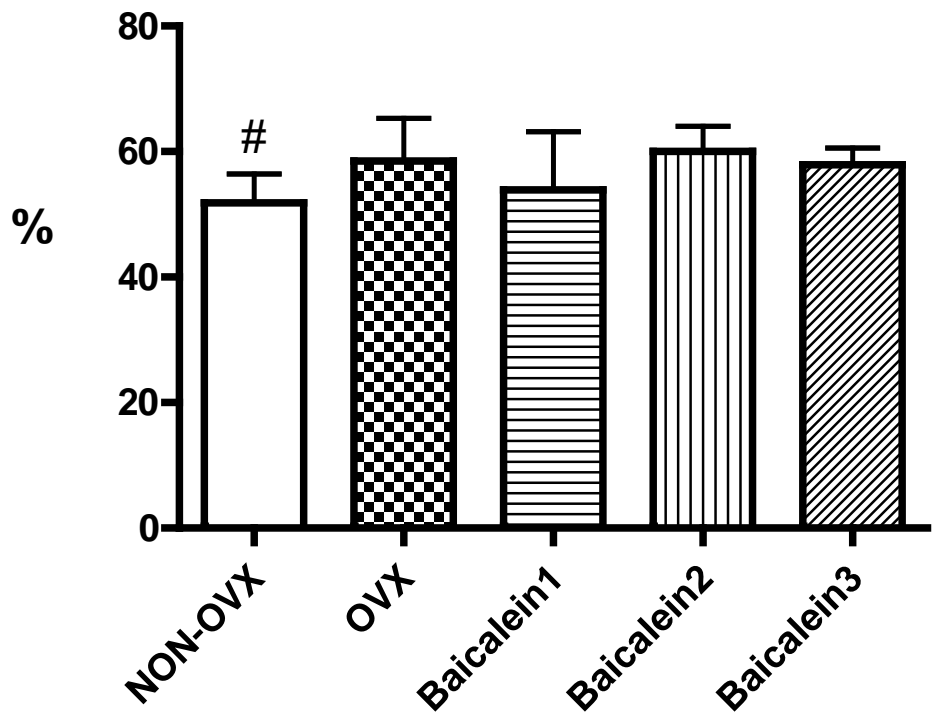

\#signifikant vs. Baicalein2

Abbildung 59: Verhältnis von Typ-2A-Muskelfasern zur Summe aller Fasern im M. longissimus in Prozent an gesamten Fasern auf $1 \mathrm{~mm}^{2}$

Es zeigte sich ein signifikant höherer Anteil von Typ-2A zu den übrigen Muskelfasertypen zwischen der Baicalein2-Gruppe und der NON-OVX-Gruppe.

(Tabelle 22, Abb. 59)

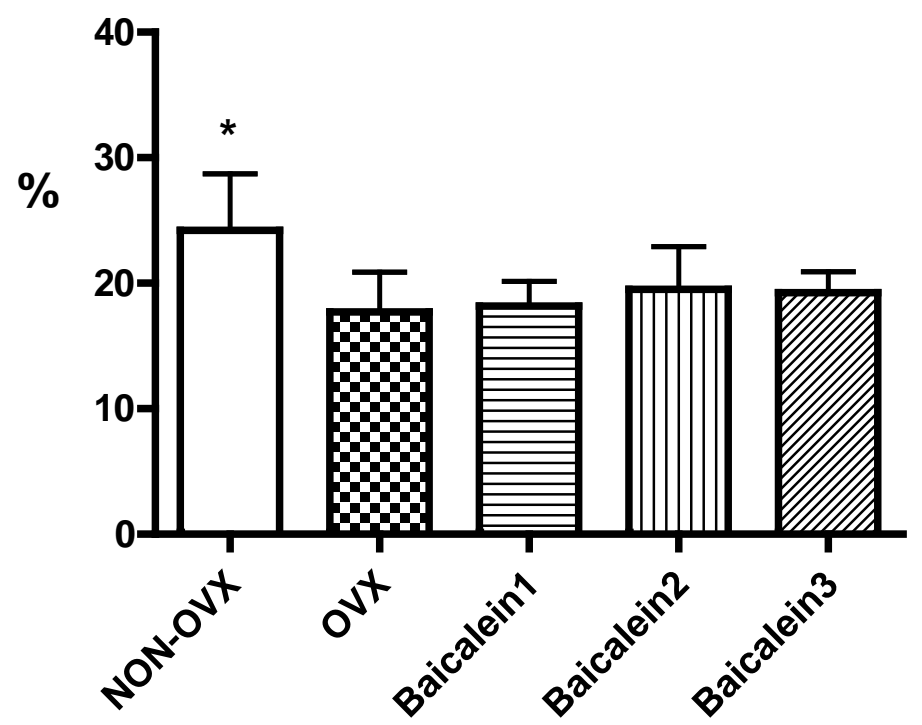

*signifikant vs. OVX, Baicalein1, Baicalein2, Baicalein3

Abbildung 60: Verhältnis von Typ-2B-Muskelfasern zur Summe aller Fasern im M. longissimus in Prozent an gesamten Fasern auf $1 \mathrm{~mm}^{2}$ 
Das Verhältnis von Typ-2B-Fasern gegenüber den restlichen Fasern war bei der NONOVX-Gruppe signifikant größer gegenüber allen anderen Gruppen. (Tabelle 22, Abb. 60)

\subsubsection{Analyse der Serumparameter}

In Tabelle 23 im Anhang sind die Mittelwerte der Ergebnisse für die drei Serumparameter Kreatinkinase (Units/Liter), Calcium und Magnesium (mmol/l) der einzelnen Versuchsgruppen dargestellt.

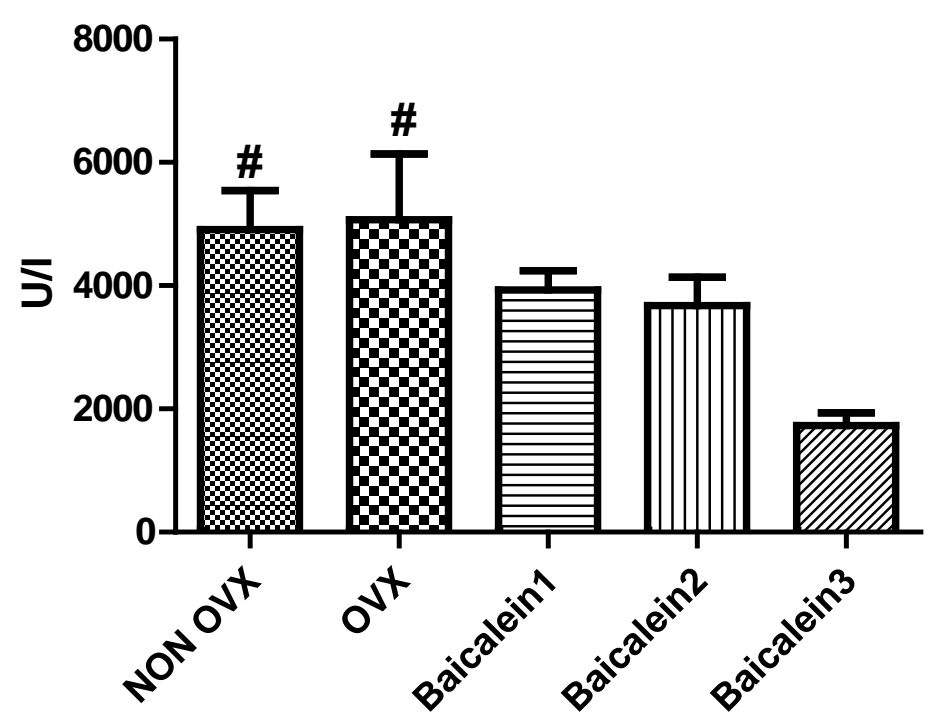

\#signifikant vs. Baicalein3

Abbildung 61: Kreatinkinase im Serum

Die statistische Analyse ergab signifikant niedrigere Werte von Kreatinkinase in der Baicalein3-Gruppe im Vergleich zur NON-OVX und OVX-Gruppe. (Tabelle 23, Abb. 61) 


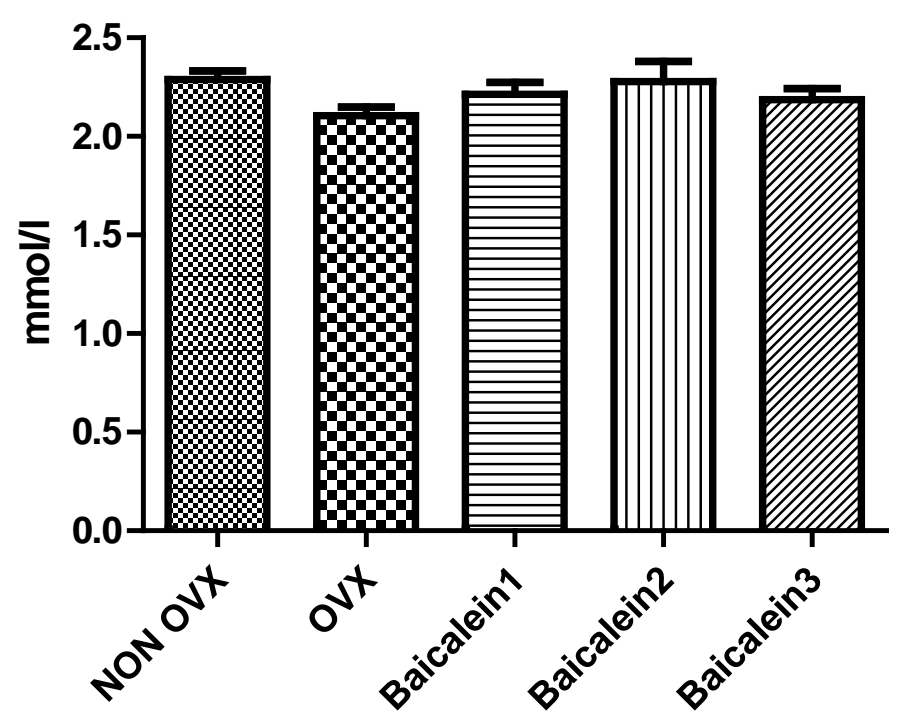

Abbildung 62: Calcium im Serum

Es ergaben sich hierbei keine statistischen Signifikanzen. (Tabelle 23, Abb. 62)

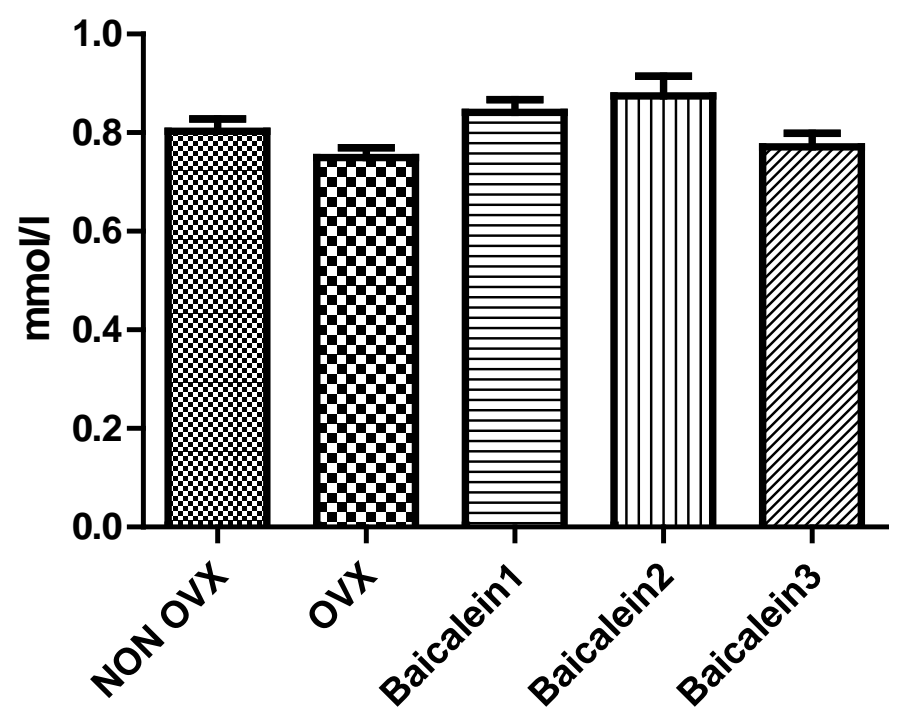

Abbildung 63: Magnesium im Serum

Der statistische Vergleich der Versuchsgruppen ergab keine Signifikanzen. (Tabelle 23, Abb. 63) 


\subsection{Zusammenfassung der Ergebnisse}

Folgende Tabellen 2 a-c dienen der Veranschaulichung der bisher genannten statistisch signifikanten Ergebnisse.

Die Versuchsgruppen sind den einzelnen Parametern gegenübergestellt.

$<$ bedeutet signifikant erniedrigt

> bedeutet signifikant erhöht

$\leftrightarrow$ bedeutet kein signifikanter Unterschied

Tabelle 2a: Zusammenfassung der Ergebnisse für die Kapillarisierung der verschiedenen Muskeln

\begin{tabular}{|c|c|c|c|c|c|}
\hline Parameter & $\begin{array}{c}\text { NON- } \\
\text { OVX } \\
\text { (1) }\end{array}$ & $\begin{array}{c}\text { OVX } \\
\text { (2) }\end{array}$ & $\begin{array}{c}\text { Baicalein1 } \\
\text { (3) }\end{array}$ & $\begin{array}{c}\text { Baicalein2 } \\
\text { (4) }\end{array}$ & $\begin{array}{c}\text { Baicalein3 } \\
\text { (5) }\end{array}$ \\
\hline $\begin{array}{c}\text { Kapillaren/MF } \\
\text { M. soleus }\end{array}$ & $\leftrightarrow$ & $\leftrightarrow$ & $>1,2$ & $>1,2$ & $>1,2$ \\
\hline $\begin{array}{c}\text { Kapillaren/MF } \\
\text { M. } \\
\text { gastrocnemius }\end{array}$ & $\leftrightarrow$ & $\leftrightarrow$ & $>1,2$ & $>1,2$ & $>1,2,4$ \\
\hline $\begin{array}{c}\text { Kapillaren/MF } \\
\text { M. longissimus }\end{array}$ & $\leftrightarrow$ & $\leftrightarrow$ & $>1$ und 2 & $>1,2,3$ & $>1,2,3$ \\
\hline
\end{tabular}


Tabelle 2b: Zusammenfassung der Ergebnisse für die Muskelfaserdurchmesser der verschiedenen Muskeln

\begin{tabular}{|l|c|c|c|c|c|}
\hline Parameter & $\begin{array}{c}\text { NON-OVX } \\
\text { (1) }\end{array}$ & $\begin{array}{c}\text { OVX } \\
\text { (2) }\end{array}$ & $\begin{array}{c}\text { Baicalein } \\
\text { 1 (3) }\end{array}$ & $\begin{array}{c}\text { Baicalein } \\
\text { 2 (4) }\end{array}$ & $\begin{array}{c}\text { Baicalei } \\
\text { n3 (5) }\end{array}$ \\
\hline $\begin{array}{l}\text { MF- DM } \\
\text { M. soleus }\end{array}$ & $\leftrightarrow$ & $\leftrightarrow$ & $\leftrightarrow$ & $>2$ & $>2$ \\
\hline $\begin{array}{l}\text { MF-DMTyp 1 } \\
\text { M. } \\
\text { gastrocnem. }\end{array}$ & $\leftrightarrow$ & $\leftrightarrow$ & $\leftrightarrow$ & $>1$ & $>1$ \\
\hline $\begin{array}{l}\text { MF-DM Myp2A } \\
\text { gastrocnem. }\end{array}$ & $\leftrightarrow$ & $\leftrightarrow$ & $\leftrightarrow$ & $>1$ & $\leftrightarrow$ \\
\hline $\begin{array}{l}\text { MF-DM } \\
\text { Typ 1 } \\
\text { M.longissim. }\end{array}$ & $\leftrightarrow$ & $\leftrightarrow$ & $\leftrightarrow$ & $>1,2,3$ & $\leftrightarrow$ \\
\hline $\begin{array}{l}\text { MF-DM } \\
\text { Typ 2A } \\
\text { M.longissim. }\end{array}$ & $\leftrightarrow$ & $\leftrightarrow$ & $\leftrightarrow$ & $>1,2$ & $\leftrightarrow$ \\
\hline $\begin{array}{l}\text { MF-DM } \\
\text { Typ1/KG } \\
\text { M.longissim. }\end{array}$ & $\leftrightarrow$ & $>1$ & $\leftrightarrow$ & $>2,3,5$ & $\leftrightarrow$ \\
\hline $\begin{array}{l}\text { MF-DM } \\
\text { Typ2A/KG } \\
\text { M.longissim. }\end{array}$ & $\leftrightarrow$ & $<1$ & $<1$ & $>1,2,5$ & $\leftrightarrow$ \\
\hline $\begin{array}{l}\text { MF-DM } \\
\text { Typ2B/KG } \\
\text { M.longissim. }\end{array}$ & $\leftrightarrow$ & $<1$ & $\leftrightarrow$ & $>1$ & $\leftrightarrow$ \\
\hline
\end{tabular}


Tabelle 2c: Zusammenfassung der Ergebnisse für die Muskelfaserflächen der verschiedenen Muskeln

\begin{tabular}{|l|c|c|c|c|c|}
\hline \multicolumn{1}{|c|}{ Parameter } & $\begin{array}{c}\text { NON- } \\
\text { OVX } \\
\text { (1) }\end{array}$ & $\begin{array}{c}\text { OVX } \\
\text { (2) }\end{array}$ & $\begin{array}{c}\text { Baicalein1 } \\
\text { (3) }\end{array}$ & $\begin{array}{c}\text { Baicalein2 } \\
\text { (4) }\end{array}$ & $\begin{array}{c}\text { Baicalein3 } \\
\text { (5) }\end{array}$ \\
\hline $\begin{array}{l}\text { MF-Flächen } \\
\text { M. soleus }\end{array}$ & $\leftrightarrow$ & $\leftrightarrow$ & $\leftrightarrow$ & $>2$ & $>2$ \\
\hline $\begin{array}{l}\text { MF-Fläche } \\
\text { Typ1 M. } \\
\text { gastrocnemius }\end{array}$ & $\leftrightarrow$ & $\leftrightarrow$ & $\leftrightarrow$ & $>1$ & $>1$ \\
\hline $\begin{array}{l}\text { MF-Fläche } \\
\text { Typ 2A M. } \\
\text { gastrocnemius }\end{array}$ & $\leftrightarrow$ & $\leftrightarrow$ & $\leftrightarrow$ & $>1$ & $>1$ \\
\hline $\begin{array}{l}\text { MF-Fläche } \\
\text { Typ 1 } \\
\text { M.longissimus }\end{array}$ & $\leftrightarrow$ & $\leftrightarrow$ & $\leftrightarrow$ & $>1,2,3,5$ & $\leftrightarrow$ \\
\hline $\begin{array}{l}\text { MF-Fläche } \\
\text { Typ 2A } \\
\text { M.longissimus }\end{array}$ & $\leftrightarrow$ & $\leftrightarrow$ & $\leftrightarrow$ & $>1,2$ & $\leftrightarrow$ \\
\hline
\end{tabular}




\section{Diskussion}

\subsection{Die ovariektomierte Ratte als Tiermodell}

Der gesamte Versuch wurde am Modell der ovariektomierten Ratte durchgeführt. Die Ratte stellt prinzipiell ein sinnvolles Tiermodell dar, weil sie bereits nach wenigen Monaten ein reifes muskuloskelettales System entwickelt, das ähnlich auf den hormonellen Umschwung nach Ovariektomie reagiert wie der menschliche Organismus [Barlet et al. 1994]. Deshalb handelt es sich hierbei um ein etabliertes Tiermodell in der Osteoporose-forschung. Mehrere Studien konnten belegen, dass sich sowohl die in dem vorliegenden Experiment verwendeten Sprague-Dawley-Ratten wie auch die Rasse der Wistar-Ratten besonders gut als Modell zur Induktion einer Osteoporose nach hormoneller Depletion eignen, da diese Rassen zuverlässig nach Ovariektomie eine Osteoporose aufweisen [Fang et al. 2015].

Darüber hinaus lassen sich Ratten kostengünstig anschaffen und halten. Sowohl das Skelett wie auch die Muskeln der Ratte sind gut definiert und präparierbar. Die durch Ovariektomie induzierten Effekte sind sowohl hinsichtlich des Knochens als auch des Muskels bereits erarbeitet worden. So wurde beispielsweise schon 1995 eine Demineralisierung des Knochens bei der overiektomierten Ratte beschrieben [Omi und Ezawa 1995].

Ebenso zeigte sich die ovariektomierte Ratte als gutes Modell zur Erprobung osteporoseinhibierender Pharmaka, da diese in der Ratte sehr ähnliche Wirksamkeit zeigen wie im Menschen. Das Rattenmodell dient dabei der pharmakologischen Testung von Substanzen auf den Knochen und den Skelettmuskel der Ratten [Kalu 1991].

Im Gegensatz zum Knochen liegen bezüglich der Rolle des Muskels im Rahmen der Osteoporose deutlich weniger Arbeiten vor. Allerdings wurden auch muskuläre Auswirkungen, wie sie auch in der vorliegenden Arbeit untersucht wurden, bedingt durch die hormonelle Depletion nach Ovariektomie am Rattenmodell, publiziert. Die Veränderungen im Skelettmuskel der Ratte scheint dabei äquivalent zur Pathologie im menschlichen Muskel, ebenso wie es beim Knochen der Fall ist. Somit leiden ovariektomierte Ratten nach spätestens 100 Tagen unter einem signifikanten Verlust an Muskelmasse [Tagliaferri et al.2014].

Diesbezüglich wurden Effekte am muskuloskelettalen System sowie am Bandapparat der ovariektomierten Ratte beschrieben, die regelhaft zu erwarten sind [Aydin et al. 2013].

Diese Erkenntnisse waren Ausgangspunkt für die Überlegung, ovariektomierte Ratten nicht nur wie bereits seit längerem üblich als Osteoporosemodell einzusetzen, sondern in gleicher Weise als Modellorganismus zur Beantwortung von Fragestellungen 
bezüglich der Sarkopenie. Ebenso wie Osteoporose beruht auch die Sarkopenie auf hormoneller Depletion. Diese Depletion wird im Rattenmodell allerdings künstlich herbeigeführt, wohingegen sie beim Menschen vor allem die postmenopausale Frau betrifft. Da es sich bei den Tiermodellen jedoch um verhältnismäßig junge Tiere handelt, stellt dies sicherlich eine Einschränkung dieses Modellorganismus dar. Letztlich hat man sich jedoch aufgrund der überwiegenden Vorteile für das Modell der overiektomierten Ratte zur Untersuchung der in vorliegender Arbeit formulierten Fragestellung, ob Baicalein die postmenopausal auftretende Sarkopenie positiv beeinflusst, entschieden.

\subsection{Analyse der Körper- und Muskelgewichte}

Die Körpergewichte der nicht ovariektomierten Kontrollgruppe lagen signifikant unter denen der ovariektomierten Gruppe. Somit konnte eine Gewichtszunahme unter Östrogenmangel, wie sie bereits in der Literatur beschrieben wurde, induziert werden [Komrakova et al. 2010]. Diese Zunahme des Gesamtkörpergewichtes lässt sich primär durch eine Vermehrung des Gesamtkörperfettes erklären, wie sie typischerweise in ovariektomierten Ratten oder postmenopausalen Frauen hinlänglich deklariert wurde [Jung et al. 2014].

Insgesamt kommt es unter Östrogenmangel zu einer Verhältnisumstellung des Fett- und Muskelgewebes. Während das Körperfett unter Östrogenmangel zunimmt, kommt es zu einem erheblichen Verlust an Muskelmasse.

Im vorliegenden Experiment konnte dieser Zustand reproduziert werden, da die Ratten aus der ovariektomierten und ansonsten unbehandelten Gruppe die größten Körpergewichte aufwiesen. Schwieriger wird die Beurteilung der drei BaicaleinGruppen, weil deren Körpergewichte genau zwischen denen der ovariektomierten und nicht ovariektomierten Gruppe lagen. Diese Tatsache lässt verschiedene Schlüsse zu. So könnte die Verabreichung des Baicaleins dem Östrogenmangel durch einen atrophiehemmenden Effekt auf den Skelettmuskel entgegengewirkt haben, wodurch gleichzeitig die oben erwähnte Verhältnisänderung von Muskulatur zugunsten von Fettgewebe nicht stattgefunden hätte. In diesem Fall läge das Körpergewicht der Baicalein-Gruppen noch unter dem der ovariektomierten Kontrollgruppe, weil in den Baicalein-Gruppen eine Zunahme der sogenannten lean body mass aufgetreten sein könnte. Ebenso wäre eine synergistische Wirkung von Östrogenmangel und Baicalein denkbar, sodass es ebenfalls in den Baicalein-Gruppen zu einer Zunahme des Körperfetts gekommen wäre. Als Indiz für die Korrektheit dieser Annahme ließe sich anführen, dass die reinen Muskelgewichte von M. soleus und gastrocnemius auf keine 
Zunahme der individuellen Muskelmasse schließen lassen. So lassen sich bei der Betrachtung der Muskeleigengewichte des M. soleus noch Tendenzen erkennen, die eine vermehrte Masse dieses Muskels in den Baicalein-Gruppen nahelegen, mit einem verminderten Gewicht in der ovariektomierten Kontrollgruppe. Dieser Punkt unterstützt die Annahme einer muskelstimulierenden Wirkung des Baicaleins. Andererseits kann beim M. gastrocnemius diese Annahme nicht bekräftigt werden. Bei diesem Muskel nehmen die Gewichte mit steigender Baicaleindosis ab und sind in der ovariektomierten Kontrollgruppe größer als in der nicht ovariektomierten Gruppe. Diese Tatsache widerspricht einer muskelstimulierenden Wirkung des Baicaleins und legt eher den Schluss nahe, dass es unter Östrogenmangel zu einer Einlagerung von Fettgewebe oder Wasser kam.

Eventuell könnte die Gewichtsabnahme des M. gastrocnemius in den Baicalein-Gruppen auch auf einer Hemmung dieser unphysiologischen Einlagerungen in den Muskel durch das Baicalein beruhen. Diese These könnte durch Daten aus der Literatur unterstützt werden, wonach antientzündliche und antifibrotische Wirkungsweisen des Baicaleins nachgewiesen wurden. Zwar wurden diese bisher an anderen Gewebetypen wie dem Nierengewebe dargestellt, jedoch ist solch eine Wirkung auch auf den Muskel denkbar [Wang W et al. 2015].

\subsection{Analyse der Verhältnisse von Kapillarisierung zu Muskelfasern}

Die zu prüfende Fragestellung hinsichtlich der Kapillarisierung des Skelettmuskels war, ob der Wirkstoff Baicalein, in unterschiedlicher Dosierung verabreicht, dem Effekt der Dekapillarisierung bei Östrogenmangel entgegenwirken konnte. Östrogen übt bekanntermaßen einen angioproliferativen Effekt auf den Skelettmuskel aus [Wend et al. 2012]. Der Verlust von Kapillaren in Skelettmuskeln bei Sarkopenie wurde bereits in vorangegangenen Studien mit teilweise 25\% der Kapillaren der Muskulatur im Alter beschrieben [Rogers und Evans 1993]. Ebenso konnte gezeigt werden, dass es bei Sarkopenie zu einer gesteigerten Apoptose in Endothelzellen des Muskels mit daraus resultierend verminderter Anzahl von Kapillaren im Skelettmuskel kommt [Wang H et al. 2014].

Es wurden bisher keine Studien zur Wirkung von Baicalein auf die Kapillarisierung des Skelettmuskels publiziert. Es soll daher im Folgenden gezeigt werden, inwiefern die im Versuch gemessenen Werte die oben genannten Aussagen unterstützen können, das heißt, ob Baicalein den Verlust an Kapillaren im Skelettmuskel unter Östrogenmangel verhindern kann. 
Tatsächlich zeigte das Baicalein einige Signifikanzen bei allen drei ausgewerteten Muskeln. Beim M. soleus waren die Werte aus der Baicalein-1 mg-Gruppe, ebenso wie die aus der Baicalein-10 mg und der Baicalein-100 mg-Gruppe signifikant größer gegenüber denen aus der ovariektomierten und nicht ovariektomierten Versuchsgruppe. Die Größe des Unterschiedes ist hier proportional zur Wirkstoffmenge. Im Gegensatz zum M. soleus und gastrocnemius zeigte beim M. longissimus die Baicalein10 mg- Gruppe den größten Effekt auf die Kapillarisierung.

Insgesamt ist das Resultat der Analyse von Kapillarisierung unter Applikation von Baicalein vielversprechend, da der erwartete Verlust an Kapillaren unter Baicaleingabe nicht beobachtet werden konnte. Stattdessen wurden sogar signifikant mehr Kapillaren pro ausgewerteten Muskelzellen gemessen. Somit konnte die Hypothese, das Baicalein subkutan appliziert die Angiogenese im Skelettmuskel trotz Östrogenmangel stimuliert, unterstützt werden. Das der Östrogenmangel selbst für die zusätzliche Angiogenese verantwortlich sein könnte ist nicht anzunehmen, aufgrund der oben angeführten angioproliferativen Wirkung des Östrogens [Kyriakides et al. 2001] auf den Skelettmuskel. Dennoch muss die unterstützte Hypothese mit der Einschränkung versehen werden, dass bei den vorliegenden Werten kein signifikanter Unterschied zwischen ovariektomierter und nicht ovariektomierter Gruppe nachgewiesen werden konnte. Diese Tatsache könnte darauf beruhen, dass die Zeitspanne des Versuchs nicht ausreichend war, um eine gewünschte, deutliche Entkapillarisierung des sarkopenischen Skelettmuskels, wie sie in anderen Studien am Rattenmodell nachgewiesen wurde zu erzeugen [Rogers und Evans 1993].

\subsection{Anaylse der Muskelfaserdurchmesser}

Bezüglich der Muskelfaserdurchmesser ging es um die Prüfung der Hypothese, ob Baicalein in der Lage ist, die zu erwartende Abnahme von Muskelfaserdurchmesser unter Östrogenverlust zu beeinflussen. Der Östrogenmangel im Skelettmuskel bewirkt wie verschiedene Studien zeigten eine Abnahme des Durchmessers aller Muskelfasertypen. Es wäre also bei den ovariektomierten Ratten im durchgeführten Experiment eine Muskelfaseratrophie zu erwarten [Rogers und Evans 1993]. Hierbei galt es somit, den Einfluss des Baicaleins auf die tatsächliche Muskelfaserdicke der verschiedenen Skelettmuskeln zu untersuchen. 
Die Werte der Muskelfaserdurchmesser beim M. soleus waren bei den Gruppen der Baicalein-10 mg und der Baicalein-100 mg-Gruppe signifikant größer als die Werte der OVX-Gruppe. Bei der Auswertung dieser Werte in Relation zum Körpergewicht konnte die These, dass Baicalein der Muskelatrophie entgegenwirkt, unterstützt werden. Auch hier lagen die Werte aus den Gruppen Baicalein-10 mg und Baicalein-100 mg signifikant über denen der OVX-Gruppe.

Im Verhältnis zu den Muskeleigengewichten zeigten sich hingegen keine Signifikanzen, jedoch wies auch hier die Baicalein-100 mg-Gruppe die größten Werte auf, ebenfalls wies die NON-OVX-Gruppe größere Faserdurchmesser als die OVX-Gruppe auf. Während bei den absoluten Daten ohne Relation zu den Gewichten die NON-OVX gegenüber der OVX-Gruppe nur tendenziell größere Werte zeigte, konnte nachdem diese ins Verhältnis zum Körpergewicht gesetzt wurden, eine deutliche Signifikanz der NONOVX gegenüber der OVX-Gruppe bestätigt werden. Auf diesem Weg konnte die These der Wirksamkeit des Baicaleins im Sinne einer hypertrophen Wirkung auf die Muskelfasern beim M. soleus erhärtet werden.

Beim M. gastrocnemius konnten die drei verschiedenen Muskelfasertypen-1, -2A und -2B vermessen werden. Den Fasern vom Typ-1 der Gruppen Baicalein-10 mg und Baicalein-100 mg konnte ein signifikant dickerer Faserdurchmesser im Vergleich zur NON-OVX-Gruppe nachgewiesen werden. Ebenfalls waren die Fasern des Typs-2A der Gruppe Baicalein-10 mg von signifikant größerem Durchmesser gegenüber denen der NON-OVX-Gruppe. Tendenziell konnte bei allen mit Baicalein behandelten Gruppen größere mittlere Faserdurchmesser gemessen werden als bei der OVX-Gruppe. Interessanterweise wies jedoch an dieser Stelle die Gruppe mit der mittleren Baicaleindosierung die größten Muskelfaserdurchmesser auf, wohingegen die Werte der Baicalein-100 mg, also der höchsten Dosierung teilweise unter der niedrigsten Baicaleindosierung von $1 \mathrm{mg}$ lagen. Diese Tatsache lässt die Überlegung zu, ob das hochdosierte Baicalein eventuell nach Applikation in das Unterhautgewebe zu lokalen Unverträglichkeitsreaktionen führen könnte, die sich negativ auf umliegende Muskeln auswirken.

Darüber hinaus ließen sich, nachdem diese Werte wiederum in Relation zum Köper- und Muskelgewicht gesetzt wurden einige Tendenzen feststellen. So lagen die Werte von Typ-1-, 2A- und 2B-Fasern in nahezu allen Baicalein-Gruppen über denen der OVXGruppe. Zudem zeigten sich tendenziell größere Werte für den Faserdurchmesser in der NON-OVX- im Vergleich zur OVX-Gruppe. Die Muskelfaserdurchmesser in Relation zum Körpergewicht aufgetragen, konnten die obenstehende Beobachtung des stärksten Effektes in der mittleren Dosierung bekräftigen. Auch hier lagen diese Werte über denen der höchsten 100 mg Dosierung.

Insgesamt unterstreichen die oben im Text beschriebenen Ergebnisse aus den BaicaleinGruppen jedoch eine hypertrophieinduzierende Wirkung einer Behandlung des unter Östrogenmangel leidenden Skelettmuskels mit Baicalein. 
Deutlicher sind die Werte beim M. longissimus. Hier zeigten sich bei den Typ-1-Muskelfasern eindeutige Signifikanzen der Baicalein-10 mg-Gruppe im Vergleich zur der nicht ovariektomierten, der ovariektomierten und der Baicalein-1 mg-Gruppe.

Die Baicalein-10 mg-Gruppe der Typ-2A-Fasern lag ebenfalls signifikant über den Werten der nicht ovariektomierten und ovariektomierten Gruppe.

In Relation zum Körpergewicht erwies sich zusätzlich die NON-OVX-Gruppe signifikant größer gegenüber der ovariektomierten Versuchsgruppe. Diese Tatsache belegt die Grundannahme der Sarkopenieentstehung nach Ovariektomie mit resultierendem Östrogenmangel. Die Baicalein-10 mg-Gruppe erwies sich auch in Relation zum Körpergewicht als die aussagekräftigste Versuchsgruppe. Passend dazu waren die Werte der Typ-1- und Typ-2A-Faserdurchmesser ansteigend von Baicalein-1 mg zur Baicalein10 mg-Gruppe, während sie in der Baicalein-100 mg-Gruppe wieder rückläufig waren.

Zusammenfassend konnte der zu erwartenden Atrophie der Skelettmuskulatur [Wang H et al. 2014], deren Merkmal eine Abnahme des Muskelfaserdurchmessers gewesen wäre, entgegengewirkt werden. Besonders die Größenzunahme im vorliegenden Experiment der schnellzuckenden Typ-2A-Fasern ist hervorzuheben, da diese normalerweise in besonderm Ausmaß von der Sarkopenie betroffen sind, da es in betroffenen Muskeln vor allem zu einem Verlust an glykolytischer Enzymkapazität und damit insbesondere zu einer Reduktion der Typ-2A-Muskelfasern kommt [Rogers und Evans 1993].

Die Annahme, das Lipoxygenaseinhibitoren einer Muskelatrophie entgegenwirken, konnte bereits durch klinische Studien nachgewiesen werden. Hierbei wurde ebenfalls ein positiver Effekt auf die Regenationsfähigkeit des Muskels, dessen Fetteinlagerung sowie auf die Stabilität der Sehnen beschrieben [Oak et al. 2014]. Insbesondere die nachgewiesenen Effekte von Lipoxygenaseinhibitoren auf die Atrophie des Skelettmuskels, lassen auf eine ähnliche Wirkung des Baicaleins auf den von Sarkopenie betroffenen Muskel vermuten. Die vorliegenden Daten aus dieser Arbeit unterstützen diese Annahme.

\subsection{Analyse der Muskelfaserflächen}

Ähnlich wie bei der Analyse der Muskelfaserdurchmesser, stand bei der Auswertung der Muskelfaserflächen die Frage im Vordergrund, inwieweit die gemessenen Werte eine Aussage darüber zulassen, ob das Baicalein eine Wirkung auf die Fläche der untersuchten Skelettmuskeln der ovariektomierten Tiere ausübt. Dem zugrunde liegt die Tatsache, dass eine reine Zunahme an Muskelquerschnitt nicht unbedingt eine physiologische Muskelhypertrophie bedeuten muss. Hingegen kann eine Zunahme an 
Muskelquerschnitt auch auf einer vermehrten Einlagerung von Fett oder Wasser beruhen. Solche Fetteinlagerungen sind in höherem Alter der Frauen als physiologisch anzusehen und rühren von einer Umstellung der Enzymaktivität dahingehend, dass zunehmend Triglyceride anstelle von Glukose zur oxidativen Energiegewinnung verwendet werden, sodass es $\mathrm{zu}$ einer Einlagerung solcher Triglyceride kommt [Forsberg et al. 1991].

Die statistische Analyse der Muskelfaserflächen ergab beim M. soleus signifikant größere Flächen der mittleren und maximalen Baicaleindosierung im Vergleich zur ovariektomierten Gruppe. Der Unterschied zwischen ovariektomierter und nicht ovariektomierter Gruppe ist statistisch nicht signifikant, obgleich tendenziell bei Betrachtung des Diagramms deutlich eine Tendenz zugunsten der nicht ovariektomierten Versuchsgruppe gegenüber der ovariektomierten erkennbar ist. Zusätzlich zu dem bereits beschriebenen Problem der eventuell zeitlich ungenügenden Dauer des Versuchs könnte das verhältnismäßig junge Alter der Ratten einen Erklärungsansatz darstellen. In Studien wurden bislang vor allem die atrophen Effekte des Östrogenmangels an Muskeln von älteren Ratten, die zum Teil über ein Jahr alt waren, sowie an teilweise immbolisierten oder sogar denervierten Muskeln erprobt [Lightfoot et al. 2014].

Setzt man die Werte der Muskelfaserflächen wiederum in Relation zum Körpergewicht, konnten die Gruppen Baicalein-10 mg und Baicalein-100 mg als signifikant größer gegenüber der ovariektomierten Gruppe nachgewiesen werden. In Relation zum Körpergewicht verfügte schließlich auch die nicht ovariektomierte Gruppe über signifikant größere Muskelfaserflächen als die ovariektomierte Versuchsgruppe. Dies verdeutlicht den Effekt des Östrogens auf das Körpergewicht. In Relation zum Muskelgewicht war nur die Baicalein-100 mg Gruppe signifikant größer als die ovariektomierte Gruppe. Die Werte der restlichen Gruppen konnten vorherige Aussagen der Flächenzunahme in allen Baicalein-Gruppen bekräftigen.

Beim M. gastrocnemius erwiesen sich die Muskelfaserflächen von Typ-1-Fasern der Baicalein-10 mg und der Baicalein-100 mg als statistisch signifikant größer als die nicht ovariektomierte Gruppe. Bei den Typ-2A-Fasern konnten noch die Werte der Baicalein$10 \mathrm{mg}$ als signifikant erhöht gegenüber der nicht ovariektomierten Gruppe nachgewiesen werden. Die übrigen Werte stimmten in der Tendenz mit den vorherigen Aussagen überein, wenngleich keine statistischen Signifikanzen herauskamen. Interessant erscheint auch hier die Flächenzunahme der Typ-2A-Muskelfasern, da diese laut Literatur am stärksten vom Östrogenmangel betroffen seien. Zudem sei eine Umstellung von schnellen Typ-2 zu langsam zuckenden Typ-1-Fasern zu beobachten [Ciciliot et al. 2013].

Die untersuchten Muskelfasern im M. longissimus wiesen noch deutlichere Signifikanzen auf. Hier lag bezüglich Faserfläche von Typ-1 und -2A die Baicalein-10 mgGruppe signifikant über der ovariektomierten Gruppe und bei den Typ-1-Fasern sogar über allen anderen Versuchsgruppen. 
Außerdem wiesen auch die Baicalein-1 mg und die Baicalein-100 mg-Gruppe tendenziell größere Faserflächen gegenüber den ovariektomierten Tieren auf.

Beim M. longissimus konnte zudem eine Signifikanz zwischen ovariektomierter und nicht ovariektomierter Gruppe zugunsten der nicht ovariektomierten nachgewiesen werden. Dies gilt sowohl für die Werte in Relation zum Körpergewicht, wie auch für die absoluten Werte. Somit konnte bei diesem Muskel der experimentelle Ausgangspunkt, dass die Ovariektomie bei den Ratten zu einer Sarkopenie führt, wie er bereits aus der Literatur angeführt wurde, bestätigt werden.

Eine Umgehung der Atrophie von Typ-1- und 2A-Fasern durch Baicalein insbesondere in mittlerer Dosierung verabreicht, kann aufgrund der vorliegenden Daten angenommen werden, da unter anderem die Typ-2A-Muskelfasern eine Größenzunahme aufzeigten. An dieser Stelle ist jedoch festzustellen, dass der Grund für diese scheinbar deutliche Hypertrophie nicht eindeutig darstellbar ist. Schließlich kann eine solche Zunahme an Muskelfaserfläche und Muskelfaserdurchmesser, wie bereits angesprochen auf einer unter Östrogenmangel vermehrt stattfindenden Einlagerung von Wasser und intramuskulärem Fettgewebe beruhen [Forsberg et al. 1991].

Zum anderen kann es unter Östrogenmangel zu einer Zunahme von sogenanntem nichtkontraktilen Muskelgewebe kommen, welches ein pathologisches Merkmal darstellt. Dieses sogenannte nicht-kontraktile Muskelgewebe ist nur schwer von normalem quergestreiftem Muskelgewebe zu differenzieren. Eine Möglichkeit zur Unterscheidung bietet beispielsweise die 31P-Magnetresonanzspektroskopie [Layec et al. 2015].

Im Fall der vorliegenden Ergebnisse von teilweise signifikanter Muskelfaserflächen- und Durchmesserzunahme stellt sich natürlich die Frage, ob die Wirkung des Baicaleins nicht auch auf einer unphysiologischen Zunahme von nicht-kontraktilem Muskelgewebe, das heißt Fett und Wasser, beruhen könnte.

Diese Frage lässt sich im Rahmen dieser Arbeit nicht abschließend klären, weil hier nur die mikroskopische Auswertung von Schnittbildern vorgenommen wurde. Auf diesen mikroskopischen Bildern waren jedoch keine größeren Fettansammlungen zu erkennen, wie sie in Muskulatur mit pathologischen Fetteinlagerungen zu erwarten wäre. Da genauere Untersuchungen, wie die oben aufgeführte 31P-Magnetresonanzspektroskopie oder eine Ultraschalldarstellung der Muskulatur in vivo zwecks Unterscheidung von kontraktilem und nicht-kontraktilem Muskelgewebe [Agyapong-Badu et al. 2014] in dieser Arbeit nicht verwendet wurden, bleibt eine Ungewissheit bestehen, worauf tatsächlich die gemessenen Größenunterschiede der Baicalein-Gruppen gegenüber den unbehandelten Gruppen beruhen. Denkbar wäre, dass Baicalein aufgrund seiner drei Hydroxylgruppen im Gewebe eine hydrophile Wirkung aufweist, infolgedessen Wasser in den Muskel eingelagert würde.

Ob dieser Effekt allein für die beschriebenen Beobachtungen ausreicht, ist jedoch fraglich. Interessant erscheint der Aspekt des gleichmäßigen Effektes auf oxidativarbeitende wie glykolytisch-arbeitende Muskelfasern innerhalb der Baicalein-Gruppen. 
Somit müsste, falls es tatsächlich für die Hypertrophie der Muskelfasern verantwortlich wäre, das Baicalein sowohl auf die oxidativen wie auch die glykolytischen Stoffwechselwege in den jeweiligen Muskelfasern wirken. Eine solche Wirkung bleibt damit weiterhin hypothetisch denkbar, wobei die beschriebenen Beobachtungen diese Annahme unterstützen. Wie bereits erwähnt ist die Grundlage für eine belegte Wirksamkeit insofern nur eingeschränkt gegeben, da die ovariektomierte Kontrollgruppe nicht durchweg signifikant niedrigere Werte beinhaltete als die nicht ovariektomierte Kontrollgruppe. Diese Tatsache ließe sich eventuell auf das zeitliche Setting des Experimentes zurückführen. Möglicherweise würde nach einer längeren Dauer des Versuchs ein deutlicherer Unterschied zwischen ovariektomierter und nicht ovariektomierter Gruppe auftreten, da sich die erwarteten Veränderungen bei den ovariektomierten Tieren in einem längeren Zeitraum eher manifestieren würden.

\subsection{Analyse der Verhältnisse von Muskelfasertypen im M. longissimus}

Die Auswertung der Verhältnisse von den drei verschiedenen Muskelfasertypen im M. longissimus zeigte tendenziell größere Anteile sowohl von Typ-2A-, wie auch Typ-2BMuskelfasern in der Baicalein-10 mg-Gruppe, die bereits in den vorangegangenen Parametern die deutlichsten Ergebnisse produzierte. Mögliche Gründe hierfür wurden bereits erwähnt. Bezüglich der Typ-1-Muskelfasern konnten keine Tendenzen abgeleitet werden, die Ergebnisse hier erscheinen im Vergleich der Versuchsgruppen homogen, sodass nicht von einer Beeinflussung durch das Baicalein ausgegangen werden kann. Allerdings galt es vor allem die Wirkung des Baicaleins auf die, bei ovariektomierten Ratten erwartete Atrophie und verhältnismäßige Abnahme von Typ-2-Muskelfasern zu prüfen [Ciciliot et al. 2013].

In diesem Kontext konnte ein Effekt des Baicaleins durch die vorliegenden Ergebnisse angedeutet werden. Immerhin zeigte sich eine Zunahme des Anteils schneller Typ-2AMuskelfasern am Gesamtfaseranteil. Diese Tendenz wiederspricht der aus der Literatur ableitbaren Annahme der anteiligen Abnahme der schnell zuckenden Muskelfasern, dem sogenannten fast-to-slow fiber type shift [Ciciliot et al. 2013]. Zusätzlich wurden beim M. longissimus wie auch beim $M$. gastrocnemius die Typ-2B-Muskelfasern analysiert. Es ließen sich speziell bezüglich der Typ-2B-Muskelfasern keine konkreten Voraussagen aus der Literatur ableiten was deren Verhältnisdynamik während eines Östrogenmangels bei Ovariektomie angeht. Im Rahmen dieses Versuchs zeigten sie weitestgehende Übereinstimmung mit den Tendenzen der Typ-2A-Fasern, die sich oft in gleicher Weise innerhalb der Versuchsgruppen veränderten wie die Typ-2B-Fasern. 
Eine Einschränkung der beschriebenen Ergebnisse der Muskelfaseranteile könnten Messungenauigkeiten darstellen. Solche Messfehler könnten im Rahmen der Auszählung der verschiedenen Muskelfasertypen nach deren Anfärbungsgrad durch Amylasefärbung und Morphologie der Fasern entstanden sein. Schließlich ist dieses Vorgehen immer von einer subjektiven Einschätzung und selbstverständlich Erfahrung des Mikroskopierenden abhängig und somit nicht in Vollständigkeit reliabel. Genauso wie für die Auswertung der Muskelfaserflächen und Durchmesser hängt auch die Zählung der unterschiedlichen Muskelfasertypen zunächst von der Qualität der Färbemethode und deren Durchführung ab. Die stetige Verbesserung der Färbeprotokolle im Laufe der letzten Jahre, erlaubte erst die in dieser Arbeit unternommene Unterteilung in drei, anstatt wie bisher in zwei Muskelfasertypen. Gleichwohl kann eine qualitativ hochwertige Färbemethode nicht das fachlich korrekte Auswerten durch den Mikroskopeur ersetzen. Wenngleich die Qualität der produzierten Schnitte und deren Färbung insgesamt gut gelang, könnten bei der Auszählung und Ausmessung der einzelnen Parameter Fehler gemacht worden sein. Allerdings wären in diesem Fall solche Fehler über alle Versuchsgruppen gleichmäßig verteilt und somit statistisch nicht schwerwiegend.

Zusammenfassend betrachtet lassen die vorliegenden Versuchsergebnisse eine positive Wirkung von Baicalein auf den hormonell depletierten Skelettmuskel der Ratte annehmen. Die Hypothese, dass Baicalein die Angiogenese im Skelettmuskel fördert, kann durch die vorliegenden Ergebnisse bekräftigt werden, da eine signifikante Zunahme an Kapillaren, in den mit Baicalein behandelten Versuchsgruppen, ermittelt wurde. Beim M. gastrocnemius und M. soleus war die Anzahl an Kapillaren im Muskel proportional zur Baicaleindosierung, während sie im M. longissimus in der Baicalein10 mg-Gruppe, also der mittleren Dosierung am höchsten war. Obwohl auch bei den $\mathrm{Mm}$. gastrocnemius und soleus die Werte der Baicalein-Gruppen bereits signifikant über denen der Kontrollgruppen lagen, waren die Ergebnisse der Faserdurchmesser beim M. longissimus am aussagekräftigsten, vor allem von Typ-2A- und Typ-1-Fasern der Baicalein-10 mg-Gruppe. Die Ergebnisse für die Muskelfaserflächen konnten diesen Eindruck verstärken, da auch hier Signifikanzen der Baicalein-Gruppen gegenüber den Kontrollgruppen beschrieben werden konnten. Zudem konnte bei der Auswertung der Verhältnisse von Muskelfasertypen zueinander eine Zunahme von Typ-2A-Muskelfasern im M. longissimus nachgewiesen werden, was einem unter Östrogenmangel erwarteten fast-to-slow fibre type shift widerspricht. Neben diesen offensichtlich positiven Wirkungen des Baicaleins auf den Skelettmuskel unter Östrogenmangel müssen die lokalen Entzündungen rund um die Einstichstelle erwähnt werden. Daher erscheint es sinnvoll weitere Versuche anzuschließen, um die optimale Applikationsform herauszufinden. So könnte man das Baicalein beispielsweise über das Futter verabreichen. Ebenso sollte in weiteren Studien untersucht werden, welches die am besten geeignetste Dosierung des Baicaleins darstellt. 


\subsection{Analyse der Serumparameter}

Die Analyse der Serumwerte von Magnesium und Calcium ergab keine statistisch signifikanten Differenzen zwischen den Versuchsgruppen. Dies legt den Schluss nahe, dass weder das verabreichte Baicalein, noch die erfolgte Ovariektomie der Ratten einen Einfluss auf deren Elektrolythaushalt, stellvertretend hierfür auf die Parameter Magnesium und Calcium, hatten.

Somit ist davon auszugehen, dass die Skelettmuskulatur der Ratten funktionstüchtig war, aufgrund der Beobachtung, dass die Tiere aus den Baicalein-Gruppen keine abweichenden Bewegungsmuster im Vergleich zu den unbehandelten Ratten zeigten. Eine exaktere Bestimmung der muskulären Leistungsfähigkeit der Ratten war kein Bestandteil des Versuches und könnte in folgenden Arbeiten untersucht werden.

Als Marker zur Beurteilung des Zustandes der Skelettmuskulatur dient das Enzym Kreatinkinase, welches auch im Klinikalltag entsprechend eingesetzt wird. Die Kreatinkinase gibt vor allem Aufschluss über die Intaktheit der Skelettmuskulatur. Es kann darüber hinaus auch als Marker einer Sarkopenie, das heisst einer ungewollten Reduktion von Muskulatur genutzt werden [Palus et al. 2014].

Im Rahmen dieser Arbeit erwies sich die Serumkonzentration der Kreatinkinase der Baicalein-100 mg-Gruppe als signifikant erniedrigt gegenüber der NON-OVX und OVXGruppe. Dies unterstreicht möglicherweise einen positiven Effekt von Baicalein auf den Skelettmuskel. Ein niedriger Kreatinkinasewert deutet auf eine unversehrte Skelettmuskulatur hin. Dabei ist zu erwähnen, dass tendenziell alle Baicalein-Gruppen niedrigere Kreatinkinasewerte als die Kontrollgruppen aufzeigten. Diese Beobachtung könnte auf einem entzündungshemmenden Effekt des Baicaleins auf die Muskelzellen beruhen, der zu deren Intaktheit beiträgt, sodass weniger Kreatinkinase ins Serum der Ratten gelangt. Allerdings könnte die niedrigere Kreatinkinasekonzentration im Serum auch auf einer stärkeren Schonung der Muskulatur der Ratten beruhen. Dies deckt sich jedoch nicht mit der Beobachtung der Ratten. Bislang konnten keine Korrelate der Sarkopenie oder Osteoporose im Serum betroffener Patienten bezüglich oben genannter Parameter Calcium und Magnesium herausgearbeitet werden [Huo et al. 2015]. 


\section{Zusammenfassung}

Das Ziel dieser Arbeit war es herauszufinden, ob der Wirkstoff Baicalein in verschiedenen Dosierungen sub cutem injiziert, den unter Östrogenmangel erwartbaren degenerativen Veränderungen wie Muskelfaserschwund und Muskelfaseratrophie im Skelettmuskel der Ratte entgegenwirken konnte.

Zur Klärung dieser Fragestellung wurden 61 weibliche, drei Monate alte Ratten der Rasse Sprague Dawley in fünf Gruppen eingeteilt. Zu Versuchsbeginn wurden vier der fünf Gruppen beidseitig ovariektomiert, damit diese Ratten daraufhin eine Osteoporose entwickelten. Acht Wochen später wurde bei allen Ratten eine Osteotomie mit Plattenosteosynthese der Tibia durchgeführt. Peri- und postoperativ starben elf Ratten, sodass fortan das Gesamtkollektiv 50 Versuchstiere betrug.

Es wurde entsprechend angeführter Studien angenommen, dass die ovariektomierten Ratten acht Wochen nach Ovariektomie unter einer Osteoporose mit einhergehenden degenerativen Veränderungen der Skelettmuskulatur litten. Dementsprechend wurde ein künstlicher Östrogenmangel erzeugt, der als Modell einer postmenopausalen Frau mit Östrogenmangel bereits etabliert ist.

Unmittelbar ab dem Zeitpunkt der Osteotomie wurde mit der Baicaleintherapie begonnen. Ab dem ersten postoperativen Tag für insgesamt vier Wochen wurde den dafür vorgesehenen Ratten die jeweilige Dosierung Baicalein täglich subkutan appliziert. Die insgesamt 30 Tiere, die Baicalein verabreicht bekamen, wurden in drei Gruppen von jeweils zehn Tieren aufgeteilt. Die erste Gruppe bekam für die nächsten vier Wochen Baicalein $1 \mathrm{mg} / \mathrm{kg} \mathrm{KG}$; die nächste Gruppe $10 \mathrm{mg} / \mathrm{kg}$ KG Baicalein und die letzte Gruppe $100 \mathrm{mg} / \mathrm{kg}$ KG Baicalein.

Die anschließende Auswertung der Wirkung von Baicalein auf den Skelettmuskel gelang über das Anfertigen mikroskopischer Schnittbilder der drei entnommenen Muskeln Soleus, Gastrocnemius und Longissimus. Um eine Aussage bezüglich der untersuchten Parameter Muskelfaserdicke und Muskelfaserfläche treffen zu können, mussten die Schnitte durch eine Amylase-Enzymfärbung behandelt werden. Um die ebenfalls untersuchte Kapillarisierung beurteilen zu können, wurde zusätzlich eine PAS-Färbung durchgeführt.

Die so entstandenen Schnitte wurden mithilfe spezieller Mikroskopiersoftware am Mikroskop und Computer ausgewertet. Dabei kamen für die erwähnten Parameter unterschiedliche Signifikanzen und Tendenzen heraus. Die Hypothese, dass Baicalein die Angiogenese im Skelettmuskel stimuliert, konnte durch die vorliegenden Ergebnisse bekräftigt werden, da tatsächlich eine signifikante Zunahme an Kapillaren beobachtet wurde. 
In den Muskeln Gastrocnemius und Soleus war die Anzahl der Kapillaren pro Muskelfaser proportional zur verabreichten Menge an Baicalein und jeweils signifikant über den Kontrollgruppen der ovariektomierten und nicht ovariektomierten Tiere. Im M. longissimus zeigte hingegen die mittlere Baicaleindosierung den stärksten Effekt auf die Kapillarisierung.

Die Auswertung der Muskelfaserdurchmesser ergab beim M. soleus größere Faserdurchmesser in den Gruppen der $10 \mathrm{mg}$ - und $100 \mathrm{mg}$-Dosierung gegenüber der ovariektomierten Gruppe. Die berechneten Verhältniswerte zum Körpergewicht unterstrichen diese Aussage, da hierbei auch die nicht ovariektomierte Gruppe signifikant größere Werte als die ovariektomierte Versuchsgruppe aufzeigte. Die gemessenen Faserdurchmesser der Muskeln gastrocnemius und longissimus zeigten sehr ähnliche Ergebnisse. Beim M. gastrocnemius erwiesen sich die Gruppen Baicalein$1 \mathrm{mg}$ und Baicalein-100 mg bezüglich der Typ-1-Muskelfasern und die Gruppe Baicalein$10 \mathrm{mg}$ bei den Typ-2A-Muskelfasern am aussagekräftigsten erhöht im Vergleich zu den Kontrollgruppen.

Der M. longissimus zeigte die deutlichste Faserdurchmesserzunahme bei den Typ-1Aund 2A-Fasern der Gruppe Baicalein-10 mg. Nach Auftragen gegen das entsprechende Körpergewicht konnte hier ebenso ein signifikant erhöhter Faserdurchmesser der NONOVX- gegenüber der OVX-Gruppe nachgewiesen werden.

Bezüglich der Muskelfaserflächen zeigten sich beim M. soleus Signifikanzen der Baicalein-10 mg und Baicalein-100 mg-Gruppe gegenüber der OVX-Gruppe. Diese konnten im Verhältnis zum Körpergewicht beibehalten werden und bei der Baicalein$100 \mathrm{mg}$ auch im Verhältnis zum Muskelgewicht. Die Werte für Flächen von Typ-1- und Typ-2A-Fasern des M. gastrocnemius erwiesen sich ebenfalls bei der mittleren und höchsten Baicaleindosierung als signifikant größer, hier allerdings nur verglichen mit der NON-OVX-Gruppe. Bei den Typ-2A-Fasern zeigten zudem die Baicalein-1 mg und Baicalein-100 mg-Gruppe tendenziell größere Flächenwerte als die NON-OVX-Gruppe. Die Flächenwerte des M. longissimus stellten sich wiederum in der Baicalein-10 mgGruppe signifikant größer gegenüber der OVX-Gruppe dar. Des Weiteren konnten beim M. longissimus die Aussagen durch signifikant größere Flächen der NON-OVX gegenüber der OVX-Gruppe unterstrichen werden. Diese Ergebnisse bekräftigen die Annahme, dass Baicalein, vor allem in $10 \mathrm{mg}$ - bis $100 \mathrm{mg}$-Dosierung einer Skelettmuskelatrophie entgegenwirkt.

Die Verhältnisse der verschiedenen Muskelfasertypen beim $M$. longissimus waren eindeutig zugunsten der Typ-2A-Muskelfasern verschoben. Diese waren entgegen der eigentlich erwarteten Abnahme unter Östrogenmangel in der Baicalein-10 mg-Gruppe am höchsten. Die Auswertung der Verhältnisse der unterschiedlichen Muskelfasertypen konnte somit ebenfalls die Hypothese erhärten, dass Baicalein eine Sarkopenie mit entsprechendem fast-to-slow fibre type shift [Ciciliot et al. 2013] positiv beeinflusst.

Die Ergebnisse für die Serumparameter unterstreichen die gemachten Aussagen, wobei die Kreatinkinase einen signifikanten Effekt zeigte. So waren die Kreatinkinasewerte im Serum der Baicalein-100 mg-Gruppe signifikant niedriger als die der NON-OVX- und 
OVX-Gruppen, was möglicherweise auf einen protektiven Effekt des Baicaleins auf die Muskelzellen hindeutet.

Als Fazit dieser Arbeit lässt sich zusammenfassen, dass Baicalein entsprechend den aufgeführten Ergebnissen einen positiven Effekt auf die Atrophie des Skelettmuskels, wie sie unter Östrogenmangel auftritt, zu haben scheint. Gegenstand nachfolgender Arbeiten könnte die Applikationsform und genaue Dosierung des Baicaleins sein. 


\section{Tabellenteil}

Tabelle 3: Körpergewichte zu Versuchsbeginn, Osteotomie und Tötung in Gramm

\begin{tabular}{|l|l|l|l|l|l|}
\hline & NON-OVX & OVX & $\begin{array}{l}\text { Baicalein } \\
\mathbf{1}\end{array}$ & $\begin{array}{l}\text { Baicalein } \\
\mathbf{2}\end{array}$ & $\begin{array}{l}\text { Baicalein } \\
\mathbf{3}\end{array}$ \\
\hline $\begin{array}{l}\text { Versuchs } \\
\text {-beginn }\end{array}$ & $\mathbf{2 6 5 , 1}$ & $\mathbf{2 7 3 , 9}$ & $\mathbf{2 7 2 , 5}$ & $\mathbf{2 6 1 , 2}$ & $\mathbf{2 6 5 , 2}$ \\
\hline SD & 16,5 & 18,6 & 11,1 & 13,7 & 14,6 \\
\hline $\begin{array}{l}\text { Osteo- } \\
\text { tomie }\end{array}$ & $\mathbf{3 0 6 , 5}$ & $\mathbf{3 8 3 , 5}$ & $\mathbf{3 8 7 , 1}$ & $\mathbf{3 7 0 , 0}$ & $\mathbf{3 5 5 , 0}$ \\
\hline $\begin{array}{l}\text { SD } \\
\text { Tötung }\end{array}$ & $\mathbf{3 1 1 , 1}$ & $\mathbf{3 4 9 , 7} \#$ & $\mathbf{3 4 4 , 6}$ & $\mathbf{3 4 0 , 9}$ & $\mathbf{3 3 6 , 4}$ \\
\hline SD & 10,4 & 47,8 & 17,0 & 30,0 & 22,3 \\
\hline
\end{tabular}

\# signifikant vs. NON-OVX

Tabelle 4: Gewichte des M. gastrocnemius in Gramm

\begin{tabular}{|l|l|l|l|l|l|}
\hline & $\begin{array}{l}\text { NON- } \\
\text { OVX }\end{array}$ & OVX & Baicalein1 & Baicalein2 & Baicalein3 \\
\hline Muskelgewicht & $\mathbf{1 , 5 5}$ & $\mathbf{1 , 8 1}$ & $\mathbf{1 , 8 3}$ & $\mathbf{1 , 6 4}$ & $\mathbf{1 , 4 5}$ \\
\hline SD & 0,34 & 0,37 & 0,24 & 0,51 & 0,50 \\
\hline
\end{tabular}

Tabelle 5: Gewichte des M. soleus in Gramm

\begin{tabular}{|l|l|l|l|l|l|}
\hline & $\begin{array}{l}\text { NON- } \\
\text { OVX }\end{array}$ & OVX & Baicalein1 & Baicalein2 & Baicalein3 \\
\hline Muskelgewicht & $\mathbf{0 , 1 4}$ & $\mathbf{0 , 1 4}$ & $\mathbf{0 , 1 4}$ & $\mathbf{0 , 1 5}$ & $\mathbf{0 , 1 5}$ \\
\hline SD & 0,01 & 0,03 & 0,02 & 0,03 & 0,03 \\
\hline
\end{tabular}


Tabelle 6: Uterusgewichte in Gramm

\begin{tabular}{|l|l|l|l|l|l|}
\hline & $\begin{array}{l}\text { NON- } \\
\text { OVX }\end{array}$ & OVX & Baicalein1 & Baicalein2 & Baicalein3 \\
\hline Uterusgewicht & $\mathbf{0 , 6 4 \#}$ & $\mathbf{0 , 1 1}$ & $\mathbf{0 , 1 0}$ & $\mathbf{0 , 1 4}$ & $\mathbf{0 , 1 5}$ \\
\hline SD & 0,16 & 0,02 & 0,01 & 0,04 & 0,03 \\
\hline
\end{tabular}

\# signifikant vs. allen übrigen Gruppen

Tabelle 7: Verhätnisse von Kapillaren zu Muskelfasern beim M. soleus

\begin{tabular}{|l|l|l|l|l|l|}
\hline & $\begin{array}{l}\text { NON- } \\
\text { OVX }\end{array}$ & OVX & Baicalein1 & Baicalein2 & Baicalein3 \\
\hline $\begin{array}{l}\text { Kapillaren/MF } \\
\text { auf 0,5 mm }\end{array}$ & $\mathbf{1 , 0 9}$ & $\mathbf{1 , 0 9}$ & $\mathbf{1 , 4 4 ^ { \# * }}$ & $\mathbf{1 , 5 6 ^ { \# * }}$ & $\mathbf{1 , 6 5}^{\# *}$ \\
\hline SD & 0,09 & 0,12 & 0,20 & 0,30 & 0,20 \\
\hline
\end{tabular}

\# signifikant vs. NON-OVX, * signifikant vs. OVX

Tabelle 8: Mittelwerte der Verhältnisse von Kapillaren zu Muskelfasern beim M. gastrocnemius

\begin{tabular}{|l|l|l|l|l|l|}
\hline & $\begin{array}{l}\text { NON- } \\
\text { OVX }\end{array}$ & OVX & Baicalein1 & Baicalein2 & Baicalein3 \\
\hline $\begin{array}{l}\text { Kapillaren/MF } \\
\text { auf 0,5 mm }\end{array}$ & $\mathbf{0 , 9 5}$ & $\mathbf{1 , 0 5}$ & $\mathbf{1 , 3 4 \#}$ & $\mathbf{1 , 2 7 \#}$ & $\mathbf{1 , 4 7 \# *}$ \\
\hline SD & 0,09 & 0,12 & 0,15 & 0,23 & 0,13 \\
\hline
\end{tabular}

\#signifikant vs. NON-OVX und OVX; *signifikant vs. Baicalein2 
Tabelle 9: Verhältnis von Kapillaren zu Muskelfasern M. longissimus

\begin{tabular}{|l|l|l|l|l|l|}
\hline & $\begin{array}{l}\text { NON- } \\
\text { OVX }\end{array}$ & OVX & Baicalein1 & Baicalein2 & Baicalein3 \\
\hline $\begin{array}{l}\text { Kapillaren/MF } \\
\text { auf 0,5 mm }\end{array}$ & $\mathbf{0 , 9 1}$ & $\mathbf{0 , 9 5}$ & $\mathbf{1 , 1 1 \#}$ & $\mathbf{1 , 4 4 \# *}$ & $\mathbf{1 , 3 4 \# *}$ \\
\hline SD & 0,13 & 0,07 & 0,18 & 0,13 & 0,14 \\
\hline
\end{tabular}

\#signifikant vs. NON-OVX und OVX; *signifikant vs. Baicalein1

Tabelle 10: Muskelfaserdurchmesser beim M. soleus

\begin{tabular}{|l|l|l|l|l|l|}
\hline & $\begin{array}{l}\text { NON- } \\
\text { OVX }\end{array}$ & OVX & Baicalein1 & Baicalein2 & Baicalein3 \\
\hline $\begin{array}{l}\text { DM in } \\
\boldsymbol{~}\end{array}$ & $\mathbf{6 2 , 8 3}$ & $\mathbf{5 6 , 1 1}$ & $\mathbf{6 3 , 1 9}$ & $\mathbf{6 5 , 0 0 \#}$ & $\mathbf{6 7 , 0 7 \#}$ \\
\hline SD & 5,82 & 3,22 & 3,54 & 8,63 & 8,31 \\
\hline
\end{tabular}

\#signifikant vs. OVX

Tabelle 11: Muskelfaserflächen im M. soleus

\begin{tabular}{|l|l|l|l|l|l|}
\hline & $\begin{array}{l}\text { NON- } \\
\text { OVX }\end{array}$ & OVX & Baicalein1 & Baicalein2 & Baicalein3 \\
\hline $\begin{array}{l}\text { FlächeMF } \\
\text { in } \boldsymbol{\mu m}^{2}\end{array}$ & $\mathbf{3 1 6 1}$ & $\mathbf{2 5 1 1}$ & $\mathbf{3 1 8 4}$ & $\mathbf{3 4 0 8 \#}$ & $\mathbf{3 6 3 0 \#}$ \\
\hline SD & 571 & 268 & 358 & 886 & 831 \\
\hline
\end{tabular}

\#signifikant vs. OVX 
Tabelle 12: Relationen von Muskelfaserdurchmesser zum Muskel- und Körpergewicht beim M. soleus

\begin{tabular}{|l|l|l|l|l|l|}
\hline & $\begin{array}{l}\text { NON- } \\
\text { OVX }\end{array}$ & OVX & Baicalein1 & Baicalein2 & Baicalein3 \\
\hline $\begin{array}{l}\text { DM MF / } \\
\text { KG in } \\
\boldsymbol{\mu m} / \mathrm{g}\end{array}$ & $\mathbf{0 , 2 1 \#}$ & $\mathbf{0 , 1 6}$ & $\mathbf{0 , 1 8}$ & $\mathbf{0 , 1 9 \#}$ & $\mathbf{0 , 2 0 \#}$ \\
\hline SD & 0,02 & 0,02 & 0,01 & 0,02 & 0,03 \\
\hline $\begin{array}{l}\text { DM MF / } \\
\text { MG in } \\
\text { mm/g }\end{array}$ & $\mathbf{0 , 4 4}$ & $\mathbf{0 , 4 2}$ & $\mathbf{0 , 4 6}$ & $\mathbf{0 , 4 6}$ & $\mathbf{0 , 5 7}$ \\
\hline SD & 0,05 & 0,08 & 0,08 & 0,06 & 0,25 \\
\hline
\end{tabular}

\#signifikant vs. OVX

Tabelle 13: Relationen von Muskelfaserfläche zum Körper- und Muskelgewicht beim M. soleus

\begin{tabular}{|l|l|l|l|l|l|}
\hline & $\begin{array}{l}\text { NON- } \\
\text { OVX }\end{array}$ & OVX & Baicalein1 & Baicalein2 & Baicalein3 \\
\hline $\begin{array}{l}\text { Fläche } \\
\text { MF / KG } \\
\text { in } \mu \text { m }^{2} / \mathbf{g}\end{array}$ & $\mathbf{1 0 , 4 6 \#}$ & $\mathbf{7 , 1 3 3}$ & $\mathbf{9 , 2 1 2}$ & $\mathbf{1 0 , 1 5 \#}$ & $\mathbf{1 0 , 5 8 \#}$ \\
\hline SD & 2,053 & 0,9166 & 1,094 & 2,309 & 2,458 \\
\hline $\begin{array}{l}\text { Fläche } \\
\text { MF / MG } \\
\text { in } \\
\text { mm }\end{array}$ & $\mathbf{2 2 , 0 1}$ & $\mathbf{1 8 , 5 8}$ & $\mathbf{2 3 , 2 7}$ & $\mathbf{2 4 , 0 5}$ & $\mathbf{2 9 , 3 1 \#}$ \\
\hline \begin{tabular}{l} 
SD \\
\hline
\end{tabular} & 4,145 & 2,857 & 4,781 & 3,077 & 10,48 \\
\hline
\end{tabular}

\#signifikant vs. OVX 
Tabelle 14: Muskelfaserdurchmesser beim M. gastrocnemius

\begin{tabular}{|l|l|l|l|l|l|}
\hline & $\begin{array}{l}\text { NON- } \\
\text { OVX }\end{array}$ & OVX & Baicalein1 & Baicalein2 & Baicalein3 \\
\hline $\begin{array}{l}\text { DM } \\
\text { Typ1 MF } \\
\text { in } \boldsymbol{\mu m}\end{array}$ & $\mathbf{4 2 , 2 5}$ & $\mathbf{4 5 , 8 5}$ & $\mathbf{4 6 , 6 8}$ & $\mathbf{5 0 , 0 7 \#}$ & $\mathbf{4 8 , 9 5 \#}$ \\
\hline $\begin{array}{l}\text { SD } \\
\text { DM } \\
\text { Typ2A } \\
\text { MF in } \\
\boldsymbol{\mu m}\end{array}$ & $\mathbf{6 8 , 7 2}$ & $\mathbf{7 2 , 5 6}$ & $\mathbf{7 4 , 4 6}$ & $\mathbf{8 0 , 5 5 *}$ & $\mathbf{7 5 , 3 7}$ \\
\hline $\begin{array}{l}\text { SD } \\
\text { DD }\end{array}$ & 7,40 & 5,03 & 6,15 & 5,85 & 4,65 \\
\hline $\begin{array}{l}\text { DM } \\
\text { in } \boldsymbol{\mu m}\end{array}$ & $\mathbf{5 3 , 5 2}$ & $\mathbf{5 3 , 8 1}$ & $\mathbf{5 5 , 7 4}$ & $\mathbf{5 8 , 0 7}$ & $\mathbf{5 4 , 2 3}$ \\
\hline \begin{tabular}{l} 
SD \\
\hline
\end{tabular} & 7,98 & 5,20 & 5,92 & 6,08 & 3,06 \\
\hline
\end{tabular}

\#signifikant vs. NON-OVX; *signifikant vs. NON-OVX 
Tabelle 15: Muskelfaserflächen im M. gastrocnemius

\begin{tabular}{|l|l|l|l|l|l|}
\hline & $\begin{array}{l}\text { NON- } \\
\text { OVX }\end{array}$ & OVX & Baicalein1 & Baicalein2 & Baicalein3 \\
\hline $\begin{array}{l}\text { FlächeTyp1- } \\
\text { MF in } \boldsymbol{\mu m}^{2}\end{array}$ & $\mathbf{1 4 3 7}$ & $\mathbf{1 7 0 0}$ & $\mathbf{1 7 6 8}$ & $\mathbf{2 0 2 9 \#}$ & $\mathbf{1 9 3 2 \#}$ \\
\hline SD & 256 & 187 & 392 & 445 & 366 \\
\hline $\begin{array}{l}\text { FlächeTyp2A- } \\
\text { MF in } \mu m^{2}\end{array}$ & $\mathbf{3 7 9 6}$ & $\mathbf{4 2 0 8}$ & $\mathbf{4 4 5 8}$ & $\mathbf{5 2 7 3 \#}$ & $\mathbf{4 5 4 7}$ \\
\hline SD & 809 & 587 & $\mathbf{7 4 5}$ & 1432 & 615 \\
\hline $\begin{array}{l}\text { FlächeTyp2B- } \\
\text { MF in } \boldsymbol{\mu m}^{2}\end{array}$ & $\mathbf{2 3 3 9}$ & $\mathbf{2 3 2 9}$ & $\mathbf{2 5 1 5}$ & $\mathbf{2 7 3 1}$ & $\mathbf{2 3 6 1}$ \\
\hline SD & & & & 265 \\
\hline
\end{tabular}

\#signifikant vs. NON-OVX 
Tabelle 16: Relationen von Muskelfaserdurchmesser zum Muskel- und Körpergewicht beim M. gastrocnemius

\begin{tabular}{|c|c|c|c|c|c|}
\hline & $\begin{array}{l}\text { NON- } \\
\text { OVX }\end{array}$ & OVX & Baicalein1 & Baicalein2 & Baicalein3 \\
\hline $\begin{array}{l}\text { DM } \\
\text { Typ1/KG } \\
\text { in } \mu \mathrm{m} / \mathrm{g}\end{array}$ & 0,14 & 0,13 & 0,14 & 0,15 & 0,14 \\
\hline SD & 0,01 & 0,01 & 0,02 & 0,02 & 0,01 \\
\hline $\begin{array}{l}\text { DM } \\
\text { Typ2A/KG } \\
\text { in } \mu \mathrm{m} / \mathrm{g}\end{array}$ & 0,18 & 0,15 & 0,16 & 0,17 & 0,16 \\
\hline SD & 0,03 & 0,02 & 0,02 & 0,02 & 0,01 \\
\hline $\begin{array}{l}\text { DM } \\
\text { Typ2B/KG } \\
\text { in } \mu \mathrm{m} / \mathrm{g}\end{array}$ & 0,22 & 0,21 & 0,22 & 0,24 & 0,22 \\
\hline SD & 0,03 & 0,03 & 0,02 & 0,04 & 0,02 \\
\hline $\begin{array}{l}\text { DM } \\
\text { Typ1/MG } \\
\text { in } \mu \mathrm{m} / \mathrm{g}\end{array}$ & 28,14 & 26,50 & 26,12 & 33,03 & 40,01 \\
\hline SD & 4,92 & 6,81 & 5,56 & 9,16 & 20,65 \\
\hline $\begin{array}{l}\text { DM } \\
\text { Typ2A/MG } \\
\text { in } \mu \mathrm{m} / \mathrm{g}\end{array}$ & 35,65 & 31,06 & 31,16 & 38,65 & 44,58 \\
\hline SD & 7,36 & 8,01 & 6,34 & 11,64 & 25,86 \\
\hline $\begin{array}{l}\text { DM } \\
\text { Typ2B/MG } \\
\text { in } \mu \mathrm{m} / \mathrm{g}\end{array}$ & 45,54 & 41,58 & 41,39 & 52,32 & 60,51 \\
\hline SD & 6,77 & 8,82 & 6,13 & 11,38 & 30,64 \\
\hline
\end{tabular}


Tabelle 17: Relationen von Muskelfaserflächen zu den Körper- und Muskelgewichten beim M. gastrocnemius

\begin{tabular}{|c|c|c|c|c|c|}
\hline & $\begin{array}{l}\text { NON- } \\
\text { OVX }\end{array}$ & OVX & Baicalein1 & Baicalein2 & Baicalein3 \\
\hline $\begin{array}{l}\text { FlächeTyp1/KG } \\
\text { in } \mu \mathrm{m}^{2} / \mathrm{g}\end{array}$ & 4,75 & 4,84 & 5,12 & 6,08 & 5,61 \\
\hline SD & 0,83 & 0,67 & 1,18 & 1,33 & 1,08 \\
\hline $\begin{array}{l}\text { FlächeTyp2A/KG } \\
\text { in } \mu \mathrm{m}^{2} / \mathrm{g}\end{array}$ & 7,73 & 6,61 & 7,28 & 8,16 & 6,85 \\
\hline SD & 2,39 & 1,32 & 1,61 & 1,42 & 0,72 \\
\hline $\begin{array}{l}\text { FlächeTyp2B/KG } \\
\text { in } \mu \mathrm{m}^{2} / \mathrm{g}\end{array}$ & 12,56 & 11,99 & 12,89 & $15,76 \#$ & 13,20 \\
\hline SD & 2,79 & 2,10 & 2,17 & 4,07 & 1,74 \\
\hline $\begin{array}{l}\text { FlächeTyp1/MG } \\
\text { in } \mathrm{mm}^{2} / \mathrm{g}\end{array}$ & $0,94^{*}$ & $0,98^{*}$ & 0,99* & 1,29 & 1,54 \\
\hline SD & 0,17 & 0,26 & 0,32 & 0,21 & 0,67 \\
\hline $\begin{array}{l}\text { FlächeTyp2A/MG } \\
\text { in } \mathrm{mm}^{2} / \mathrm{g}\end{array}$ & 1,54 & 1,34 & 1,41 & 1,77 & 1,98 \\
\hline SD & 0,45 & 0,37 & 0,42 & 0,44 & 1,06 \\
\hline $\begin{array}{l}\text { FlächeTyp2B/MG } \\
\text { in } \mathrm{mm}^{2} / \mathrm{g}\end{array}$ & $2,47^{*}$ & $2,38^{*}$ & $2,47^{*}$ & 3,27 & 3,51 \\
\hline SD & 0,37 & 0,44 & 0,47 & 0,38 & 1,49 \\
\hline
\end{tabular}

\#signifikant vs. OVX; *signifikant vs. Baicalein3; 
Tabelle 18: Muskelfaserdurchmesser beim M. longissimus

\begin{tabular}{|l|l|l|l|l|l|}
\hline & $\begin{array}{l}\text { NON- } \\
\text { OVX }\end{array}$ & OVX & Baicalein1 & Baicalein2 & Baicalein3 \\
\hline $\begin{array}{l}\text { DM } \\
\text { Typ1 } \\
\text { MF in } \\
\mu \text { m }\end{array}$ & $\mathbf{4 8 , 5 4 \#}$ & $\mathbf{4 7 , 5 4 \#}$ & $\mathbf{4 9 , 2 8 \#}$ & $\mathbf{5 4 , 1 8}$ & $\mathbf{5 0 , 5 7}$ \\
\hline $\begin{array}{l}\text { SD } \\
\text { Dyp2A } \\
\text { MF in } \\
\boldsymbol{\mu m}\end{array}$ & 2,04 & 3,37 & 2,99 & 2,37 & 2,57 \\
\hline $\begin{array}{l}\text { SD } \\
\text { DM }\end{array}$ & 5,03 & 7,57 & 7,27 & 3,88 & 6,22 \\
\hline $\begin{array}{l}\text { DM } \\
\text { Typ2B } \\
\text { in } \boldsymbol{\mu m}\end{array}$ & $\mathbf{5 4 , 8 2}$ & $\mathbf{5 3 , 3 1}$ & $\mathbf{5 4 , 1 3}$ & $\mathbf{5 8 , 5 9}$ & $\mathbf{5 3 , 8 8}$ \\
\hline \begin{tabular}{l} 
SD \\
\hline
\end{tabular} & 5,98 & 5,35 & 5,39 & 4,39 & 3,48 \\
\hline
\end{tabular}

\#signifikant vs. Baicalein2 
Tabelle 19: Muskelfaserflächen im M. longissimus

\begin{tabular}{|c|c|c|c|c|c|}
\hline & $\begin{array}{l}\text { NON- } \\
\text { OVX }\end{array}$ & OVX & Baicalein1 & Baicalein2 & Baicalein3 \\
\hline $\begin{array}{l}\text { Fläche } \\
\text { Typ1-MF } \\
\text { in } \mu \mathrm{m}^{2}\end{array}$ & 1883\# & 1809\# & 1941\# & 2339 & 2038\# \\
\hline SD & 158 & 256 & 229 & 201 & 207 \\
\hline $\begin{array}{l}\text { Fläche } \\
\text { Typ2A- } \\
\text { MF in } \\
\mu^{2}\end{array}$ & 4789\# & 4514\# & 5398 & 5974 & 5206 \\
\hline SD & 629 & 903 & 949 & 530 & 811 \\
\hline $\begin{array}{l}\text { Fläche } \\
\text { Typ2B- } \\
\text { MFin } \mu \mathrm{m}^{2}\end{array}$ & 2425 & 2280 & 2376 & 2763 & 2315 \\
\hline SD & 556 & 462 & 526 & 424 & 296 \\
\hline
\end{tabular}

\#signifikant vs. Baicalein2 
Tabelle 20: Verhältnis von Muskelfaserdurchmesser und Körpergewicht beim M. longissimus

\begin{tabular}{|l|l|l|l|l|l|}
\hline & $\begin{array}{l}\text { NON- } \\
\text { OVX }\end{array}$ & OVX & Baicalein1 & Baicalein2 & Baicalein3 \\
\hline $\begin{array}{l}\text { DM } \\
\text { Typ1/KG } \\
\text { in } \mu \mathrm{m} / \mathbf{g}\end{array}$ & $\mathbf{0 , 1 6}$ & $\mathbf{0 , 1 3 \# *}$ & $\mathbf{0 , 1 4 \#}$ & $\mathbf{0 , 1 6}$ & $\mathbf{0 , 1 4 \#}$ \\
\hline SD & 0,01 & 0,01 & 0,01 & 0,01 & 0,01 \\
\hline $\begin{array}{l}\text { DM } \\
\text { Typ2A/KG } \\
\text { in } \boldsymbol{\mu m} / \mathbf{g}\end{array}$ & $\mathbf{0 , 1 8 \#}$ & $\mathbf{0 , 1 5 \# *}$ & $\mathbf{0 , 1 5 *}$ & $\mathbf{0 , 1 7}$ & $\mathbf{0 , 1 5}$ \\
\hline $\begin{array}{l}\text { SD } \\
\text { DM }\end{array}$ & 0,01 & 0,02 & 0,01 & 0,01 & 0,01 \\
\hline $\begin{array}{l}\text { Typ2B/KG } \\
\text { in } \boldsymbol{\mu m} / \mathbf{g}\end{array}$ & $\mathbf{0 , 2 5}$ & $\mathbf{0 , 2 1 \# *}$ & $\mathbf{0 , 2 3}$ & $\mathbf{0 , 2 6}$ & $\mathbf{0 , 2 3}$ \\
\hline \begin{tabular}{l} 
SD \\
\hline
\end{tabular} & 0,01 & 0,03 & 0,02 & 0,02 & 0,02 \\
\hline
\end{tabular}

\#signifikant vs. Baicalein2; *signifikant vs. NON-OVX 
Tabelle 21: Relationen von Muskelfaserflächen zum Körpergewicht beim M. longissimus

\begin{tabular}{|l|l|l|l|l|l|}
\hline & $\begin{array}{l}\text { NON- } \\
\text { OVX }\end{array}$ & OVX & Baicalein1 & Baicalein2 & Baicalein3 \\
\hline $\begin{array}{l}\text { FlächeTyp1/KG } \\
\text { in } \boldsymbol{~ m}^{2} / \mathbf{g}\end{array}$ & $\mathbf{6 , 2 2}$ & $\mathbf{5 , 1 6 \# *}$ & $\mathbf{5 , 6 1 \#}$ & $\mathbf{7 , 1 1}$ & $\mathbf{5 , 8 7 \#}$ \\
\hline SD & 0,47 & 0,96 & 0,72 & 0,78 & 0,50 \\
\hline $\begin{array}{l}\text { Fläche } \\
\text { Typ2A/KG } \\
\text { in } \mu m^{2} / g\end{array}$ & $\mathbf{8 , 0 1}$ & $\mathbf{6 , 5 1}$ & $\mathbf{6 , 8 6}$ & $\mathbf{8 , 4 1}$ & $\mathbf{6 , 6 7}$ \\
\hline $\begin{array}{l}\text { SD } \\
\text { SDäche } \\
\text { Typ2B/KG } \\
\text { in } \boldsymbol{\mu m}{ }^{2} / \mathbf{g}\end{array}$ & 1,76 & 1,59 & 1,48 & 1,44 & 0,73 \\
\hline \begin{tabular}{l} 
SD \\
\hline
\end{tabular} & 2,02 & 3,35 & 2,59 & 2,15 & 2,57 \\
\hline
\end{tabular}

\#signifikant vs. Baicalein2; *signifikant vs. NON-OVX 
Tabelle 22: Verhältnisse verschiedener Fasertypen im M. longissimus in Prozent am Gesamtfaseranteil pro $1 \mathrm{~mm}^{2}$

\begin{tabular}{|l|l|l|l|l|l|}
\hline & $\begin{array}{l}\text { NON- } \\
\text { OVX }\end{array}$ & OVX & Baicalein1 & Baicalein2 & Baicalein3 \\
\hline $\begin{array}{l}\text { Anteil Typ1 } \\
\text { MF/Summe } \\
\text { aller Fasern } \\
\text { in \% }\end{array}$ & $\mathbf{2 3 , 9 3}$ & $\mathbf{2 3 , 7 6}$ & $\mathbf{2 4 , 2 5}$ & $\mathbf{2 1 , 1 0}$ & $\mathbf{2 2 , 9 4}$ \\
\hline $\begin{array}{l}\text { SD } \\
\text { AnteilTyp2A } \\
\text { MF/Summe } \\
\text { aller Fasern } \\
\text { in \% }\end{array}$ & $\mathbf{5 1 , 8 7 \#}$ & $\mathbf{5 8 , 4 8}$ & $\mathbf{5 3 , 9 1}$ & $\mathbf{6 0 , 0 4}$ & $\mathbf{5 7 , 8 9}$ \\
\hline $\begin{array}{l}\text { SD } \\
\text { AnteilTyp2B } \\
\text { MF/Summe } \\
\text { aller Fasern } \\
\text { in \% }\end{array}$ & $\mathbf{2 4 , 2 0 *}$ & $\mathbf{1 7 , 7 2}$ & $\mathbf{1 8 , 2 0}$ & $\mathbf{1 9 , 5 3}$ & $\mathbf{1 9 , 2 6}$ \\
\hline \begin{tabular}{l} 
SD \\
\hline
\end{tabular} & 4,53 & 3,17 & 1,96 & 3,39 & 1,66 \\
\hline
\end{tabular}

\#signifikant vs. Baicalein2; *signifikant vs. OVX, Baicalein1,Baicalein2,Baicalein3 
Tabelle 23: Ergebnisse der Serumparameter

\begin{tabular}{|l|l|l|l|l|l|}
\hline & $\begin{array}{l}\text { NON- } \\
\text { OVX }\end{array}$ & OVX & Baicalein1 & Baicalein2 & Baicalein3 \\
\hline $\begin{array}{l}\text { Kreatinkinase } \\
\text { im Serum } \\
\text { in U/1 }\end{array}$ & $\mathbf{4 9 1 1 \#}$ & $\mathbf{5 0 6 9 \#}$ & $\mathbf{3 9 3 1}$ & $\mathbf{3 6 8 0}$ & $\mathbf{1 7 2 7}$ \\
\hline SD & 2007 & 3014 & 993 & 1374 & 662 \\
\hline $\begin{array}{l}\text { Calcium } \\
\text { im Serum } \\
\text { in mmol/1 }\end{array}$ & $\mathbf{2 , 2 8}$ & $\mathbf{2 , 1 1}$ & $\mathbf{2 , 2 1}$ & $\mathbf{2 , 2 8}$ & $\mathbf{2 , 1 9}$ \\
\hline $\begin{array}{l}\text { SD } \\
\text { Magnesium } \\
\text { im Serum } \\
\text { in mmol/1 }\end{array}$ & $\mathbf{0 , 8 0}$ & $\mathbf{0 , 7 5}$ & $\mathbf{0 , 8 4}$ & $\mathbf{0 , 8 7}$ & $\mathbf{0 , 7 7}$ \\
\hline SD & 0,07 & 0,05 & 0,08 & 0,12 & 0,08 \\
\hline
\end{tabular}

\#signifikant vs. Baicalein3 


\section{Literaturverzeichnis}

Agyapong-Badu S, Warner M, Samuel D, Narici M, Cooper C, Stokes M (2014): Anterior thigh composition measured using ultrasound imaging to quantify relative thickness of muscle and non-contractile tissue: a potential biomarker for musculoskeletal health. Physiol Meas $\underline{35}$ (10), 2165-2176

Aydin A, Kenar H, Atmaca H, Alici T, Gacar G, Müezzinoğlu ÜS, Karaöz E (2013): The short- and long- term effects of estrogen deficiency on apoptosis in musculoskeletal tissues: an experimental animal model study. Arch Iran Med 16 (5), 271-276

Barlet JP, Coxam V, Davicco MJ, Gaumet N (1994): Modèles animaux d'ostéoporose postménopausique. Reprod Nutr Dev $\underline{34}$ (3), 221-236

Batsis JA, Mackenzie TA, Barre LK, Lopez-Jimenez F, Bartels SJ (2014): Sarcopenia, sarcopenic obesity and mortality in older adults: results from the National Health and Nutrition Examination Survey III. Eur J Clin Nutr 68 (9), 7-1001

Baum S (2008): The PAS Reaction for Staining Cell Walls. CSH Protoc DOI: $10.1101 /$ pdb.prot4956.

Bean JF, Kiely DK, LaRose S, Alian J, Frontera WR (2007): Is stair climb power a clinically relevant measure of leg power impairments in at-risk older adults? Arch Phys Med Rehabil (5), 9-604.

Benninghoff A, Drenckhahn D: Anatomie Band 1. 15., korr. Auflage; Elsevier Verlag, München u.a. 1994

Chen S (2011): Natural products triggering biological targets-a review of the antiinflammatory phytochemicals targeting the arachidonic acid pathway in allergy asthma and rheumatoid arthritis. Curr Drug Targets 12 (3) 288-301

Ciciliot S, Rossi AC, Dyar KA, Blaauw B, Schiaffino S (2013): Muscle type and fiber type specificity in muscle wasting. Int J Biochem Cell Biol $\underline{45}$ (10), 2191-2199

Cruz-Jentoft AJ, Baeyens JP, Bauer JM, Boirie Y, Cederholm T, Landi F, Martin FC, Michel JP, Rolland Y, Schneider SM, Topinková E, Vandewoude M, Zamboni M (2010) European Working Group on Sarcopenia in Older People: Sarcopenia: European consensus on definition and diagnosis: Report of the European Working Group on Sarcopenia in Older People. Age Ageing (4), 23-412

Dickhuth HH, Mayer F, Röcker K, Berg A: Sportmedizin für Ärzte. Deutscher Ärzteverlag, Köln 1997 
Fang J, Yang L, Zhang R, Zhu X, Wang P (2015): Are there differences between SpragueDawley and Wistar rats in long-term effects of ovariectomy as a model for postmenopausal osteoporosis? Int J Clin Exp Pathol $\underline{8}$ (2) 1491-1502

Forsberg AM, Nilsson E, Werneman J, Bergström J, Hultman E (1991): Muscle composition in relation to age and sex. Clin Sci 11 (2) 249-256

Gaire BP, Moon SK, Kim H (2014): Scutellaria baicalensis in stroke management: Nature's blessing in traditional Eastern medicine. Chin J Integr Med 20 (9),20-712

Gao Y, Kostrominova TY, Faulkner JA, Wineman AS (2008): Age-related changes in the mechanical properties of the epimysium in skeletal muscles of rats. J Biomech (2), 9-465

Grisso JA, Kelsey JL, Strom BL, Chiu GY, Maislin G, O'Brien LA, Hoffman S, Kaplan F (1991): Risk factors for falls as a cause of hip fracture in women. The Northeast Hip Fracture Study Group. N Engl J Med (19), 31-1326

Hadji P, Klein S, Gothe H, Häussler B, Kless T, Schmidt T, Steinle T, Verheyen F, Linder R (2013): The epidemiology of osteoporosis-Bone Evaluation Study (BEST): an analysis of routine health insurance data. Dtsch Arztebl Int (4), 7-52

Hoff E, Brechtel L, Strube P, Konstanczak P, Stoltenburg-Didinger G, Perka C, Putzier M (2013): Noninvasive monitoring of training induced muscle adaptation with 31P-MRS: fibre type shifts correlate with metabolic changes. Biomed Res Int DOI: $10.1155 / 2013 / 417901$.

Huo YR, Suriyaarachchi P, Gomez F, Curcio CL, Boersma D, Gunawardene P (2015): Comprehensive nutritional status in sarco-osteoporotic older fallers. J Nutr Health Aging 19 (4), 474-480

Jung SR, Kim SH, Ahn NY, Kim KJ (2014): Changes of bone metabolism based on the different interventions with exercise type or additional intake material in ovariectomized rats. J Exerc Nutrition Biochem 18 (1), 111-117

Kaji H (2014): Interaction between Muscle and Bone. J Bone Metab $\underline{21}$ (1), 29-40

Kalu DN (1991): The ovariectomized rat model of postmenopausal bone loss. Bone Miner $\underline{15}$ (3), 175-191

Khor SC, Abdul KN, Wan NWZ, Mohd YA, Makpol S (2014): Vitamin E in Sarcopenia: Current Evidences on Its Role in Prevention and Treatment. Oxid Med Cell Longev, doi: 10.1155/2014/914853. Epub 2014 Jul 6

Kim S, Won CW, Kim BS, Choi HR, Moon MY (2014): The association between the low muscle mass and osteoporosis in elderly Korean people. J Korean Med Sci 29 (7), 9951000 
Komrakova M, Stuermer EK, Werner C, Wicke M, Kolios L, Sehmisch S (2010): Effect of human parathyroid hormone hPTH (1-34) applied at different regimes on fracture healing and muscle in ovariectomized and healthy rats. Bone $\underline{47}$ (3), 480-492

Kyriakides ZS, Kremastinos DT, Karayannakos P (2001): Estrogen stimulates angiogenesis in normoperfused skeletal muscle in rabbits. Circulation $\underline{103}$ (21), 8-107

Layec G, Hart CR, Trinity JD, Le Fur Y, Jeong EK, Richardson RS (2015): Skeletal muscle work efficiency with age: the role of non-contractile processes. Clin Sci 128 (3) 213-223

Lightfoot AP, McCormick GA, McArdle A (2014): Mechanisms of skeletal muscle ageing; avenues for therapeutic intervention. Curr Opin Pharmacol (16) 116-121

Löffler G; Petrides P: Biochemie und Pathobiochemie. 8. Korr. Auflage; Springer, Heidelberg u.a. 2007

Mitchell CJ, Churchward-Venne TA, Bellamy L, Parise G, Baker SK, Phillips SM (2013): Muscular and systemic correlates of resistance training-induced muscle hypertrophy. PLoS One (10), Published online 2013 Oct 9. doi: 10.1371/journal.pone.0078636

Oak NR, Gumucio JP, Flood MD, Saripalli AL, Davis ME, Harning JA (2014): Inhibition of 5-LOX, COX-1, and COX-2 increases tendon healing and reduces muscle fibrosis and lipid accumulation after rotator cuff repair. Am J Sports Med 42 (12), 2860-2868

Omi N, Ezawa I (1995): The effect of ovariectomy on bone metabolism in rats. Bone $\underline{17}$ (4), 163-168

Palus S, Von Haehling S, Springer J (2014): Muscle wasting: an overview of recent developments in basic research. Int J Cardiol 176 (3), 640-644

Pata RW, Lord K, Lamb J (2014): The effect of Pilates based exercise on mobility, postural stability, and balance in order to decrease fall risk in older adults. J Bodyw Mov Ther (3), 7-361

Prior SJ, Blumenthal JB, Katzel LI, Goldberg AP, Ryan AS (2014): Increased skeletal muscle capillarization after aerobic exercise training and weight loss improves insulin sensitivity in adults with IGT. Diabetes Care (5), 75-1469

Rizzoli R, Stevenson JC, Bauer JM, Van Loon LJ, Walrand S, Kanis JA, Cooper C, Brandi ML, Diez-Perez A, Reginster JY (2014): The role of dietary protein and vitamin D in maintaining musculoskeletal health in postmenopausal women: A consensus statement from the European Society for Clinical and Economic Aspects of Osteoporosis and Osteoarthritis (ESCEO). Maturitas (14) 378-5122, 5-234

Rogers MA, Evans WJ (1993): Changes in skeletal muscle with aging: effects of exercise training. Exerc Sport Sci Rev (21), 65-102 
Rossiter HB, Howlett RA, Holcombe HH, Entin PL, Wagner HE, Wagner PD (2005): Age is no barrier to muscle structural, biochemical and angiogenic adaptations to training up to 24 months in female rats. J Physiol (3), 993-1005

Roubenoff R (2007): Physical activity, inflammation, and muscle loss. Nutr Rev (12), 12208

Samaras N, Papadopoulou MA, Samaras D, Ongaro F (2014): Off-label use of hormones as an antiaging strategy: a review. Clin Interv Aging (9), 86-1175

Schiltenwolf M, Hollo D: Begutachtung der Haltungs- und Bewegungsorgane. 6., korr. Auflage; Thieme, Stuttgart 2014

Silbernagel S, Pape HC, Kurtz A: Physiologie, 7., korr. Auflage; Thieme, Stuttgart 2014

Tagliaferri C, Salles J, Landrier JF, Giraudet C, Patrac V, Lebecque P (2014): Increased body fat mass and tissue lipotoxicity associated with ovariectomy or high-fat diet differentially affects bone and skeletal muscle metabolism in rats. Eur J Nutr DOI: 10.1007/s00394-014-0790-0.

Tarantino U, Baldi J, Celi M, Rao C, Liuni FM, Iundusi R, Gasbarra E (2013): Osteoporosis and sarcopenia: the connections. Aging Clin Exp Res (25) 5-93

Terracciano C, Celi M, Lecce D, Baldi J, Rastelli E, Lena E (2013): Differential features of muscle fiber atrophy in osteoporosis and osteoarthritis. Osteoporos Int 24 (3), 10951100

Thomassen M, Murphy RM, Bangsbo J (2013): Fibre type-specific change in FXYD1 phosphorylation during acute intense exercise in humans. J Physiol (6), 33-1523

Thompson BJ, Conchola EC, Palmer TB, Stock MS (2014): Effects of aging on maximal and rapid velocity capacities of the leg extensors. Exp Gerontol (14), 531-5565, 2-233

Wang H, Listrat A, Meunier B, Gueugneau M, Coudy-Gandilhon C, Combaret L (2014): Apoptosis in capillary endothelial cells in ageing skeletal muscle. Aging cell $\underline{13}$ (2), 254262

Wang W, Zhou PH, Xu CG, Zhou XJ, Hu W, Zhang J (2015): Baicalein attenuates renal fibrosis by inhibiting inflammation via down-regulating NF- $\kappa B$ and MAPK signal pathways. J Mol Histol $\underline{46}$ (3), 283-290

Wang Y, Han E, Xing Q, Yan J, Arrington A Wang C (2015): Baicalein upregulates DDIT4 expression which mediates mTOR inhibition and growth inhibition in cancer cells. Cancer Lett $\underline{358}$ (2), 170-179

Wend K, Wend P, Krum SA (2012): Tissue-Specific Effects of Loss of Estrogen during Menopause and Aging. Front Endocrinol 3, doi: 10.3389/fendo.2012.00019 
Woźniak D, Dryś A, Matkowski A (2014): Antiradical and antioxidant activity of flavones from scutellariae baicalensis radix. Nat Prod, 1-4

Zhang L, Li C, Lin G, Krajcsi P, Zuo Z (2011): Hepatic metabolism and disposition of baicalein via the coupling of conjugation enzymes and transporters-in vitro and in vivo evidences. AAPS J (3), 89-378

Zhang X, Zhu Y, Chen X, Zhang Y1, Zhang Y2, Jia Y, Wang H, Liu Y, Xiao L (2014): Baicalein ameliorates inflammatory-related apoptotic and catabolic phenotypes in human chondrocytes. Int Immunopharmacol (2), 8-301 


\section{Tabellenverzeichnis}

Tabelle 1: Aufteilung der Tiere und Behandlung

Tabelle 2a: Zusammenfassung der Ergebnisse für die Kapillarisierung der verschiedenen

Muskeln

Tabelle 2b: Zusammenfassung der Ergebnisse für die Muskelfaserdurchmesser der verschiedenen Muskeln .70

Tabelle 2c: Zusammenfassung der Ergebnisse für die Muskelfaserflächen der verschiedenen Muskeln .71

Tabelle 3: Körpergewichte zu Versuchsbeginn, Osteotomie und Tötung in Gramm .86

Tabelle 4: Gewichte des M. gastrocnemius in Gramm. .86

Tabelle 5: Gewichte des M. soleus in Gramm .86

Tabelle 6: Uterusgewichte in Gramm .87

Tabelle 7: Verhätnisse von Kapillaren zu Muskelfasern beim M. soleus .87

Tabelle 8: Mittelwerte der Verhältnisse von Kapillaren zu Muskelfasern beim M. gastrocnemius 87

Tabelle 9: Verhältnis von Kapillaren zu Muskelfasern M. longissimus .88

Tabelle 10: Muskelfaserdurchmesser beim M. soleus. .88

Tabelle 11: Muskelfaserflächen im M. soleus .88

Tabelle 12: Relationen von Muskelfaserdurchmesser zum Muskel- und Körpergewicht beim M. soleus.

Tabelle 13: Relationen von Muskelfaserfläche zum Körper- und Muskelgewicht beim M. soleus.

Tabelle 14: Muskelfaserdurchmesser beim M. gastrocnemius . .90

Tabelle 15: Muskelfaserflächen im M. gastrocnemius. .91

Tabelle 16: Relationen von Muskelfaserdurchmesser zum Muskel- und Körpergewicht beim M. gastrocnemius

Tabelle 17: Relationen von Muskelfaserflächen zu den Körper- und Muskelgewichten beim M. gastrocnemius.

Tabelle 18: Muskelfaserdurchmesser beim M. longissimus 
Tabelle 19: Muskelfaserflächen im M. longissimus..................................................95

Tabelle 20: Verhältnis von Muskelfaserdurchmesser und Körpergewicht beim M. longissimus.

Tabelle 21: Relationen von Muskelfaserflächen zum Körpergewicht beim M. longissimus

Tabelle 22: Verhältnisse verschiedener Fasertypen im M. longissimus in Prozent am Gesamtfaseranteil pro $1 \mathrm{~mm}^{2}$. . .98

Tabelle 23: Ergebnisse der Serumparameter .99 


\section{Abbildungsverzeichnis}

Abbildung 1: weiße, hellere versus rote, dunklere Muskelfasertypen innerhalb eines

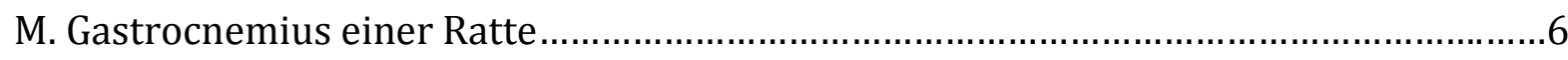

Abbildung 2: Prävalenz der Osteoporose in Deutschland.............................................10

Abbildung 3: Baicalein und seine Metaboliten.......................................................15

Abbildung 4: freipräparierte Adnexe....................................................................18

Abbildung 5: Ligatur der Adnexe ...........................................................................

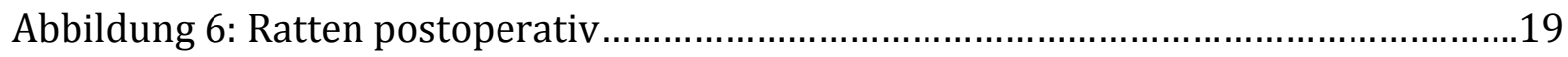

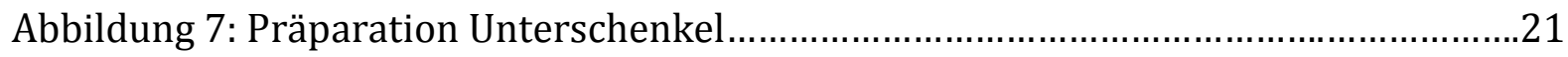

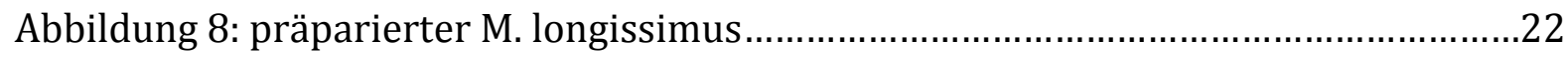

Abbildung 9: entnommene Muskeln gastrocnemius und soleus.....................................23

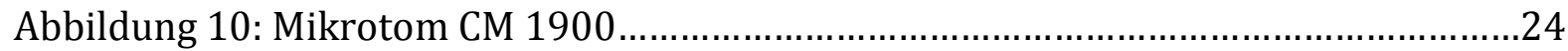

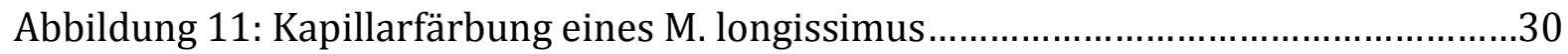

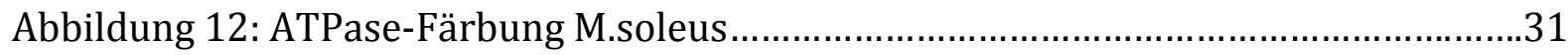

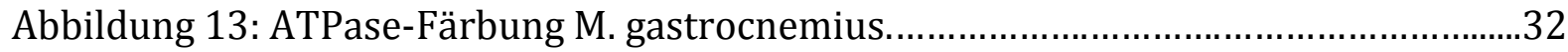

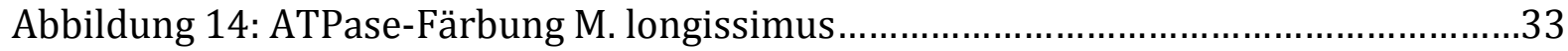

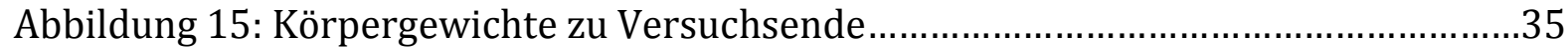

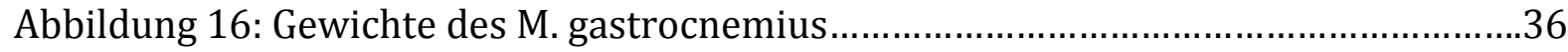

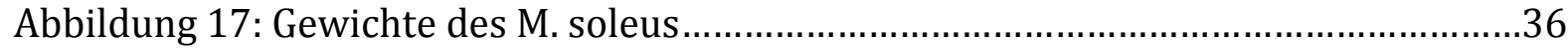

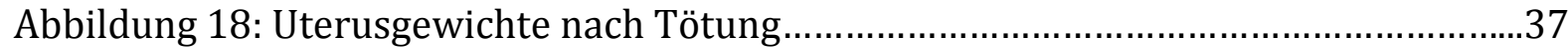

Abbildung 19: Verhältnis von Kapillaren zu Muskelfasern beim M. soleus......................38

Abbildung 20: Verhältnisse von Kapillaren zu Muskelfasern beim M. gastrocnemius.....39

Abbildung 21: Verhältnis von Kapillaren zu Muskelfasern beim M. longissimus..............40

Abbildung 22: Durchmesser der Muskelfasern M. soleus.............................................41

Abbildung 23: Mittelwerte der Muskelfaserflächen im M. soleus....................................42

Abbildung 24: Relation von Muskelfaserdurchmesser zum Körpergewicht beim

M. soleus. 
Abbildung 25: Relation von Muskelfaserdurchmesser zum Muskelgewicht beim M. soleus.

Abbildung 26: Relation von Muskelfaserfläche zum Körpergewicht beim M. soleus.......44

Abbildung 27: Relation von Muskelfaserfläche zum Muskelgewicht beim M. soleus.......45

Abbildung 28: Typ-1-Muskelfaserdurchmesser beim M. gastrocnemius........................46

Abbildung 29: Typ-2A-Muskelfaserdurchmesser beim M. gastrocnemius.......................46

Abbildung 30: Typ-2B-Muskelfaserdurchmesser beim M. gastrocnemius........................47

Abbildung 31: Typ-1-Muskelfaserflächen im M. gastrocnemius...................................48

Abbildung 32: Typ-2A-Muskelfaserflächen im M. gastrocnemius....................................49

Abbildung 33: Mittelwerte der Typ-2B-Muskelfaserflächen im M. gastrocnemius...........49

Abbildung 34: Relation von Muskelfaser-Typ-1-Durchmesser zum Körpergewicht

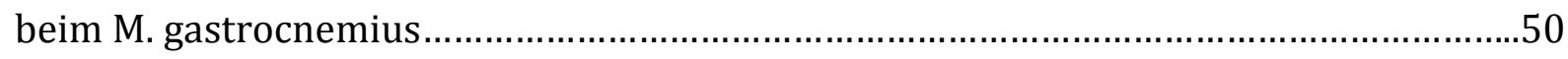

Abbildung 35: Relation von Muskelfaser-Typ-2A-Durchmesser zum Körpergewicht beim M.gastrocnemius.

Abbildung 36: Relation von Muskelfaser-Typ-2B-Durchmesser zum Körpergewicht beim M. gastrocnemius.

Abbildung 37: Relation von Muskelfaser-Typ-1-Durchmesser zum Muskelgewicht beim M. gastrocnemius....

Abbildung 38: Relation von Muskelfaser-Typ-2A-Durchmesser zum Muskelgewicht beim M. gastrocnemius

Abbildung 39: Relation von Muskelfaser-Typ-2B-Durchmesser zum Muskelgewicht beim M. gastrocnemius

Abbildung 40: Relation von Muskelfaser-Typ-1-Fläche zum Körpergewicht

beim M. gastrocnemius

Abbildung 41: Relation von Muskelfaser-Typ-2A-Fläche zum Körpergewicht

beim M. gastrocnemius

Abbildung 42: Relation von Muskelfaser-Typ-2B-Fläche zum Körpergewicht beim M. gastrocnemius. .55

Abbildung 43: Relation von Muskelfaser-Typ-1-Fläche zum Muskelgewicht beim M. gastrocnemius

Abbildung 44: Relation von Muskelfaser-Typ-2A-Fläche zum Muskelgewicht beim M. gastrocnemius 
Abbildung 45: Relation von Muskelfaser-Typ-2B-Fläche zum Muskelgewicht

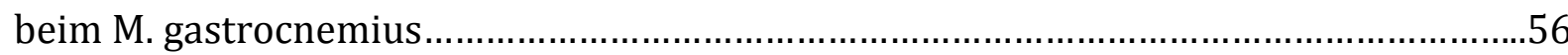

Abbildung 46: Typ-1-Muskelfaserdurchmesser beim M. longissimus..............................57

Abbildung 47: Typ-2A-Muskelfaserdurchmesser beim M. longissimus............................58

Abbildung 48: Typ-2B-Muskelfaserdurchmesser beim M. longissimus............................58

Abbildung 49: Typ-1-Muskelfaserflächen im M. longissimus........................................59

Abbildung 50: Typ-2A-Muskelfaserflächen im M. longissimus......................................60

Abbildung 51: Typ-2B-Muskelfaserflächen im M. longissimus.....................................60

Abbildung 52: Relation von Muskelfaser-Typ-1-Durchmesser zum Körpergewicht

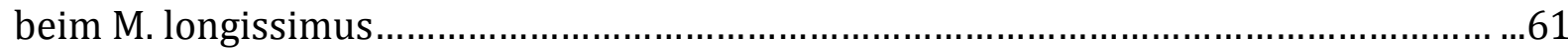

Abbildung 53: Relation von Muskelfaser-Typ-2A-Durchmesser zum Körpergewicht beim M. longissimus.

Abbildung 54: Relation von Muskelfaser-Typ-2B-Durchmesser zum Körpergewicht beim M. longissimus.

Abbildung 55: Relation von Muskelfaser-Typ-1-Fläche zum Körpergewicht beim M. longissimus.

Abbildung 56: Relation von Muskelfaser-Typ-2A-Fläche zum Körpergewicht beim M. longissimus .64

Abbildung 57: Relation von Muskelfaser-Typ-2B-Fläche zum Körpergewicht beim M. longissimus. .64

Abbildung 58: Verhältnis von Typ1-Muskelfasern zur Summe aller Fasern im M. longissimus in Prozent an gesamten Fasern auf $1 \mathrm{~mm}^{2}$ .65

Abbildung 59: Verhältnis von Typ-2A-Muskelfasern zur Summe aller Fasern im M. longissimus in Prozent an gesamten Fasern auf $1 \mathrm{~mm}^{2}$ .66

Abbildung 60: Verhältnis von Typ-2B-Muskelfasern zur Summe aller Fasern im M. longissimus in Prozent an gesamten Fasern auf $1 \mathrm{~mm}^{2}$ .66

Abbildung 61: Kreatinkinase im Serum .67

Abbildung 62: Calcium im Serum .68

Abbildung 63: Magnesium im Serum .68 


\section{Danksagung}

Zunächst möchte ich mich bei meinem Doktorvater, Herrn PD Dr. Sehmisch bedanken. Zum einen für die Annahme meiner Dissertation, verbunden mit der Ermutigung, eine experimentelle Arbeit durchzuführen. Zum anderen für sein ergebnisorientiertes Bemühen beim Korrigieren.

Ebenso gilt mein Dank der hervorragenden Unterstützung durch die Mitarbeiterinnen im Labor der Unfallchirurgie. Hier zu erwähnen sind Frau Anette Witt für ihre permanente Ansprechbarkeit hinsichtlich formaler Fragen zur Dissertation, Frau Ramona Castro-Machguth insbesondere für die Hilfe beim Färben der Schnitte und ganz besonders Frau Marina Komrakova für ihre Geduld beim Korrekturlesen und Hilfe beim Erstellen der Statistiken.

Des Weiteren bedanke ich mich bei Frau Ruth Wigger, Mitarbeiterin im Institut für Nutztierwissenschaften, die mich freundlichst ins Mikrotom sowie die Mikroskopiersoftware einwies.

Ich habe es allen genannten Personen zu verdanken, dass ich meine Arbeit vor Ende meines Studiums abschließen konnte. 


\section{Lebenslauf}

Mein Name ist Jens Henning Kling, ich wurde am 20.04.1985 als Sohn des Dipl.-Ing. Harry Kling (†) und der Reiseverkehrskauffrau Barbara Schäfer, geborene Junge, geboren. Meine Schwester Anne-Catherine Kling wurde am 02.08.1982 geboren. Ich wuchs in Kassel, Hessen auf, wo ich ab 1991 bis 1995 die Hupfeldschule und anschließend von 1995 das Wilhelmsgymnasium bis zum Abitur 2004 besuchte.

Im Anschluss daran leistete ich von Oktober 2004 bis zum Juni 2005 meinen neunmonatigen Grundwehrdienst beim Gebirgsjägerbatallion 233 in Mittenwald, Bayern. Nach einem darauffolgenden Praktikum im OP des Rotes-Kreuz-Krankenhaus, Kassel entschied ich mich für ein Medizinstudium. Zuvor absolvierte ich jedoch die Ausbildung zum Gesundheits- uns Krankenpfleger in den Diakonie Kliniken Kassel von 2005 bis 2008. Nach der Ausbildung ging ich für ein sechsmonatiges Volontariat nach Nepal, wo ich in einem Waisenhaus bei Kathmandu sowie an Health Camps von Zahnärzten und Gynäkologen in Westnepal teilnahm. In der Zeit bis zum Studienbeginn im Wintersemester 2010 in Göttingen arbeitete ich als Krankenpfleger in Davos, Schweiz, und belegte das achtmonatige medizinische Vorbereitungssemester der Semmelweis-Universität in Budapest. Im Sommer 2011 nahm ich an der Sommerschule der Theodor-Billroth-Akademie zur Förderung des akademischen Nachwuchses in der Chirurgie in Tübingen teil. Meinem Interesse an der Chirurgie ging ich auch in meiner Tätigkeit als Rufdienststudent in der Allgemeinchirurgie an der UMG von 2014 bis 2015 nach. Meine Famulaturen absolvierte ich in der Herzchirurgie des Klinikums Kassel (02.2013), der plastischen Chirurgie des Assaf-Harofeh-Krankenhauses in Tel Aviv, Israel (08.2013), der Allgemeinchirurgie des Hadassah-Universitätsklinikums in Jerusalem, Israel (09.2013), sowie in der Praxis für Allgemeinchirurgie Loweg et al. Göttingen (02.2015).

Das Studium der Humanmedizin werde ich voraussichtlich im Herbst 2016 abschließen. Meine Dissertation habe ich im Februar 2014 in der Abteilung für Unfallchirurgie und Orthopädie, Plastische- und Wiederherstellungschirurgie der Universitätsmedizin Göttingen unter der Betreuung von Herrn PD Dr. med. Sehmisch begonnen. 